\title{
Fetischisierung des Filmerlebnisses und der Kinogeschichte (Cluster I)
}

Filmgeschichte erscheint uns als Geschichtsbildmodellierung, die in einem Spannungsfeld steht zwischen der Rekonstruktion von Vergangenem und dem präsentischen filmischen Erlebnis der Bewegtbilder auf der phänomenalen Ebene. ${ }^{1}$ Praktiken der Digitalisierung von Filmen aus der vordigitalen Produktionszeit - ob in der konkreten Transition, der Bildbearbeitung oder auf der Distributions- und Editionsebene - implizieren die Modellierung von Filmgeschichte und unserer Vorstellung generell von Vergangenem. Damit wird auch unsere Wahrnehmung von Geschichtlichkeit in Gestalt eines Narrativs formiert. Das oben genannte Spannungsfeld resultiert in diesem Fall aus dem Zusammenspiel von rahmenden Diskursen und dispositivischen Konfigurationen, die Vorstellungen des Vergangenen modellieren, sowie dem konkreten präsentischen Erlebnis historischer Filme. Bei Letzterem werden zum einen durch diskursive Rahmungen historisierende Lektüren als Rezeptionshaltung nahegelegt (vgl. Entwicklung des semio-pragmatischen Ansatzes in $\rightarrow$ Kap. 3). Zum anderen werden auf Produzentenseite zugleich spezifische ästhetische Praktiken angewendet, um die zeitliche Schichtung aus Vergangenem und Gegenwärtigem sinnlich zu vermitteln. Um diese soll es im vorliegenden $\rightarrow$ Kap. 4 im Besonderen gehen.

Als Prämisse dieser Studie gilt, dass die untersuchten Geschichtsbildmodellierungen unter dem Vorzeichen kultureller Praktiken von Digitalisierung geschehen (vgl. $\rightarrow$ Kap. 2). Insbesondere auf der Distributionsund Editionsebene liegt das Augenmerk in den nachfolgenden Überlegungen auf digitalisierten Filmen, die aus einer vordigitalen Produktionszeit stammen und die unter diesen Vorzeichen als Ware auf dem Markt zirkulieren (sollen). Gemäß der Leitannahme der politischen Ökonomie verspricht Zirkulation Profit, welcher wiederum an ein kommuniziertes und seinerseits zirkulierendes Gebrauchswertversprechen der Ware gebunden ist (vgl. das Zwischenfazit $\rightarrow$ Kap. 3.9). An dieser Stelle kommt nach Wolfgang Fritz Haug (2009) die

1 Geschichtsbildmodellierung - vor allem auch unter medialen Bedingungen - ist nicht umstandslos mit Filmhistoriografie gleichzusetzen, sondern erfordert eine Präzisierung der Begriffe, vgl. hierzu $\rightarrow$ Kap. 3. Dies wird mit Blick auf den Begriff der Historiografie am Ende von $\rightarrow$ Kap. 5 und $\rightarrow$ Kap. 6 aufgenommen und erweitert. 
Warenästhetik zum Tragen - die sinnliche Erscheinung der Ware in ihrer ökonomischen Funktionsbestimmtheit und diese im Zusammenspiel mit der Verheißung von Mehrwert für den Rezipienten (vgl. weitere Ausführungen hierzu unten).

Die warenästhetische Dimension von digitalisierten Filmen wird besonders greifbar im Format des Werbeclips. Deshalb soll es in diesem Abschnitt um die geschichtsbildformierende Kraft von Werbeclips als besondere, zumal populäre Form gehen.

Konkret bedeutet dies, dass im vorliegenden Kapitel filmästhetische Phänomene der Reprise als kulturelle Praktiken untersucht werden, welche Bildern unter heutigen medialen Bedingungen und Interessen sowohl eine historische als auch zugleich eine aktuelle Bedeutung verleihen. ${ }^{2}$ Das Besondere der hier untersuchten ästhetischen Praktiken liegt darin, dass sie unter den oben formulierten Vorzeichen vornehmlich Diskurse um Filmrestaurierung zur Anschauung bringen - und dies unter ökonomischen Prämissen der Vermarktung digitaler Neu-Editionen.

Weitere Untersuchungen in diesem Kapitel widmen sich den ästhetischen Strategien eines exemplarischen Clips zur Re-Edition eines Klassikers ${ }^{3}$, der die entsprechende DVD mit all ihren digitalen Qualitäten als Träger wie Nutzungsform bewirbt.

Die letzten beiden Analysen fokussieren die wirkungsästhetische Aushandlung der Werte von alt und neu in Werbeclips zu digitalen Technologien. An dieser Stelle wird dann ein Exkurs zum hier wirksamen medienhistoriografischen Modell unternommen.

Bei allen Untersuchungen sind als Grundprinzipien medial vermittelte zeitliche Differenzerfahrungen entscheidend. Dies hat zur Konsequenz, dass das aktuelle Kapitel unterschiedliche theoretische Konzepte zur medienhistoriografisch wirksamen Erfahrungsbildung 4 thematisiert:

- Zunächst werden die bildphilosophischen und -theoretischen Überlegungen von Gilles Deleuze zu Affekt-Bildern sowie zu Erinnerungs-Bildern als

2 Zum Begriff der Reprise nach Niney (2012) vgl. ausführlich die begrifflichen Modellierungen im Zwischenfazit $\rightarrow$ Kap. 3.9.

3 Vgl. zu Konstitution, Funktionsweisen und Vermittlung des Labels Klassiker auch Acland (1990) beziehungsweise zum Komplex Kanon(bildung) H.-B. Heller (1989) in $\rightarrow$ Kap. 2 und Klinger (2006a) in $\rightarrow$ Kap. 3 .

$4 \mathrm{Zu}$ den methodologischen und wahrnehmungstheoretischen Entwürfen von Verfahren der medienhistoriografisch wirksamen Erfahrungsbildung vgl. die Überlegungen im Zwischenfazit $\rightarrow$ Kap. 3.9. Die Kap. 4-7 widmen sich unterschiedlichen Aspekten und Phänomenen von medienhistoriografischer Erfahrungsbildung (zum Überblick vgl. Erläuterungen in $\rightarrow$ Kap. 1). 
jeweils (zeitlich) wechselseitige Bilder wahrnehmungstheoretisch perspektiviert (Deleuze 1997: 97; Deleuze greift diesen Begriff von Gaston Bachelard auf).

- Dies wird mit Ansätzen zur Kritik einer Warenästhetik und mit Positionen zu ästhetischen Strategien von Filmtrailern als Werbefilme für Filme vermittelt.

- In einem letzten Schritt der theoretischen Vorbemerkungen werden die obigen Überlegungen mit der Systematisierung eines Wahrnehmungsmodus verbunden, der sich bei der spezifischen Problematik eines Warenfetischismus von ästhetischen beziehungsweise filmischen Objekten ergibt.

Pointiert zusammengefasst: Im Fokus steht im Folgenden die Heterogenität temporaler Horizonte von Filmbildern als (zeitlich) wechselseitige Bilder. Die Funktionalisierung ihrer wirkungsästhetischen Formierungen wird als Prozess der Fetischisierung analysiert und wahrnehmungstheoretisch konzeptualisiert. In einem letzten Schritt wird dies auf das Modell der medienhistoriografisch wirksamen Erfahrungsbildung bezogen und im Anschluss der Begriff memophänomenal in diesem Kontext eingeführt.

\section{1 Ästhetische Strategien der historiografisch wirksamen Erfahrungsbildung. Zeitliche Differenzerfahrung und wechselseitige Bilder}

Filmgeschichte als Konstruktion der Gegenwart wird im Folgenden unter medialen Aspekten perspektiviert: Digitalisierung vermittelt sich in der beschriebenen Perspektive als eine ästhetische und diskursive Praxis, die die Medien- wie Filmgeschichte ${ }^{5}$ unter jeweils spezifischen Interessen wie Bedürfnissen aktualisiert und zugleich als ständige präexistente Referenz und Differenzgröße benötigt (u. a. Klinger 2006a; F. Heller 2013a). Deshalb bedeutet jeder Kontext, in dem digital und Film diskursiv und ästhetisch aufeinander bezogen werden, eine Vermittlung von zeitlichen Differenzen.

Insofern wird Filmgeschichte hier in Form einer clusterartigen Anordnung, als zeitliche Komplexion begriffen. Dies hat mehrere Implikationen:

5 Mediengeschichte wird als erweiterter Kontext begriffen, zu dem relational die historische Dimension des Einzelmediums Films eingebettet gesehen wird. Hier schließe ich an Traditionen medienarchäologischen Denkens an, frage aber vor allem auch nach den gegenseitigen Einflüssen von Medienumgebungen auf das Verständnis von Film und den Folgen für die Vorstellung von historischer Dynamik; vgl. hierzu Winkler (2000) und vor allem Thorburn/H. Jenkins (2004). 
- Film- und im weiteren Sinne Mediengeschichte wird als ein Konstrukt wie Produkt tatsächlicher medialer Anordnungen von Distributions- und Rezeptionsmodi gesehen (vgl. oben). ${ }^{6}$

- In diesem systematischen, weil dispositiven Zusammenhang realisiert sich Historizität auf der Basis von ästhetischen Wahrnehmungseffekten, die in dieser räumlichen Anordnung und zeitlichen Differenzerfahrung vermittelt werden. Dies bedeutet aber auch, die Rolle des wahrnehmenden und nutzenden Subjekts genauer zu befragen und Funktionen von Immersion beim Zuschauer, des Imaginären wie der Erinnerung mit einzubeziehen.

- Historizität wird im vorliegenden Zusammenhang als diskursiver, ästhetischer und dispositivischer Wahrnehmungseffekt verstanden. ${ }^{7}$ So wird davon ausgegangen, dass mehrere Sinnschichten gleichzeitig sinnlich angeboten werden. Es ist die Idee eines Clusters, in dem mehrere historische Verweismöglichkeiten gleichzeitig und achronologisch offeriert werden.

Diese Überlegungen verbinden sich mit den Analyseobjekten: Die Tatsache, dass Werbeclips von Restaurierungen und Neu-Editionen von historischen Werken in den Fokus genommen werden, trägt insofern die Frage nach den historiografisch wirksamen Verhältnismäßigkeiten schon in sich.

So stehen in diesem Kapitel mediale und ästhetische Formen im Mittelpunkt, die unterschiedliche zeitliche Horizonte entwerfen und es dem $\mathrm{Zu}$ schauer damit ermöglichen, über Bewegtbilder zeitliche Differenzerfahrungen simultan im Wahrnehmungsakt zu erleben. Dieser Ansatz rekurriert auf wahrnehmungstheoretische Adaptionen zeitphilosophischer Überlegungen von Gilles Deleuzes zum Film (1991/1985 sowie 1997/1983). ${ }^{8}$

Der erste von Deleuze entlehnte Begriff bezeichnet die sogenannten AffektBilder: Deleuzes Überlegungen zu Affekt-Bildern als zeitlich heterogene und wechselseitige Bilder sind ein fruchtbarer Ansatz, um Parameter medienhistoriografischer Erfahrungsbildung beschreibbar zu machen. ${ }^{9}$ Deleuze bezieht

6 Siehe hierzu etwa den Dispositivbegriff von Distelmeyer mit Blick auf die DVD (2012: $3^{2} \mathrm{ff}$ ).

7 Zum Vergangenheitseindruck als Effekt vgl. grundsätzlich in kulturkritischer Perspektive Jameson (1984) in $\rightarrow$ Kap. 2 sowie in filmtheoretischer Perspektive im Horizont semiopragmatischer Ansätze $\rightarrow$ Kap. 3 .

8 Vgl. dazu näher und grundlegender F. Heller (2010a).

9 An dieser Stelle vertrete ich entgegen der herkömmlichen Deleuze-Rezeptionsweise die Position, dass das Bewegungs-Bild (1983) und das Zeit-Bild (1985), wie sie in den gleichnamigen zwei Bänden entwickelt werden, nicht wirklich antagonistische Konzeptionen darstellen. Oft wird das Bewegungs-Bild mit seiner Bindung an das ,sensomotorische Band' mit dem narrativen Film identifiziert, während das Zeit-Bild dem modernen Film zugeordnet wird, in dem Zeit nach Deleuze ,sichtbar' wird, nur noch losgelöste Situationen darstellt, die Charaktere sich nicht mehr räumlich verorten können usw. Beiden Konzeptionen wohnt Deleuzes spezifische Denkweise inne, in dynamischen Heterogenitäten und in verzeitlichter 
den Begriff im ersten seiner beiden Kinobücher vor allem zunächst auf Großaufnahmen, wie sie exemplarisch in Dreyers La PAssion de Jeanne D'ArC vorkommen (Deleuze 1991/1983: 144 f.; Abb. 4.1).

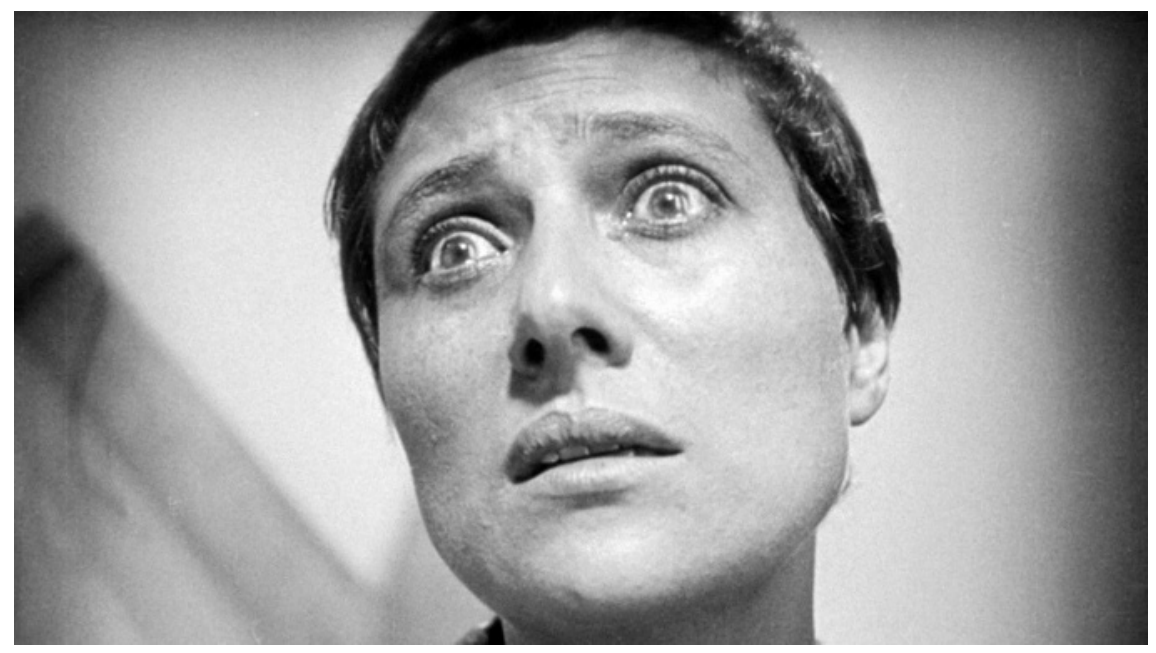

Abb. 4.1

Später relativiert er diesen Fokus und betont, dass es mehr auf den Kontext als auf die tatsächliche Einstellungsgröße ankomme. Wie Affekte sich filmisch entwürfen, sei nicht an die Bestimmung (,Größe $)$ des Raumes im filmischen Bild gebunden, stelle vielmehr eine Entität, einen konkreten Ausdruck dar (jenseits denotativer Qualitäten).

Affekte seien in sich heterogen - es gebe affektive Singularitäten - etwa ein Bild, das dann aber in virtueller Verbindung mit anderen stehe. Affekt konstituiert sich filmisch in einem Wechselspiel aus Moment und virtuellem Zusammenhang, wobei der virtuelle Zusammenhang in der Montage der Bilder im Moment immer als Potenzial, als Möglichkeit, nicht aber als zwangsläufige, fixierte Konsequenz enthalten ist - als Komplexität mit koexistierenden Schichten. Affekt als Entität, wie Deleuze ihn begreift, hat seine Qualität im „Dividuellen“, ist immer mit einem Potenziellen verbunden (Deleuze 1997a/1983: 147-148).

Perspektive zu denken. Deleuze diskutiert die beiden Bildkonzepte in den zwei Bänden an den unterschiedlichsten Konfigurationen und methodischen Vorgaben, wobei oft die Kategorien zwischen Bewegungs-Bild und Zeit-Bild in den Befunden anhand der Filmbeispiele verschwimmen. 
Vor diesem Hintergrund nennt Deleuze mit erneutem Rekurs auf Dreyers Jeanne D’Arc die Montage als affektive Szenenaufgliederung („découpage affectif“). Dreyer zitierend spricht er von "fließende(n) Großaufnahmen“: Die Zusammenhänge werden "flüssig“ - alle Einstellungen werden affektiv durchtränkt (Deleuze 1997a: 150-151). Im Möglichen sind Empfindungsqualitäten an- wie zugleich simultan abwesend. Somit schaffen Affekt-Bilder auch ein vom metrischen System abgelöstes Raum-Zeit-Gefüge (Deleuze 1997a: 153 f.). ${ }^{10}$ Deleuze denkt so Affekt-Bilder als eine Koaleszenz, als ein ständiges Wechselspiel zwischen affektivem Moment und affektiven Potenzialitäten, die einen eigenen Wahrnehmungsraum - losgelöst vom metrischen System - entwerfen. Es entsteht ein filmisches „System der Emotion“ (Deleuze 1997a: 154). Wichtig ist an dieser Stelle hervorzuheben, dass der Affektbegriff nach Deleuze von psychoanalytischen Dimensionierungen abzugrenzen ist (Morsch 2010 und 2011). Bei Deleuze wird der Körper zum Schauplatz von Intensitäten, Affekten, Sensationen und Empfindungen, die die Ordnung der Subjektivität ebenso hinter sich lassen wie das Regime der Repräsentation. Die Perzepte und Affekte, die Bewegtbilder hervorbringen, verdanken sich für ihn nichtmenschlichen Kräften, sie übersteigen den Horizont anthropozentrischer und psychologisch fundiert gedachter Subjektivität. In einer deleuzianischen Lektüre bringt das Kino ,eigensinnige' Perzepte, Affekte und Empfindungskomplexe hervor, die alltagsweltliche Vorstellungen vom Subjekt und dessen Konzepte von Erfahrungshorizonten überwinden (Morsch 2010: 70-74).

Dieses Wechselspiel zwischen An- wie Abwesenheit, zwischen Aktuellem und Virtuellem findet sich auch im Konzept Deleuzes zu den sogenannten Erinnerungs-Bildern - hier noch deutlicher auf der Zeitebene angesiedelt (Deleuze 1997b: u. a. $132 \mathrm{ff}$ ): Ausgehend von der Annahme, dass das filmische Bild in sich zunächst keine Zeit-Zeichen trägt (u. a. F. Heller 2010) - das heißt, dass in philosophischer sowie phänomenologischer Perspektive der filmische Wahrnehmungsakt zunächst immer ein präsentischer ist -, lässt sich Vergangenheit als pragmatischer und ästhetischer Effekt beim Zuschauer konzeptualisieren:

Die Vergangenheit vermischt sich nicht mit der mentalen Existenz der Erinnerungs-Bilder, die sie in uns aktualisieren. Es ist die Zeit, in der sie sich bewahrt: sie ist das virtuelle Element, in das wir eindringen, um die ,reine Erinnerung' aufzufinden, die sich in einem Erinnerungs-Bild aktualisieren wird. artigen Raums bekundet, ist eine Vielfalt an Potenzialen oder Singularitäten“ (Deleuze 1997a: 153). 
Dieses besäße keinerlei Vergangenheitszeichen, hätten wir den Keim davon nicht in der Vergangenheit aufgespürt (Deleuze 1997b: 132).

Wahrnehmungstheoretisch auf Filmbilder gewendet, bedeutet dieser philosophische Ansatz: Aufgrund der Rahmung sowie der formalästhetischen Manifestation wird der präsentischen Filmerfahrung vom Zuschauer die virtuelle Qualität eines Vergangenheitsbezugs und damit einer Erinnerung zugeschrieben, die nach Deleuze in Anschluss an Bergson zunächst innerlich und subjektiv ist (mentales Bild). ${ }^{11}$ Die qualitative Einordnung von Bildern als Vergangenheit baut auf der Zuschreibung der Präexistenz der Bilder auf: „Kurz, die Vergangenheit erscheint als die allgemeinste Form eines Schon-da [„déjàlà “], einer allgemeinen Präexistenz, die unsere Erinnerungen voraussetzen“ (Deleuze 1997b: 132). Die Vergangenheit koexistiert mit der Gegenwart, wird von ihr aus gedacht.

Die zeitlichen Verhältnisse werden als interagierende Schichtungen ${ }^{12}$ gesehen, die in Erinnerungen angesteuert werden:

[D]ie Vergangenheit [erweist sich] als die Koexistenz der [...] mehr oder weniger zusammengezogenen Kreise [...]. Zwischen der Vergangenheit als allgemeiner Präexistenz und der Gegenwart als unendlich zusammengezogener Vergangenheit gibt es die Gesamtheit der Vergangenheits-Kreise, die eine Vielzahl von ausgedehnten oder verengten Regionen, Sedimenten, Schichten bilden: jede Region mit ihren Eigenschaften, ihren Schattierungen, [...] ihren Singularitäten, ihren Glanzpunkten [...]. Je nachdem welcher Natur die Erinnerung ist, der wir nachgehen, müssen wir in den einen oder anderen Kreis springen (Deleuze 1997b: 133).

Prinzipien der koaleszierenden An- wie Abwesenheit sind maßgeblich für Deleuzes Denken. Aktuelles und Virtuelles koexistieren simultan und stehen damit im Verhältnis der Koaleszenz ${ }^{13}$ : „Es entsteht dabei ein zweiseitiges Bild: ein aktuelles und ein virtuelles" (Deleuze 1997b: 96, Hervorh. FH). Filmbilder

11 Wie der Lebensphilosoph Henri Bergson schon in Materie und Gedächtnis (1991) anhand seiner zeitphilosophischen Überlegungen erläutert, sind - hier verkürzt dargestellt Wahrnehmungen der Gegenwart von außen („Wahrnehmungs-Bilder“ bei Bergson) und innerliche Erinnerungen („Erinnerungs-Bilder“ bei Bergson) nicht voneinander zu trennen: Die tagtägliche Wahrnehmung sei durchtränkt von Erinnerungen. Die beiden Bildformen als Modus der Weltbegegnung seien nicht voneinander zu trennen. Vgl. hierzu überblicksartig, auch in methodologischer und theoriegeschichtlicher Perspektive, Oger (1991: bes. XXXV).

12 In meinem Ansatz werden diese Schichtungen als Cluster bezeichnet und im Analyseprinzip umgesetzt, vgl. Zwischenfazit $\rightarrow$ Kap. 3.9.

13 Vgl. auch Kap. 4.3 in F. Heller (2010a: 167 ff.). 
werden also mit Deleuze verstanden als zweiseitige, wechselseitige Bilder zwischen aktuellem Bild und Erinnerungs-Bild.

Bei der Untersuchung der zu behandelnden Beispiele stellen sich nun vor dem Hintergrund dieser zeitphilosophischen wie bildtheoretischen Überlegungen folgende Fragen für die nachstehenden filmästhetischen Analysen:

- Wie wird diskursiv und ästhetisch das Präexistente der Bilder erfahrbar gemacht? Wie werden zeitliche Differenzerfahrungen vermittelt - im Horizont des Konzepts von wechselseitigen Bildern?

- Welche Rolle spielen hierbei die von Deleuze genannten zeitphilosophisch bedeutsamen Begriffe wie etwa "Glanzpunkte“ oder "Singularitäten“ als mögliche sich konkretisierende ästhetische Verfahren in Form von phänomenal wirksamen (An-)Reizen?

- In diesem Sinne ist zudem grundsätzlicher zu fragen: Wie wird auf diese Weise Erinnerung als Lektüre- und Erwartungshaltung beziehungsweise dann als sich konkretisierender Erlebnismodus initiiert?

\subsection{Medienhistoriografisch wirksame Erfahrungsbildung im Format Werbeclip. Wirkungsästhetische Verfahren in einem warenästhetischen Horizont}

Nach Vinzenz Hedigers Studie Verführung zum Film (2001) besteht eine Hauptfunktion des (Film-)Trailers - eines Werbeclips für Filme - darin, Begehren des Konsums zu wecken (2001: 225). Dabei beschreibt Hediger insbesondere zwei interagierende Funktionsweisen: Hier komme es zum Zusammenwirken von unmittelbaren Schlüsselreizen und virtueller Erinnerung..$^{14} \mathrm{Im}$ Kapitel Nostalgia for the Coming Attraction erläutert der Autor, wie Trailer Erinnerungen an frühere filmische Genüsse und Erlebnisse instrumentalisieren, um sie als Projektion auf das Kommende positiv zu nutzen. Es geht dabei „um die Erinnerung an bestimmte Filme und Kinoerlebnisse, die beim Sehen von Trailern aktiviert wird und die in den Aufbau von Schlüsselszenarien einfließt“" (Hediger 2001: 225). Diese Schlüsselszenarien basieren auf sogenannten „narrativen Images“ und deren Interaktion mit der Erinnerung:

Das Schlüsselszenario (was ich mir unter dem Film vorstelle, wenn ich ihn sehen will) basiert notwendigerweise auf dem narrativen Image (der Information, die

14 Dies wird hier in $\rightarrow$ Kap. 4 mit den obigen Begriffen und Konzepten von Deleuze wahrnehmungstheoretisch präzisiert. Eine andere nuancierte Perspektivierung findet sich in den Ausführungen in $\rightarrow$ Kap. 6 unter dem Stichwort ,prosthetic memory' im Kontext der Diskussion von Erinnerungskulturen und filmischen Modi der Erfahrung. 
mir zur Verfügung gestellt wird) und auf der Erinnerung an die Werbebotschaft (was von dieser Information hängenbleibt) (Hediger 2001: 230).

Wenn es um die Vermittlungsform dieser „Images“ mit Blick auf den hier diskutierten Gegenstandsbereich geht, wird im Folgenden weniger von Schlüsselszenarien gesprochen als vielmehr von Schlüsselreizen oder -spannungen: In den folgenden Beispielclips werden nicht nur Filme, sondern vor allem auch Anwendungen digitaler Technologien oder digitale Träger beworben. Wenn nach Hediger Trailer Unterhaltungswerte simulieren (Hediger 2001: 235), so simulieren die hier analysierten Clips das Unterhaltungspotenzial von Filmen auf der DVD beziehungsweise Blu-Ray-Disc. Vor diesem Hintergrund ist das filmisch konstruierte „Image“ nicht allein das einer im Film erzählten Geschichte - etwa in Form einer lückenhaft wiedergegebenen Story -, sondern vielmehr vorrangig das eines sinnlichen Erlebnispotenzials. So funktionieren die Werbeclips für digitale Träger und Distributionsformen als Cluster, indem sie extrem kurze Ausschnitte meist bekannter Filmer kompilieren und damit die mitschwingenden Storys der zitierten Produktionen ineinander verschachtelt als Bedeutungshorizonte evozieren. Eine solche Gestaltung wird verwoben mit der Vermittlung eines Eindrucks von technologischer Neuerung, die sinnlich erfahrbar werden soll. Verschiedene Filme werden so fragmenthaft auf einzelne Bewegungsbilder reduziert und zu einer Metanarration neu montiert. Dadurch entsteht eine ganze Reihe von neuen sinnlichen Reizen und Attraktionen, die in unterschiedlichen Verfahren - hier werden Konzepte der Affekt- und Erinnerungs-Bilder wirksam - viele koexistierende Wahrnehmungsangebote in einer Clusterstruktur offerieren: zwischen Erfahrungen des Aktuellen und des Virtuellen, in deren Wechselspiel sich die Erfahrung von Differenzen zwischen Gegenwart und Vergangenheit manifestieren.

Um dem ökonomischen Kontext derWerbeclips Rechnung zu tragen, werden diese ästhetischen Verfahren als Form der Warenästhetik - in Anschluss an Modelle der politischen Ökonomie ${ }^{15}$ - kritisch in den Blick genommen. Damit

15 Der Rekurs auf die politische Ökonomie soll den Warencharakter von Kultur und Medien ins Zentrum rücken, wobei es weniger um die Reflexion von Verblendungszusammenhängen geht, die es zu entlarven gilt. Vielmehr steht die Reflexion der ästhetischen Strategien in diesem nicht von der Hand zu weisenden funktionsbestimmenden Kontext im Mittelpunkt: Das Memopolitische in der Form soll analysiert werden, um die Folgen der medialen Erfahrungsmodi als erinnerungskulturelle Praktiken systematisieren zu können, vgl. hierzu die Erläuterungen in $\rightarrow$ Kap. 1 sowie $\rightarrow$ Kap. 3. Die eingeschränkte Perspektive auf die Analyse der ästhetischen Strategien im bild- sowie zeittheoretischen Horizont hat ihren Grund darin, dass die denkbare Einbindung von Ansätzen aus der Werbepsychologie das Untersuchungsfeld an dieser Stelle sprengen würde. Ansätze aus dem Feld der Werbepsychologie entwickeln meist ein anders gerichtetes 
sollen die ästhetischen Praktiken entsprechend dem pragmatischen Kontext in ihren soziokulturellen Abhängigkeiten und ideologischen Implikationen verortet werden. Der Begriff von Wolfgang Fritz Haug (2009) richtet vor allem methodologisch den Fokus auf die Analyse der sinnlichen Erscheinungen von Waren in ihrer ökonomisch spezifischen Form- und Funktionsbestimmtheit. Damit wird das ästhetisch konstruierte und vermittelte Gebrauchswertversprechen einer Ware, die der Tauschwertrealisierung vorausgeht, Gegenstand der Untersuchung (Haug 2009: 22 f.).

Tatsächlich liegt in den Clips eine ästhetische Metanarration aus (Film-) Fragmenten vor, die eine neue, höchst interessante Form der Warenästhetik mit Blick auf die digitale Domäne entwickelt. Nach Haug zielt der Begriff Warenästhetik auf eine doppelte Präzisierung der Perspektive hinsichtlich der ästhetischen Erscheinungsformen von Waren:

einerseits auf ,Schönheit', d. h. auf eine sinnliche Erscheinung, die auf die Sinne ansprechend wirkt; andrerseits auf solche Schönheit, wie sie im Dienste der Tauschwertrealisierung entwickelt und den Waren aufgeprägt worden ist, um beim Betrachter den Besitzwunsch zu erregen und ihn so zum Kauf zu veranlassen (Haug 2009: 23).

Will man unter diesem Gesichtspunkt das in den Clips formulierte, ästhetische Gebrauchswertversprechen' etwa der beworbenen DVD und Blu-Ray-Disc genauer untersuchen, so ergibt sich die pikante Pointe, dass der Gebrauchswert ebenfalls in der ästhetischen Dimension liegt: Die Blu-Ray verspricht gegenüber früheren Bildtechnologien ein erweitertes ästhetisches Erleben, ein gesteigertes Unterhaltungs- und Genusspotenzial der Filmbilder. Die ästhetische Verpackung des Versprechens (Filmbilder) fällt zusammen mit dem Objekt der Vermarktung (den Filmbildern auf Blu-Ray-Disc). Und mit Blick auf die im gegebenen Kontext untersuchte Bewerbung von Unterhaltungspotenzialen digitaler Techniken bestätigt sich:

Die Warenästhetik ist gemacht, damit die Bedürfnisse sich in ihr spiegeln. [...] Diese Akzeptanz [des Produktes bei den Kunden, $\mathrm{FH}$ ] wird primär angestrebt durch Gebrauchswertversprechen im Modus der Imagination oder des auf eine Kaufentscheidung hin perspektivierten imaginären Raumes, der die Waren umgibt. Mehr als im Fordismus verschiebt sich die Darstellung von den Dingen auf die ihnen angedichteten Erlebnisfolgen (Haug 2009: 220).

Erkenntnisinteresse - etwa an Kommunikationsmodellen und -mustern in Hinblick auf die kognitiven und emotiven Reaktionen des Subjekts/Konsumenten (vgl. etwa Felser 2007 zu Informationsverarbeitungsmodellen und Einstellungsänderungen durch Werbefilme beim Konsumenten). 
Die besondere Anschlussfähigkeit von Haugs Überlegungen liegt in der Vermittlung der Begriffskomplexe des Gebrauchswertversprechens, des Imaginären sowie der realen wie versprochenen Erlebensdimension. So liegt in meinem Rekurs auf Haug vor allem der methodische Ansatz, den Blick auf das Verfahren zu richten, wie die Verkaufsargumente des Clips mit den vorgeblichen digitalen Qualitäten der beworbenen digitalen Distributionselemente wie Editionsformen wirkungsästhetisch vermittelt werden.

\subsection{Medienphänomenologische Prozesse. Warenfetischismus von ästhetischen Objekten}

Wolfgang Fritz Haug hebt in seinem Konzept der Warenästhetik hervor, welch wichtige Rolle die Vorstellung, die Imagination des Konsumenten, spielt, über die dem Produkt ein Gebrauchswert als Erlebnisfolge zugeschrieben wird. In diesem Modus des ,Andichtens' seitens der Vorstellungskraft des Rezipienten/ Konsumenten kommt dem (ästhetischen) Produkt das Potenzial einer erweiterten Erfahrungsdimension zu; mit Deleuze gesprochen: In der aktuellen ästhetischen Erscheinungsform ist für den Konsumenten immer das Potenzial eines über das Aktuelle hinausgehenden Erlebnisses enthalten; das Potenzial des ständigen ,Mehr'. Dies wird im Folgenden als Prozess der Fetischisierung gefasst, der als spezifischer Wahrnehmungsmodus und als bestimmende Rezeptionshaltung anzusehen ist.

Insbesondere der Kulturwissenschaftler Hartmut Böhme (2012) hat sich mit den wissenschaftshistorischen und künstlerischen Prozessen auseinandergesetzt, die den Fetischismus zu einem Zentrum der europäischen Kultur haben werden lassen. Fetischismus sei oft und lange Zeit als psychopathologische, sexuelle wie auch religiös-ethnologische Erscheinung in einer Randstellung gesehen und behandelt worden. Erst seit Beginn der 198oer Jahre sei er zunehmend als ein sozialpsychologisch unvermeidliches Phänomen der modernen kapitalistischen (Massen-)Kultur auf allen Ebenen wahrgenommen worden (Maters 1982, n. H. Böhme 2012: 354). Fetischismus ist insofern für H. Böhme analytisch interessant, um die Moderne in einer spezifischen Widersprüchlichkeit zu begreifen und zu verstehen. Denn der Selbstentwurf der Moderne beinhaltet eigentlich, dass Kult und Magie zugunsten der Vernunft als erfolgreich überwunden gelten. H. Böhme weist in seinen Überlegungen das Trügerische dieses Selbstentwurfes nach und zeigt die Potenziale dieser Neuperspektivierung über die kritische Beschäftigung mit Funktionen des Fetischs (vgl. auch kommentierend Konersmann 2006). Es ist ein Ansatz, dem die hier formulierten Thesen folgen (vgl. hierzu vor allem auch die Überlegungen in 
$\rightarrow$ Kap. 7); dies umso mehr, als sich in diesem Horizont auch das bereits in $\rightarrow$ Kap. 2 entwickelte Technoimaginäre der digitalen Domäne anhand von ästhetischen Phänomenen und Wahrnehmungskonfigurationen in den Blick nehmen lässt. Im Technoimaginären finden eschatologische Hoffnungen, Erwartungen und Utopien Ausdruck, wobei Vorstellungen von instrumenteller Rationalität, mythischer Begegnung mit der Welt und damit auch Tendenzen der (Selbst-)Vergöttlichung in einem Wechselspiel stehen (H. Böhme 2000: 3-4 FH).

In der Beschäftigung mit Fetischismus tut sich darüber hinausgehend nicht nur ein philosophisch-kulturkritisches, sondern auch ein wahrnehmungstheoretisches Problemfeld auf, welches die entsprechenden Untersuchungen in die Nähe von medienanalytischen Ansätzen rückt: Es geht vor allem um das Verhältnis zur Dingwelt: „Wir [H. Böhme als Autor, FH] untersuchen ,Objektbeziehungen' - und das heißt im modernen Wissenschaftsverständnis: Wir analysieren die Stellungen und Relationen, die wir zu den Dingen einnehmen" (H. Böhme 2012: 14). Dass dabei grundlegende Konfigurationen des Subjekt-Objekt-Verhältnisses ausgehandelt werden - „hier das Subjekt, dort die Objekte; hier die Gesellschaft, dort die Natur; hier der Geist, dort die Dinge“ (Konersmann 2006) -, davon zeugt die Beschäftigung H. Böhmes etwa mit der Phänomenologie von Edmund Husserl oder Maurice MerleauPonty (H. Böhme 2012: 58 f., 97 ff.). Aber auch Walter Benjamin wird wiederholt herangezogen. In Hinblick auf Ware als Fetisch (H. Böhme 2012: 283 ff.) beobachtet H. Böhme einen „seltsamen Doppelstatus“, dessen Besonderheit darin liege, „Ding und Symbol, Immanenz und Transzendenz uno loco zu vereinen“ (H. Böhme 2012: 287). Dies führt H. Böhme zu der Überlegung, „dass der Fetischismus für das ökonomische System [...] eine transzendentaleökonomische Bestimmung darstellt" (H. Böhme 2012: 287).

Für die nachstehenden Ausführungen ist bei dem Begriff, wie ihn H. Böhme entwickelt, von Bedeutung, dass Fetischismus eine Schichtung verschiedener Funktionsprinzipen umfasst, die zum einen religiöse, „kathektisch-affektive, sexuelle" sowie vor allem "wahrnehmungsästhetische Elemente“ beinhalten eben „solche, die nach dem Code bewusst/unbewusst operieren“ (H. Böhme 2012: 288).

Dabei kommen im Verhältnis zur kulturindustriellen Fetischisierung von Phänomenen Praktiken des Zurschaustellens, das heißt die ostentative Präsentation („Theatralität“) sowie vor allem Aspekte der Performanz zum Tragen (vgl. hierzu $\rightarrow$ Kap. 5). ${ }^{16}$

16 Nach H. Böhme (2012) müssen alle Dinge und Produkte, die als Tauschwerte realisiert werden sollen, „zum Markt gehen“ und dort „auftreten“. Dies kreiert Performanz oder 
Fetischismus - im Verhältnis zu einem Ding - bedeutet immer eine Substitution oder Vertretung für etwas anderes. Der Warenfetischismus funktioniert als eine systematisch erzeugte Illusion, die "das Bild einer Welt, die unsere Bedürfnisse erfüllt, [liefert, FH], einer Welt, die immer ,voll', ,reich', ,großartig‘ und ,schön' ist (und wir sind ein Teil von ihr)“(H. Böhme 2012: 333). Und weiter:

Das macht die Aura des Warenfetischs aus: Der Warenfetisch winkt mit der Partizipation am Schlaraffenland (in allen Varianten). Die Ware ist also der Code einer Utopie. Das ist ihre systematisch erzeugte Illusion. [...] Die Ware verleugnet [...] die Prosa der Wirklichkeit (H. Böhme 2012: 333-334).

Diese Formulierungen sind entscheidend für die Konzeptualisierung eines Warenfetischismus von digitalisierten historischen Filmen und der Funktionalisierung für deren Erlebensdimension.

Für den Zusammenhang von (Waren-)Fetischismus und historischer wie erinnerungskultureller Dimension sind darüber hinaus H. Böhmes Ausführungen zu Museen und Sammlungen wichtig (H. Böhme 2012: $35^{2} \mathrm{ff}$ ). Er begreift vor allem das Museum als eine räumliche Anordnung, in der der Fetischismus nach anderen Regeln funktioniert als außerhalb, wo etwa Gesetze des Marktes vorherrschen. Im Bereich der Musealisierung stehen weniger ökonomische, konsumistische, religiöse sowie sexuelle Funktionsweisen im Mittelpunkt (H. Böhme 2012: 355). Vielmehr funktioniert der Fetisch über museale Anordnungen vor allem ästhetisch. ${ }^{17}$

Auch wenn sich im vorliegenden Gegenstandsbereich, der sich mit Film beschäftigt, bei den nachfolgenden Analysen die Ebenen vermischen und überlagern (insbesondere die museale, ästhetische und ökonomische), so sind doch bestimmte Überlegungen $\mathrm{H}$. Böhmes fruchtbar zu verwerten - insbesondere diejenigen, die die Wahrnehmungskonfiguration des Musealen und damit des

Theatralität der Waren. Waren müssen ausgestellt werden. Die Entfremdungen in der Produktion und die Mechanismen des Warentauschs erzeugen zusammen den Warenfetischismus (H. Böhme 2012: 332 f.).

17 Ästhetisierung bedeutet in diesem Kontext nach H. Böhme die Herausnahme eines Gegenstandes aus seinem konkreten Gebrauchszusammenhang. H. Böhme rekurriert hier auf Kant und seine Kritik der Urteilskraft, „wo eine Bedingung der Wahrnehmung und Reflexion des Schönen die Abstandnahme von jedem Gebrauch des sinnfälligen Gegenstandes ist“ (Kant, zit. n. H. Böhme 2012: 355). Ich werde mich im Verlauf der weiteren Argumentation mit diesem Verständnis durchaus mit Blick auf den hier diskutierten Gegenstand kritisch auseinandersetzen; vgl. hierzu auch das Fazit zu Aspekten aisthetischer Historiografie in $\rightarrow$ Kap. 5 . 
Erinnerungswürdigen beschreiben (FH mit H. Böhme 2012: 355). Demzufolge wird das ästhetische Objekt zum Fetisch in den folgenden Anordnungen:

1. Durch das spezifische Dispositiv (der Musealisierung im hier gegebenen Fall der ,Historisierung ) wird ein Objekt/Phänomen mit einer besonderen Ergebenheit (,Devotion') wahrgenommen, die seiner alltagsenthobenen, exponierten Attraktion gilt.

2. Das Objekt verursacht eine ambivalente Wahrnehmungshaltung, die zwischen dem sistierten Begehren nach Aneignung und der Angst vor seiner überlegenen, ergreifenden, faszinierenden Qualität oszilliert.

3. Durch ein Wechselspiel zwischen Nähe und Ferne wird das Objekt zum Gegenstand einer Lust: Es bleibt unerreichbar in der Überhöhung, die Überhöhung muss geschützt werden; aber gleichzeitig speist sich die Lust aus der Möglichkeit des Erlebens von Nähe, der Möglichkeit, das Überhöhte und Unerreichbare in einer besonderen Anordnung betrachten und sinnlich wahrnehmen zu können (vgl. zur Relationierung von Nähe und Ferne $\rightarrow$ Kap. 7). ${ }^{18}$ H. Böhme beschreibt dieses Wechselspiel mit der Formulierung, dass erst die unbedingte Distanz bei gleichzeitig aufrechterhaltener Performanz des Fetischs diesen in ein unverfügbares Element einer Erfahrung verwandelt. Zentral ist an dieser Stelle H. Böhmes Ergänzung, dass diese Fetischerfahrung sich dadurch auszeichne, dass sie der Betrachter nur für und mit sich selbst machen könne (H. Böhme 2012: 257).

Das fetischisierte Objekt muss einerseits performativ-rituell in irgendeiner Form dem Betrachter präsent bleiben, andererseits muss es gleichzeitig in einer unbedingten Distanz gehalten werden. Die Erfahrung des Fetischs liegt im Betrachter begründet - wir sind es selbst, die auf diese Weise die Fetische konstituieren („machen“, H. Böhme 2012: 357). Der Betrachter ist demnach konstitutiver Teil des Prozesses der Fetischisierung eines Objekts. ${ }^{19}$

Durch fetischisierende Rituale der Auratisierung und memorialen Imprägnierung, hervorgerufen durch gewisse (museale) dispositivische und

18 H. Böhmes Referenzanalogie ist hier das Vitrinenglas, hinter dem das Objekt in einem Museum ausgestellt ist (H. Böhme 2012: 355). Die Relevanz der Kategorien von Nähe und Ferne spielt auf das Prinzip der Aura(tisierung) bei Walter Benjamin an; vgl. hierzu aktualisierende Lektüren von Benjamin mit Blick auf die digitale Domäne $\rightarrow$ Kap. 7 .

19 Darüber hinaus schreibt H. Böhme zum kulturkritischen, reflexiven Potenzial des Raumes des Museums: „Museen [Räume des Unveräußerlichen, FH] sind jene Orte, in denen die moderne Gesellschaft den automatisch operierenden Universalfetischismus der Waren sistier[t], indem sie ihn durch Verdopplung manifest, ästhetisch erfahrbar und psychisch wie kognitiv reflektierbar machen. Museen machen und pointieren die Fetische, von denen wir uns, außerhalb der Museen, dirigieren lassen“ (H. Böhme 2012: 357). 
ästhetische Praktiken, werden Objekte zu lebendigen Trägern der Erinnerung. Diese Objekte werden zu Medien mit einer spezifischen Funktion der Zeitlichkeit: Es sind materiale Vermittler der Erinnerung, in diesem Sinne sind sie Medien des Vergegenwärtigens (H. Böhme 2012: 362 ). ${ }^{20}$

Vor diesen Hintergrund lassen sich mit Blick auf die Problemstellung des vorliegenden Kapitels - den Zusammenhang von Fetischisierung des Filmerlebnisses und Kinogeschichte - zusammengefasst die folgenden Thesen formulieren:

- Die Fetischisierung in einem von H. Böhme als museal beschriebenen Dispositiv gilt vor allem auch für die Wahrnehmung eines zugeschriebenen Alters- wie Erinnerungswerts von Bewegtbildern.

- Der Prozess der Fetischisierung eines historischen Klassikers im Fragment entwickelt ein Wechselspiel zwischen individueller und kollektiver Erinnerung; dieses Zusammenspiel verbindet sich mit dem konkreten, phänomenalen Erlebnis der Bilder, wobei sich in ebendiesem konkreten Erlebnis die Utopie einer ultimativen, verbesserten Erinnerung vermittelt. Diese wird als sensuell-begehrenswerte konstruiert. Der Zuschauer wird zur Vollzugsinstanz des Fetisch. Dabei affirmiert der Zuschauer über den fetischisierenden Wahrnehmungsmodus zugleich den Status der Bilder als erinnerungswürdig.

- Für die wirkungsästhetische Dimension gilt: Das Wechselspiel von Nähe und Ferne muss als Spannung ständig erhalten bleiben. Zum einen muss die Lust auf Filmerfahrung partiell befriedigt werden; und zum anderen muss gleichzeitig stets die Überhöhung, das Versprechen auf ein den Moment transzendierendes Filmerlebnis gewahrt werden. Vor allem hier wird der von Deleuze geprägte Begriff der wechselseitigen Bilder wichtig werden.

\subsection{Restaurierungsdiskurs und Fetischisierung. Der Werbeclip Restoring the Classics (2012)}

Das erste Analysebeispiel ist ein Werbeclip zum 100-jährigen Geburtstag des Filmstudios Universal, in dem unter ökonomischen Prämissen der Vermarktung von Neu-Editionen Filme aus dem Archiv eine ästhetische Reprise erfahren. Der Clip legt einen besonderen Fokus auf die Vermittlung der

20 Dabei gilt wie folgt (dies wird noch präzisierend in $\rightarrow$ Kap. 7 mit dem Begriff des Glaubens wahrnehmungstheoretisch aufgeschlüsselt): „Das Transzendente ist nie das, was von sich aus immer schon transzendent ist, sondern es muss der Glaube erzeugt werden, dass es so ist" (H. Böhme 2012: 370). Deshalb nehmen nach H. Böhme Museen in der Moderne einen wichtigen Platz ein: „Museen und Sammlungen der Moderne sind nun Einrichtungen der Transzendenz-Versicherung" (H. Böhme 2012: 370). 
Restaurierung der Filme. Im Folgenden werden die formalästhetischen Verfahren, vor allem die Funktionalisierung von wechselseitigen Bildern sowie von Affekt- und Erinnerungs-Bildern untersucht und in der wahrnehmungstheoretischen Dimension - insbesondere mit Blick auf sinnliche und fetischisierende Erlebnisformen - konzeptualisiert.

Affekt- und Erinnerungs-Bilder symbolisch in ihrer zeitlichen Konfiguration. Exposition und Titelbild

Der Werbefilm startet mit einer Abfolge von Filmzitaten. Schon eingangs steht ein ikonischer Dialog nur noch auf ein Fragment reduziert; im Originaldialog in The Blues Brothers (1980) sagt Elwood (Dan Aykroyd), als die Kultprotagonisten nachts abfahrbereit im Auto sitzen: „It's a hundred and six miles to Chicago, we've got a full tank of gas, half a pack of cigarettes, it's dark, and we're wearing sunglasses.“ Jake, gespielt von John Belushi, daraufhin: „Hit it!“ Los geht's! Nur diese letzte Zeile ist als Spur des Originaldialogs zu Beginn des Clips von Universal übriggeblieben (Abb. 4.2). Beschwingte Musik setzt ein, eine Montagesequenz entwickelt sich: Ein Auto geht in einem Feuerball auf, Dr. Brown und Michael J. Fox alias Marty McFly (BACK to the Future, 1985) schauen sich verblüfft um, Teenager des BREAKFAST CLUB (1985) laufen durch die Flure ihrer High School, E. T. radelt mit seinem jungen Freund vor dem Mond den Himmel entlang (Abb. 4.3).

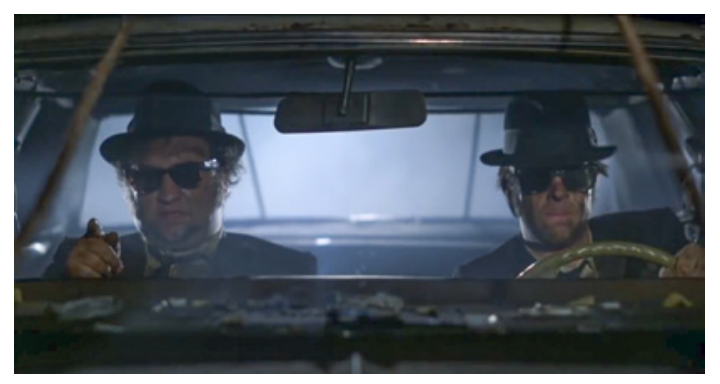

Abb. 4.2

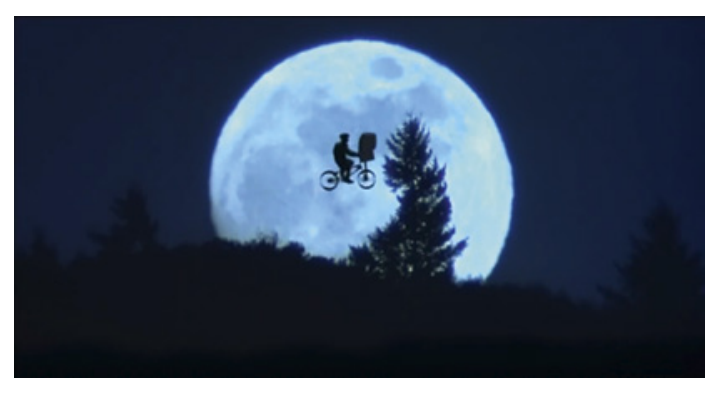

Abb. 4.3 
Dann kommt die Handlung noch näher an den Zuschauer: Plötzlich ist man mit Sam Neill in eine Herde Dinosaurier im JuRAsSic PARK (1993) geraten, man weicht mit Roy Scheider alias Brody vor dem weißen Hai zurück (JAws, 1975): „You're gonna need a bigger boat“, hört man dazu im Off.

Ein Wechsel des Bildregisters auf die Metaebene: Alle diese ikonischen, schnell in ihren Herkunftsfilmen identifizierbaren Szenen materialisieren sich in kleineren Kadern in einer Wand wie aus Bildschirmen neben- und übereinander. Sie spannen so eine Leinwand auf, die eine Fläche aus sich simultan abspielenden Sequenzen auf den einzelnen ,Bildschirmen' ergibt; einer Projektionsfläche gleich, die das Panorama von filmischen Universen aus unterschiedlichen Dekaden entfaltet. Die Fläche zitiert in ihrer Ausrichtung sowohl eine Kinoleinwand (in Form der Gesamtfläche) wie auch Fernsehmonitore. Die koexistierenden vielen kleinen Bildausschnitte nebeneinander erinnern an die Bilderfront in einer Regiekabine (Abb. 4.4).

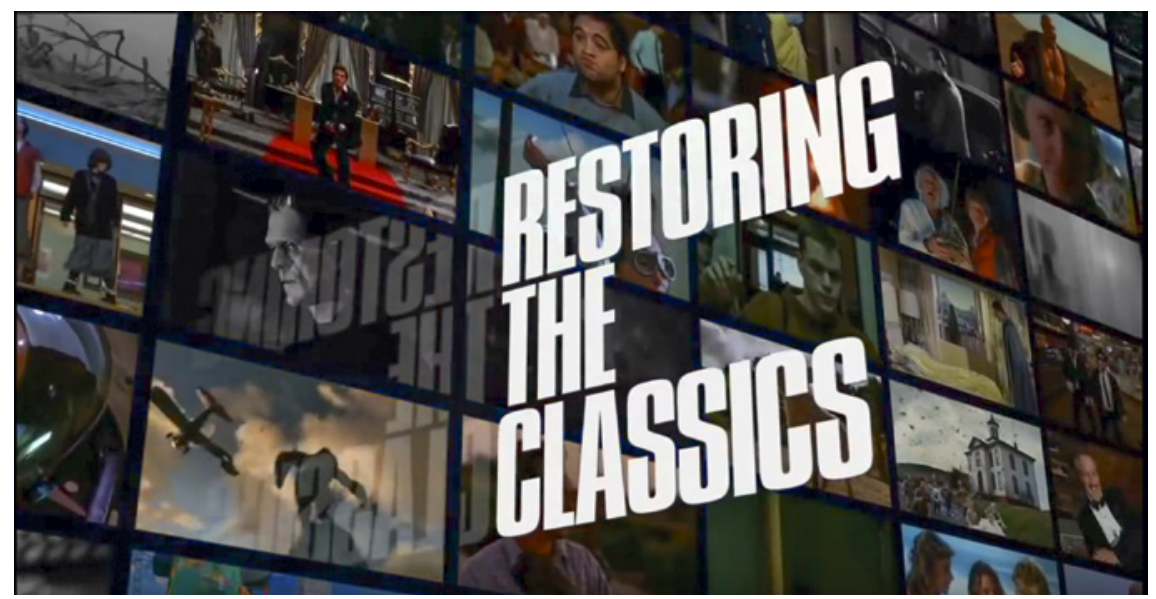

Abb. 4.4

Aus dieser leicht schräg gestellten (Lein-)Wand aus unterschiedlichen Bildfeldern erwachsen hell leuchtende, in glänzendem Weiß erstrahlende Buchstaben: „100 Years of Universal“. Diese verschwinden kurz in einem Lichtspalt in der Fläche aus den lebhaften Bildschirmen, um dann von dem folgenden leuchtend weißen Schriftzug abgelöst zu werden: „Restoring the classics“. Ebenso wie zum einen dieser Schriftzug über die Fläche der aufgespannten Bandbreite hinausweist, so leuchtet er andererseits auch zurück: Er spiegelt sich in der Leinwand aus den hier versammelten ,Klassikern', die alle aus dem Bestand von Universal stammen. 
Der Beginn des Werbeclips formuliert in dieser Konfiguration und ästhetischen Erscheinungsform mehrere für die folgenden Ausführungen konzeptuelle wie analytische Kernaspekte: Die historische Dimension der 10o Jahre Universal, um die es in diesem Clip geht, wird in den ersten Sekunden definiert über die Filminhalte, ihre ästhetische und faszinative Kraft, die durch eine die Bewegungen und Dynamik betonende Montage hervorgehoben wird. Die diegetischen Universen der Filme werden zitiert, es sind Fragmente, die entweder über die ikonografische Gestaltung (zum Beispiel E. T., Jaws) und Mise en Scène (Blues Brothers im Auto), über die Wiedererkennbarkeit von Rollenfiguren (Dr. Brown, Marty McFly, Blues Brothers) oder Schauspielern (Gregory Peck, Matt Damon) augenblicklich, im Moment - auch über den Ton! - trotz ihrer höchst fragmentarischen Form sofort identifizierbar sind - oder in ihrer exponiert ausschnitthaften Präsentation dies zumindest suggerieren. Die Fragmente evozieren im Zusammenspiel mit der dynamischen Montage Momente des Aufbruchs und der Lebendigkeit. Dies geschieht vor allem über die Vermittlung von phänomenalen Reizen: plötzlich blendende und glänzende Lichtreflexe, Kombinationen von unterschiedlichen Bewegungsrichtungen und -rhythmen in und zwischen den Bildern in der dynamischen Montage der ohnehin bereits in sich sehr bewegten Bilder.

Diese affektiv wirksamen Bilder der Eingangssequenz kreieren über ihre formalen Eigenschaften singuläre, als Glanzpunkte wirkende einzelne Reize, die über ihre Augenblicklichkeit Eindrücke des Fragmentarischen vermitteln. Gleichzeitig weisen sie gerade in ihrer Unabgeschlossenheit auch immer schon über den Moment hinaus - auf ein virtuelles Ganzes, das sich unter Umständen über individuelle Erinnerung (an die Herkunftsfilme) komplettiert. Ähnlich verhält es sich mit den Schichtungen der unterschiedlichen Bewegungsrichtungen, die über diverse diegetische Universen verschiedene dynamische Ebenen miteinander kombinieren und ein Reizstakkato ergeben, gerade weil sie in sich als Bewegung oder Geste einzeln unabgeschlossen bleiben.

Dies wird verbunden mit weiteren (An-)Reizen zur Erinnerungsaktivität wie dem pointierten Ausstellen bekannter Motive, Figuren oder Schauspielerpersonae in Großaufnahmen. Selbst bei Unkenntnis der Filme wird zumindest formal suggeriert, dass diese Bilder nicht nur in der eigenen Erinnerung vorhanden sind (sein sollten), sondern auch darüber hinausgehend im kollektiven Gedächtnis verankert sind - und damit erinnerungswürdig, wie H. Böhme es nennt. Es ist eine phänomenal vermittelte zeitliche Komplexion aus Affekt- und Erinnerungs-Bildern, die den Zuschauer mit seiner eigenen Dauer als Funktionsgröße miteinbezieht, gleichzeitig aber auch immer über die persönliche Erinnerung hin zu einem institutionalisierten, unpersönlichen Gedächtnis - man kennt die Filme - weist. 
Das Titelbild nimmt hier in seiner Gestaltung metaphorisch für das Spiel mit zeitlicher Differenzerfahrung, die in dem Clip zum Tragen kommt, eine zentrale konzeptionelle Rolle ein: Der Schriftzug definiert durch sein Erscheinen auf der Leinwand den Kontext der Reprise der Filme. Voraussetzung der hier angepriesenen digitalen Reprise ist die bekannte Präexistenz der Filme. Diese Präexistenz findet ihr Motiv bildlich in der aus den zitierten Filmen zusammengesetzten Leinwand. Diese bildet buchstäblich den Hintergrund für die nun glanzvolle Aktualisierung. Auffällig in der Gestaltung dieses Bildes sind die folgenden Aspekte mit zeit- und geschichtsphilosophischen Implikationen:

- Die Filme laufen innerhalb der Bildschirme weiter, die hier entwickelten Universen und Narrationen entfalten sich unabhängig voneinander fort und sind kontinuierlich wahrnehmbar.

- Die Filme mit ihrem Eigenleben ${ }^{21}$ stehen unabhängig von ihrem eigentlichen (historischen) Produktionszeitraum (196oer, 198oer oder 20ooer Jahre) nebeneinander in einer Fläche, koexistierend auf einer Ebene: ,Geschichte', die historische beziehungsweise zeitliche Differenz wird nicht indiziert durch eine je eigene Zeitlichkeit der einzelnen abgerufenen Filme (etwa durch Angabe von Jahreszahlen), sondern allein durch den Schriftzug der Aktualisierung, die aus dieser Ebene leuchtend herausragt: REstoRING THE Classics. Mit anderen Worten, die ,Klassiker' sind uniform auf einer

21 Der hier gebrauchte Begriff des ,Eigenlebens` erinnert nicht nur an Georges DidiHubermans Überlegungen zum Nachleben der Bilder (2010/2002). Vielmehr scheint vor allem die Quelle seines Begriffsgebrauchs, die Bildforschungen von Aby Warburg, für meine Ausführungen durchaus in vielfältiger Weise anschlussfähig: So sind dies unter anderem die phänomenologischen Tendenzen in Warburgs Überlegungen zur visuellen Raumkonstruktion von Bildern - fotografische Bilder in Stillstand und Bewegung etablieren über eine dynamische Repräsentanz vergangener Ereignisse, des Gewesenen eine besondere Beziehung zum Körper des Betrachters (Sierek 2007: 33-35): „Damit sichern sie das, was Warburg immer wieder als Nachleben in durchaus polemischer Unterscheidung zu Gedächtnis, Erinnerung, Wiedergeburt [...] beschrieb“ (Sierek 2007: 35). Mit Blick auf die in diesem $\rightarrow$ Kap. 4 im Fazit erfolgenden Modellierungen memophänomenaler Wahrnehmungsmodi von Filmgeschichte (vgl. Abschluss dieses Kap. 4) wäre insofern Warburgs Ansatz auf die Metaebene des Nachlebens von Filmwerken zu heben. In diesem Sinne ist Siereks grundsätzlicher Befund zu lesen: „In den Analysen aller möglichen kulturellen Äußerungen sucht Warburg das umfassende, ereignishafte Nachleben eines gewesenen Bildkörpers im Betrachterkörper als schwingenden Zeitkristall in Bild und Ton. Die in den kinematographischen Fluss eingelegten Bewegungsintarsien aus dem historischen Bilderteppich machen aus Ansicht eines Filmes ein Leben des Einst im Jetzt als Daseinsform der Ungleichzeitigkeit, die als differenzielles Ereignis beschreibbar bleibt, aber deswegen seiner flüchtigen Gegenwart nicht verlustig gegangen ist. Es ist das prototypische Erleben des Warburgschen Nachlebens" (Sierek 2007: 197-198). 
zeitlichen Ebene zu sehen, deren zeitliche Verortung allein in Differenz zur Gegenwart und ihren Bedingungen und Interessen geschieht. Diese Gegenwart - in Form des Schriftzugs - weist zudem über die Fläche in den Bildraum hinaus; zeitlich interpretiert, kann man dies auch als Hinausweisen in die Zukunft verstehen: Die Filme werden über die jeweilige - auch kommende - Gegenwart definiert.

Ein weiteres formales Detail kann in dieser Lesart des Titelbildes als symbolisch für die Interaktion der zeitlichen Ebenen gesehen werden. Dass der leuchtend helle Schriftzug nicht nur aus der Ebene der präexistenten Film,klassiker' fast schon eine Lichtgeburt erfährt (die Gegenwart erscheint strahlend aus der filmhistorischen Vergangenheit), ist beredt. Dass darüber hinaus sich zugleich auch die Buchstaben "Restoring the Classics“ in der Leinwand aus einem Mosaik von Filmkadern spiegeln und somit zurückstrahlen, zeigt die Verwobenheit der Zeitebenen. Die (mediale) Geschichte gebiert die Gegenwart, aber die Praktiken der Gegenwart der Restaurierung verändern auch den (aktuellen) Anblick der Filme - sie strahlen zurück. Diese Detailinterpretation gewinnt an Gewicht, wenn man bedenkt, dass man sich in dem Format eines (Werbe-)Clips befindet, der am Ende die zitierten Filme in ihrer nun aktualisierten digitalen Distributionsform auf DVD und Blu-Ray-Disc bewirbt. Die kommerziellen Interessen unter dem Vorzeichen digitaler Distributionsinstrumente und -strukturen bestimmen hier die Gegenwart.

Vor diesem Tableau ist nun das Thema des Clips aufschlussreich. Es geht um die Praktiken der Filmrestaurierung beziehungsweise den - im Englischen als Restoring bezeichneten - Prozess des Restaurierens, wobei die Restaurierung und deren Darstellung in diesem Kontext immer vor dem Hintergrund der spezifischen (kommerziellen) Interessen des Werbefilms zu sehen sind: Am Ende des zehnminütigen Werbefilms wird in Texttafeln auf die auf DVD und Blu-Ray-Disc erhältlichen restaurierten Titel von Universal hingewiesen. Dies wird zum Abschluss dieses Kapitels noch einmal mit Blick auf den hier modellierten Begriff der Warenästhetik im Zusammenhang mit Medien- und Filmgeschichte weiter ausgeführt werden.

Restaurierungsdiskurs in formalästhetischer Erscheinungsform. Archiv, Maschinen und Affekt-/Erinnerungs-Bilder In dem hier diskutierten Beispiel sticht besonders die filmische Inszenierung der technischen Abläufe von Restaurierungsprozessen hervor, die nachhaltig, so die These, mit dem Einsatz von Affekt- und Erinnerungs-Bildern arbeitet. ${ }^{22}$

22 Zur Präzisierung der Affekt- und Erinnerungs-Bilder: Aus Gründen der analytischen Schärfe werden sie hier partiell separat behandelt. Der Werbefilm aktiviert allerdings in einer Clusterstruktur immer beide Ebenen gleichzeitig. Weitere Überlegungen zu 
Dies geschieht auch ganz maßgeblich über eine hohe Schnittgeschwindigkeit und eine enorme Dichte von vermittelten Informationen.

Restaurierung als Modus der begehrenswerten Aktualisierung wird direkt zu Beginn des Clips auf offensichtlicher motivischer Ebene mit dem Versprechen auf die Entdeckung einer neuen Welt, gar eines neuen Universums verbunden. So zitiert der Werbefilm tatsächlich wiederholt das schon im Firmennamen Universal berufene Weltall, indem immer wieder nur für Augenblicke Bilder einmontiert werden, in denen im Weltraum ein gleißendes Licht hinter einem Planeten hervorkommt - ganz so, wie es auch im bekannten Logo des Studios geschieht (Abb. 4.5).

Abb. 4.5

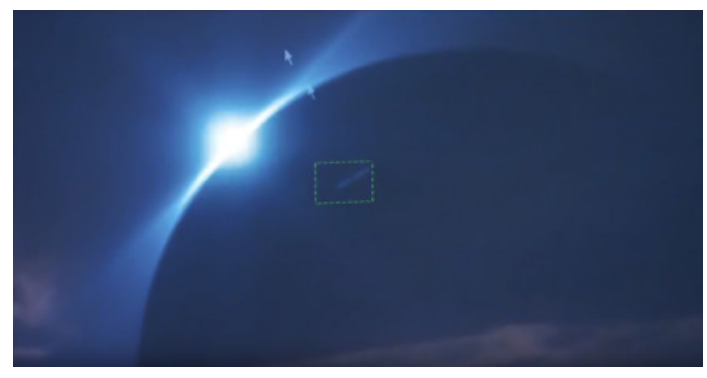

Der hier zum Einsatz kommende fragmentarische Ausschnitt des Logos betont die auf der phänomenalen Ebene wirkenden Reizeffekte, indem der Zuschauer für einen Moment vom Lichtstrahl blitzartig geblendet und sogar somatisch affiziert wird. Dies erweckt Aufmerksamkeit und vermittelt zugleich, dass dem Zuschauer nun eine neue Welt von dem Studio Universal eröffnet wird. Diese Reizbilder durchwirken den einsetzenden, zunächst technisch bestimmten Diskurs.

Dass die von Universal eröffnete Welt eine historische Dimension beinhaltet, wird in den ersten Einstellungen nach der Titelsequenz deutlich: Die Bilder des Clips sind mit der - zugegeben sehr künstlichen, aber trotzdem als solche identifizierbaren - Patina eines zerkratzten sepiafarbenen Archivbilds belegt. Neben der Materialästhetik der Bilder führt derTon ebenfalls in die analoge Ära der Mediengeschichte. Man hört das charakteristische Rattern eines Filmstreifens im Projektor. Der Zuschauer wird über die vom 20. Jahrhundert geprägte Vorstellung, was mediengeschichtlich Film bedeutet, ,abgeholt'. Die analoge Film(projektions)technik wird als Chiffre für das Medium benutzt.

Erinnerungs-Bildern und deren spezifische Wahrnehmungsmodi finden sich in $\rightarrow$ Kap. 6 unter dem Stichwort „prothetische Erinnerung“ und in $\rightarrow$ Kap. 7 unter dem Stichwort „mediated memories". 
Filmästhetisch wird der Entwicklungsprozess von Filmrestaurierung seitens des Werbefilms inszeniert, indem Bob O'Neil, Vizepräsident für Image Assets/ Preservation der Universal Studio Vaults, als Talking Head neben Filmdosen gezeigt wird: „We started preservation and restoration on a film-analog level back in the early 9o's and we have been working on it ever since“ (Hervorh. FH, Abb. 4.6).

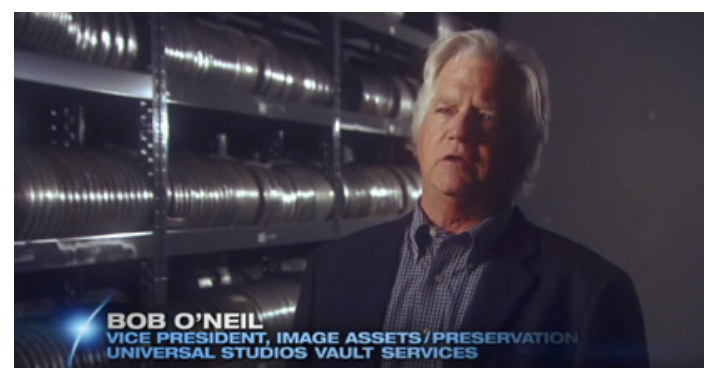

Abb. 4.6

Gemäß der Storyline des Werbefilms findet das Medium Film nun seinen Weg in die digitale Welt. Dies wird bildlich erzählt, indem eine Filmrolle aus dem Regal genommen und in einen Scanner gelegt wird. Der fließende Übergang von der analogen in die digitale Domäne wird formal über den Ton gelöst: Das rhythmische Rattern des Projektors geht über in das stakkatoartige Blitzen, das digitale Abfotografieren des Filmstreifens im offenen Scanner - visuell noch unterstützt durch das regelmäßige Flackern der Lichtquelle des Scanners. Dass es sich hier um einen organischen, bruchlosen Vorgang handelt, findet sich übersetzt in der Kameraführung. Ein beschwingter Schwenk geht von dem Blitzen des Scanners zur sich immer weiterdrehenden Filmrolle: analoge und digitale Welt vereinigt in einer einzigen Bewegung, in der die Elemente fließend ineinandergreifen, indem das eine in das andere übergeht. So folgt auch ein Match Cut von der Filmrolle im Scanner auf einen kreisrunden Regler an einer Postproduktions-Workstation (Abb. 4.7-4.9).

Dazu sieht man weiterhin verschiedene Computerbildschirme und entsprechende Tastaturen. Die Filme, die man vorher als Filmrollen in Regalen sah, sind nun in phänomenal-semantischer Form auf den Bildschirmen zu sehen, das heißt, man sieht die ästhetische Imago der Filme. Sinnbildlich gelesen drücken diese Bilder bereits Grundaspekte (retro)digitaler Workflows aus: Digitale Restaurierung funktioniert als Simulation, Emulation und Remediation $^{23}$ ursprünglich analog aufgezeichneter Informationen. Allerdings -

23 Vgl. die Definitionen der Begriffe und den Bezug zur Restaurierungspraxis bei Fossati (2009) in $\rightarrow$ Kap. 2. 
Abb. 4.7

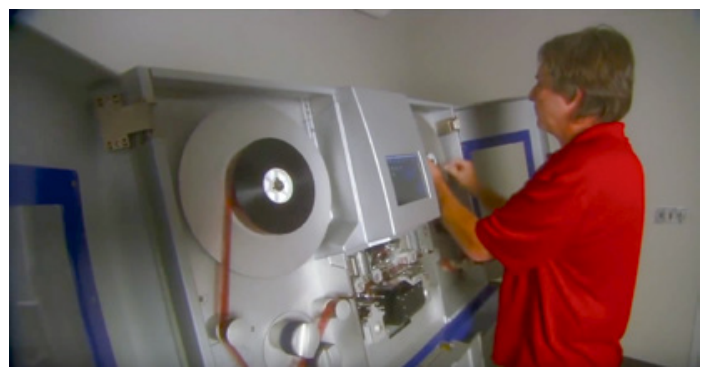

Abb. 4.8

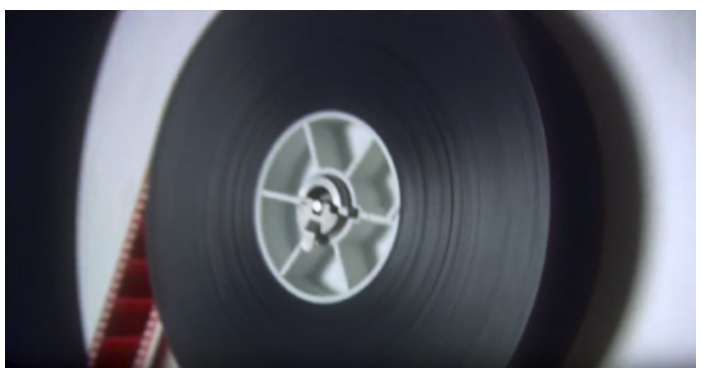

Abb. 4.9

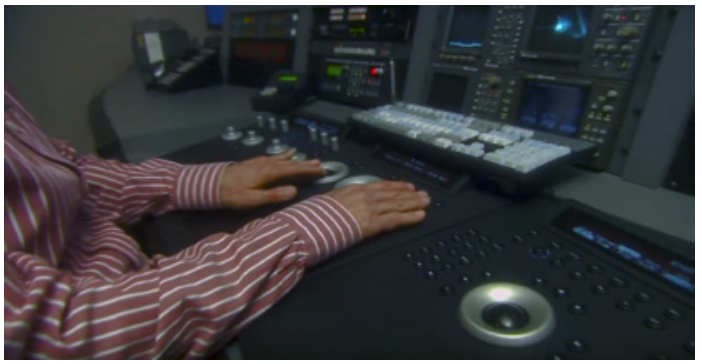

und das ist bei diesem Beispiel entscheidend - sieht man in dem vorliegenden Werbeclip den Filminhalt kaum durch den Filmstreifen, sondern vielmehr auf dem Computerbildschirm: Die phänomenale Erscheinung des Films ist schon in der digitalen Domäne und auch von dieser diskursiv gerahmt (Abb. 4.10).

Dies wird in der folgenden Einstellung augenscheinlich, wenn ein Schaden, der ursprünglich im fotochemischen Filmstreifen war, nun digital abgebildet auf dem Bildschirm erscheint. Dass es sich um einen Fehler handelt, wird darüber vermittelt, dass mit dem Cursor der digitalen Arbeitsstation eine quadratische Markierung über die Bildstelle gezogen wird und damit der Mauszeiger nachdrücklich auf den Schaden weist. Zu sehen ist ein Riss in einer weiten Einstellung von einem Himmel in der Abenddämmerung. Im übertragenen Sinne ist dies zu lesen: Die illusionsbildende Harmonie des Bildes ist phänomenal gestört. 


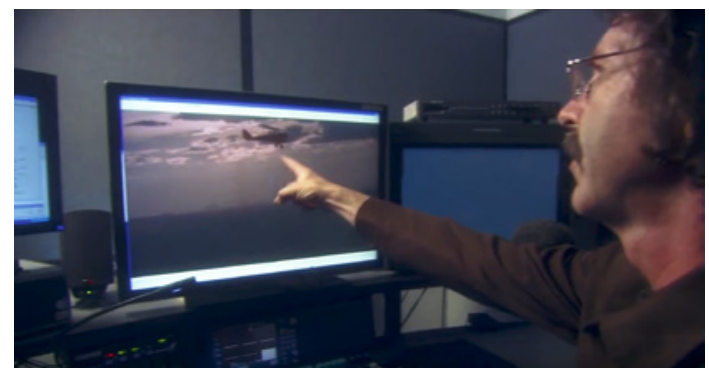

Abb. 4.10

Im Kontext des Werbefilms vermittelt diese Form der Inszenierung eines Bildbearbeitungsprozesses über die Naheinstellungen (und damit über die visuelle Betonung der Schadensidentifikation im Bild) eine Evidenz über die Notwendigkeit, Richtigkeit, gar Überlegenheit des offensichtlichen (Meta-) Eingriffs in das Bild; dies umso mehr, als vorher der nahtlose Anschluss an die analoge Filmtechnik ins Bild gesetzt wurde: eine fließende Bewegung ohne Verlust zwischen den zwei Welten von Medientechnik! Wieder wird man für einen Moment von der Sonne hinter dem Universal-Planeten geblendet. Das Bild hat hier eine einigende Botschaft: Das Universal-Universum umfasst sowohl analoge als auch digitale Filmtechnik. Diese Montagestrategie changiert insofern zwischen technisch-konkreter und höherer metaphorisch-mythischer Ebene.

Fröhliche Klaviermusik setzt ein und zeigt von der Zeit verfärbte Ausschnitte aus dem Doris-Day-Film Pillow Talk (1959) (Abb. 4.11).

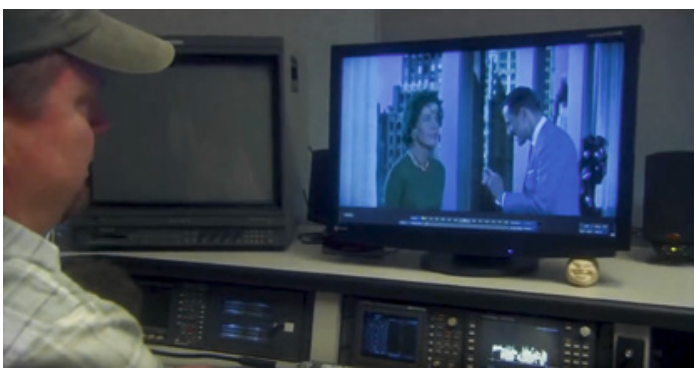

Abb. 4.11

Die Bilder sind nicht nur grünlich verfärbt, das Material weist auch deutliche Risse auf. Die Bildschäden entwickeln aber in den Bewegtbildern einen eigenen phänomenalen Rhythmus, sie ,tanzen' auf dem Bild, was sich in der Wahrnehmung des Zuschauers mit der extradiegetischen Klaviermusik, mit der der Universal-Clip nun unterlegt ist, zu einem organischen, unbekümmerten Ganzen zusammenfügt. Dieser Eindruck wird zudem vom Inhalt des restaurierten Films unterstützt, da es sich um eine verspielte Szene 
der Romantic Comedy handelt. Diese affektiv besetzten Bilder, durchtränken` mit ihrer emotionalen Stimmung die eigentlich heterogene Montage und übertragen den Rhythmus in den Bildern sowie die sorglose Atmosphäre auch assoziiert mit der Persona Doris Day - auf den Prozess der Restaurierung.

Es ist alles eine Bewegung, ein organischer Arbeitsprozess: Die verfärbten Vorher-Bilder werden nun von einem vertikalen Streifen durchfahren, einem Wischer, der dann die Bilder nun klar, mit ,natürlichen' Farben - an Referenzregionen wie Hauttönen und dem Himmel erkennbar - und ohne Kratzer hinterlässt (Abb. 4.12).

Abb. 4.12

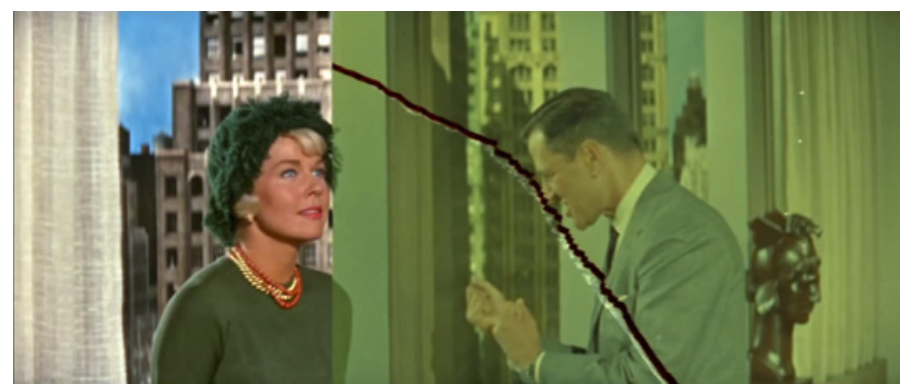

Es ist eine prototypische Darstellung von Restaurierungsprozessen (vgl. hierzu die Ausführungen in $\rightarrow$ Kap. 7 zur DIY-Restaurierung und zum Modus des vergleichenden Sehens): Der Zuschauer erfährt in der Dauer des Wischens, mit dem Streichen über das Bild, das Resultat der Restaurierung. In diesem Fall wird in der organischen Bewegung und in der besonderen Stimmung eine zeitliche Dynamik spürbar, in deren Entfaltung historische Differenzen verschwimmen und Vergangenheit wie Gegenwart kopräsent in der Transitionsbewegung erscheinen, die ein Versprechen auf ein erneuertes Erlebnis des fiktionalen Universums des Films bedeutet. Es ist ein Mehr an Erlebnis, das über das restaurierte Fragment hinausweist. Mit Deleuze lassen sich diese Bewegtbilder somit als wechselseitige beschreiben. ${ }^{24}$

24 In ähnlicher Weise wird die Behebung von Flicker anhand von All QUIET oN THE Western Front (1930) erläutert; Jittering wird mit Beispielen aus OUt of AfricA (1985) über Markierungen von Bildregionen erklärt. Die Color Correction wird an dem verfärbten Material von Pillow TAlk (1959) illustriert. To Kill A Mocking Bird (1962) ist Anschauungsbeispiel, als es um die Behebung von analogen Schäden in der digitalen Repräsentation des Films geht. Hier wird die mehrschichtige Funktion als Bild deutlich neben der Illustration der Technik: „The tear is directly over Gregory Peck.“ Es wird explizit darauf hingewiesen, welcher Star als Persona in diesem Film wiederzuerkennen ist. Auf diese Weise wird der Status des Films als ,Klassiker' suggeriert. 
Vor diesem Hintergrund ist nun die folgende Sequenz interessant - vor allem auch mit Blick auf die phänomenale Bildwirkung: Die Expertenstimme erläutert aus dem Off: „There is a selected group of titles we are working on now“. Exakt abgestimmt auf das „now“, auf das "Jetzt“, ist ein Bild montiert, in dem ,der' weiße Hai mit weit aufgerissenem Maul aus dem Wasser auf die Kamera und damit auf den Zuschauer zuspringt (Abb. 4.13); ein zutiefst gegenwärtiger Schock, der auf der Unmittelbarkeit der Affektwirkung von Filmbildern insistiert.

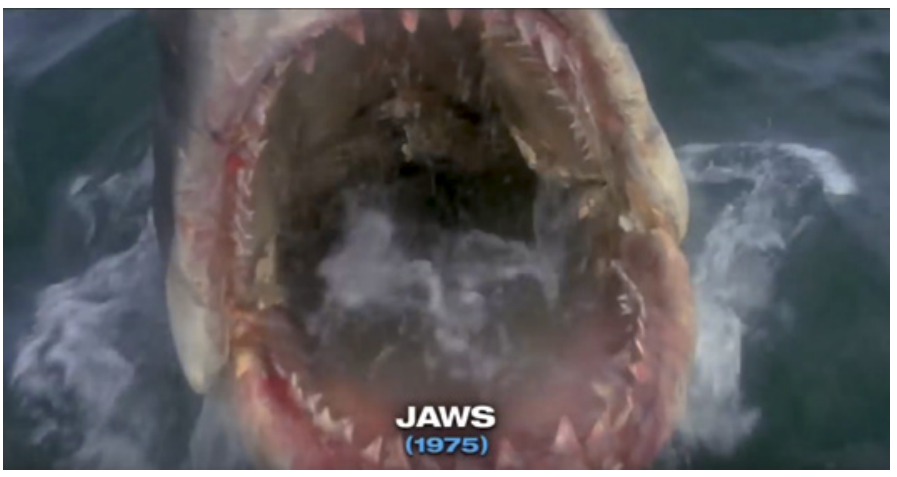

Abb. 4.13

Die Einstellung wechselt sofort in eine seitliche Halbtotale, in der man das kleine Boot sieht, das von dem riesigen Haifisch attackiert und fast in die Tiefe gerissen wird. Der Schock, der direkt auf den Zuschauer des Werbefilms gerichtet ist, wird damit noch um den Eindruck einer unfassbaren Naturgewalt erweitert.

Damit aber auch die Wirkung dieser Bilder sofort an die Erinnerung wenn nicht an die individuelle, so doch zumindest die kulturelle - gebunden werden kann, werden zusätzlich, obwohl doch ikonografisch recht eindeutig, der Titel und das Produktionsjahr dieses filmhistorisch wirkmächtigen Films eingeblendet: Jaws, 1975. So wird nicht nur der Film überdeutlich identifizierbar, er wird auch in seiner Bekanntheit und kulturellen Bedeutung vorausgesetzt. Gleichzeitig markiert die konkrete Angabe des Produktionsjahres eine historische Differenz zur Jetztzeit, die aber in der phänomenalen, im gegenwärtigen Moment funktionierenden Wirkung der Bilder aufgehoben wird. Mit anderen Worten, die formalästhetische Gestaltung und die Montage der Bilder vermitteln die höchst aktuelle Wirkmächtigkeit eines Klassikers, eines historischen Films, die sich dank der von Universal durchgeführten Restaurierung entfalten kann. Es kommt zu einem Paradox: Auf der einen Seite ist phänomenal die Nivellierung der markierten zeitlichen Differenz 
notwendig, damit der gegenwärtige Unterhaltungswert, die Attraktion für eine heutige Rezeption deutlich wird. Auf der anderen Seite kann die Leistung von Universal in der Restaurierung nur wahrnehmbar und damit gewürdigt werden, wenn die historische Dimension, die Tatsache, dass der ursprüngliche Film ,älter ist, ein Vorleben im kulturellen Gedächtnis und gar im Kanon innehat, simultan als Folie des Affekterlebens vorhanden ist. Die historische Dimension wird hier nur denotiert, sie wird in das Imaginäre und den Erinnerungsprozess des Zuschauers verlegt: Die historische Dimension bleibt dezidiert unspezifisch und konkret phänomenal meist abwesend, oder sie wird ostentativ ausgelöscht (etwa das ,Wegwischen“ von Schäden im Fall der Restaurierung von Pillow TALK). Sie wird aber als virtuelle Folie für die aktuelle Affektwirkung gleichwohl benötigt.

Affekt- und Erinnerungs-Bilder konstituieren in ihrem Zusammenwirken und in ihrer Interdependenz die ästhetischen Prinzipien dieses Werbefilms; Affekt-Bilder betonen das Präsentische der audiovisuellen Erfahrung, während Erinnerungs-Bilder über propositorische Strukturen das Wiedererkennen nahelegen: Ob dieses nun individueller oder kollektiver Natur ist - die hier beschriebenen Bildstrategien arbeiten mit der Suggestion, dass sie im kollektiven Gedächtnis einen Platz als unbedingt erinnerungswürdig innehätten.

Affekt- sowie Erinnerungs-Bilder ermöglichen heterogene zeitliche Erfahrungen, die immer auch mit Erfahrungen des Abwesenden und mit der Aktivierung des Virtuellen spielen. Im Zeichen des in diesem Kontext entstehenden Wahrnehmungsmodus einer Fetischisierung gilt es festzuhalten, dass es im Präsentischen des filmischen Eindrucks zu einer Verwebung von persönlicher und kollektiver/allgemeiner Erinnerung kommt. Über die somatisch-affektiv wirkenden Reizbilder werden diese Vergegenwärtigungen von Erinnerung als begehrenswerte vermittelt.

Insbesondere Letzteres wird in der folgenden Montagesequenz aus Titeln deutlich, die aus weiteren Fragmenten der von Universal restaurierten Filme besteht (Abb. 4.14-4.15):

Abb. 4.14

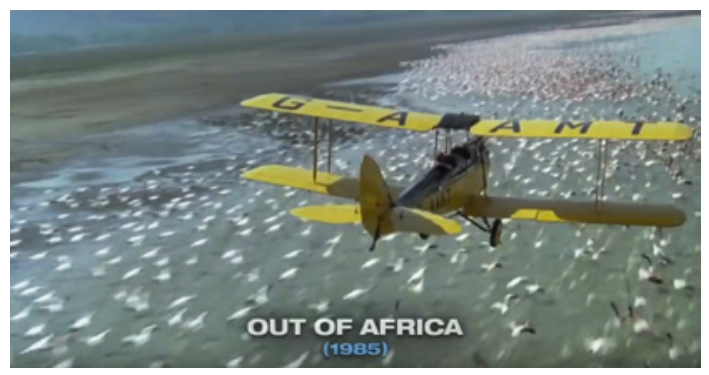




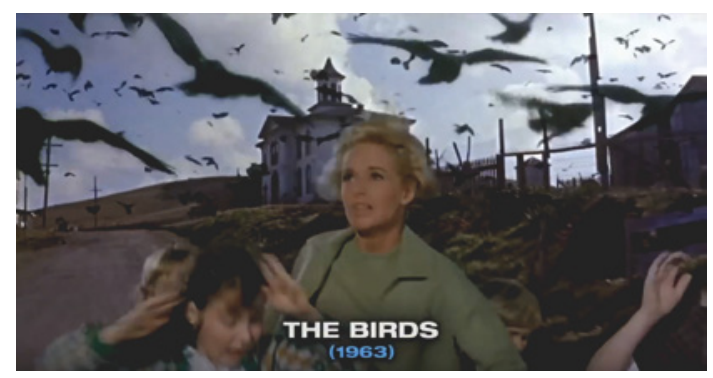

Abb. 4.15

Filmästhetisch werden Topoi wie Freiheit und Aufbruch vermittelt (so etwa im Bewegungssog eines Flugzeugs aus OUT OF AFricA, 1985). Diese werden ergänzt durch teaserhafte Bilder aus dem Horrorgenre (BRIDE OF FrANKENSTEIN, 1935); dann wieder schockhafte, affektsteigernde Einstellungen: Tippi Hedren wird frontal von einem aggressiven Schwarm von Vögeln verfolgt (THE BIRDS, 1963). ${ }^{25}$

\section{Auditive Affekt- und Erinnerungs-Bilder}

Eine besondere Rolle spielt der Ton. Im Montagezusammenhang des untersuchten Werbefilms schafft er in der Narration über Geräusche und Musik wichtige Verbindungen in der Darstellung von analoger und digitaler Filmtechnik. Im Wahrnehmungshorizont des Zuschauers wird - ähnlich wie es bei den Bildkompilationen der Fall war - eine organische, bruchlose Bewegung von der einen zur anderen kreiert. Die Stimmen der, Experten', die in Form von Talking Heads als Autoritäten eingeführt wurden, übernehmen die Funktion, als Voice-Over über Montagesequenzen ein einheitliches Narrativ über die Restaurierungsarbeit bei Universal zu konstruieren.

Überblendungen, Montage und Kameraführung unterstützen in ihrer Dynamik den Eindruck von fließenden, verlustfreien Übergängen von eigentlich sehr heterogenem Material - es fügt sich alles zu einem organischen Erlebnisfluss. Dabei ist wichtig festzuhalten, dass die fragmentarischen Filmzitate in

25 Eine auch bildmotivisch - und nicht nur filmgeschichtlich - historische Dimension wird mit der emotionalisierenden Ebene verknüpft, wenn man am Ende dieser Sequenz sich mitten auf den Schlachtfeldern des Ersten Weltkrieges wiederfindet. Die Kamera wird von flüchtenden Soldaten übersprungen und fast umgerannt, man hört Kampfgeräusche. Eine Totale enthüllt chaotisches Schlachtgetümmel im Grabenkrieg. Bombeneinschläge schleudern Erdfontänen empor, die fast das ganze Bild einnehmen. Zu dieser Montage von Bildern aus All Quiet on the Western Front (1930) hört man die Expertenstimme aus dem Off, die die Aufgabe der Filmarchivare und -restauratoren bei Universal beschreibt: die historischen Werke, die Geschichte am Leben zu erhalten und für zukünftige Generationen zu erhalten. 
den emotionalisierenden Montagesequenzen nicht in einer remediatisierten Form - etwa gerahmt von beziehungsweise in Computerbildschirmen - vom Werbefilm gezeigt werden: Die zitierten fiktionalen Erlebniswelten sind in ihren Ausschnitten nicht als Zitat markiert, das heißt im Moment des Zitierens wird die Erlebnisqualität des jeweiligen Fragments als konkret phänomenale Erfahrung funktionalisiert. ${ }^{26}$ Bei dem Ton wird dieses Verfahren zwischen Hypermediacy und Immediacy noch deutlicher (Bolter/Grusin 1999, vgl. hierzu grundlegende Ausführungen $\rightarrow$ Kap. 2 sowie den nachfolgenden Exkurs $I$ in diesem $\rightarrow$ Kap. 4 zu historiografischen Dynamiken).

Die organische Einheit, vor allem auch mit Anreizen für eine affektive, unmittelbare Reaktion seitens des Rezipienten, wird durch die immer wieder eingestreuten Passagen aus den jeweiligen diegetischen Sounddesigns der zitierten Filme gestiftet. Wenn etwa unruhiger, verstörender Flicker als Schaden im analogen Filmstreifen erklärt werden soll, so wird dies mit einer Einstellung auf Draculas Schloss aus der Filmversion von 1931 gezeigt und mit der unheimlichen Originalmusik des Films unterlegt. Diskursiv gelesen ergibt dies als Narrativ: Flicker als Verstörung der Weltwahrnehmung.

Ton als sinnliche Vermittlung des Mehrwerts einer Filmrestaurierung findet seinen deutlichsten Ausdruck, wenn der Werbeclip Audiorestaurierung illustriert. Die Wiederbelebung eines historischen Werks durch die Tonrestaurierung wird mit einem Spielfilmfragment zum Ausdruck gebracht: „I am Dracula" verkündet der ewige Untote in einem Filmausschnitt (Abb. 4.16).

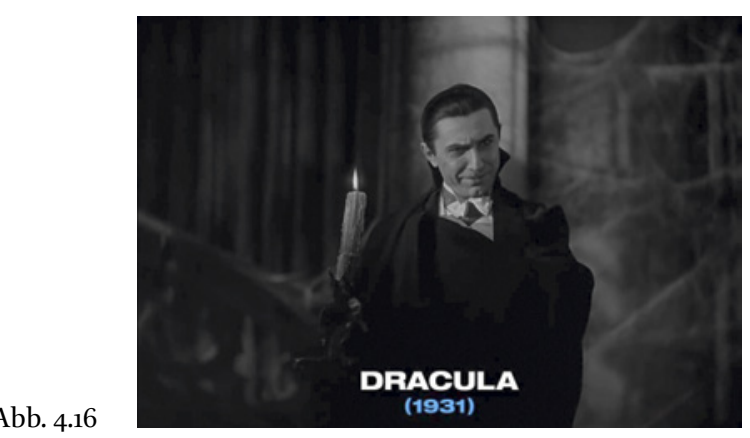

26 Dieses wirkungsästhetische Verfahren hat eine restaurierungspolitische Entsprechung: Die Mitarbeiter von Universal formulieren als Talking Heads, dass für sie bei der Restaurierung der Primat des ungestörten audiovisuellen Erlebnisses sowie der der Unterhaltung im Vordergrund steht. Nach dieser Formel würden Entscheidungen in der Restaurierung getroffen werden. Wichtig sei es, dass die Vision des Autors (Regisseurs, Kameramann etc.) beibehalten werde: „We are not altering the filmmaker's vision but we are removing things that are detrimental for the experience, that are distracting ... now we have tools to be able to deal with that." 
Die Montage des Werbefilms zeigt hier, dass digitale Technik nicht nur wiederbelebt, sondern bislang Unerhörtes wahrnehmbar macht: eine Tondimension, "that wasn't really heard in the past“ - so der Expertenkommentar des Clips. Der Zuschauer des Werbefilms kann sich direkt selbst davon überzeugen: Es wird ein Vorher-Nachher der Restaurierung am Beispiel des Fiepens von Mäusen und Ratten in Draculas Keller vorgeführt. Auch hier wird der Zuschauer mit einem Ausschnitt aus dem Spielfilm von Dracula aufgefordert: „Listen to them!“.

Auf diese Weise wird über den Ton eine organische Bewegung zwischen präsentischen Affektstimulationen und ständigen Anreizen zur Modellierung von Erinnerungs-Bildern kreiert. Wieder changieren die initiierten ErinnerungsBilder strategisch zwischen individuellen Reaktionen wie Assoziationen und einem suggerierten kollektiven filmhistorischen Wissen.

\section{Zeitliche Projektionen in die Zukunft. Ein organisches Ganzes}

Eine letzte wichtige wirkungssästhetische Funktionsweise des Zusammenwirkens von beschriebenen Affekt- und Erinnerungs-Bildern ist die Projektion der zitierten fiktionalen Universen nicht nur auf die Restaurierungstätigkeit von Universal, sondern - und damit der kommerziellen Logik folgend auch auf den Mehrwert der Distribution auf digitalen Trägern wie DVD und Blu-Ray-Disc.

Das Ende des Werbefilms weitet die Idee eines organischen Ganzen der von Universal repräsentierten Filmgeschichte auf einen gemeinschaftlichen überzeitlichen Emotionsraum und eine allgemeine Bewegung in die $\mathrm{Zu}$ kunft aus. Nachdem die einzelnen zu lösenden technischen Probleme der digitalen Filmrestaurierung vorgestellt wurden, folgt eine Montagesequenz von Spielfilmfragmenten mit lachenden Protagonisten, meist gebunden an Starpersonae - von Robert Redford und Paul Newman bis hin zu Doris Day und Rock Hudson (Abb. 4.17). Das Gelächter ist laut zu hören. Diese Exaltiertheit überträgt sich auf die gezeigten Körper: Es folgen Tanz- und Partyszenen aus den 193oer/4oer Jahren (Abb. 4.18).

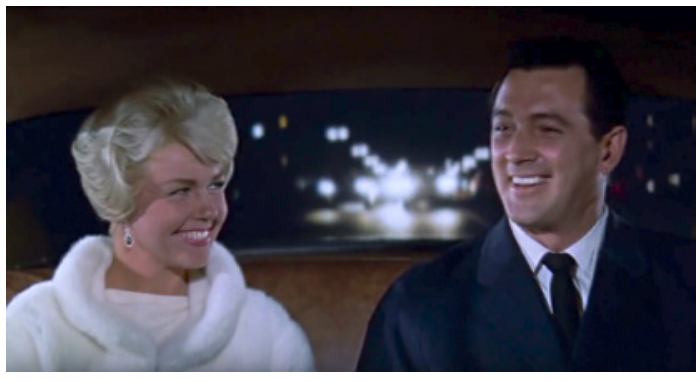

Abb. 4.17 
Abb. 4.18

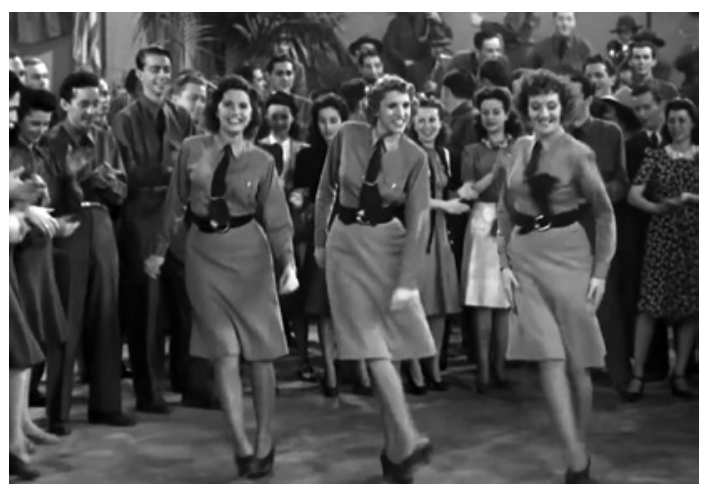

Die Experten-Voice-Over kommentiert: Man könne die Arbeit der Archivare als die eines „caretakers“ (Hüters, Pflegers) bezeichnen. Die Filme, die damals gedreht worden seien, seien nach ihrer Kinoauswertung weggeräumt („put away") und vergessen worden. Aber sie, die Filmarchivare von Universal, sähen sie als unser aller Erbe an; deshalb liege darin eine überzeitliche Verantwortung für spätere Generationen, für unsere Kinder und Enkel - Gregory Peck umarmt hierzu seine Filmtochter in einem Ausschnitt aus To KILl A MocKing BIRD (1962); Einstellungen von digitalen Arbeitsplätzen (Scanner, Bildbearbeitung); die Bildschirme zeigen panoramatische Einstellungen von einem Himmel (Abb. 4.19-4.21).

Abb. 4.19

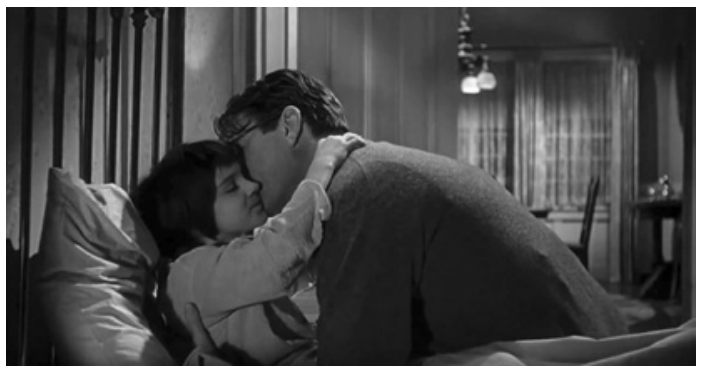

Abb. 4.20

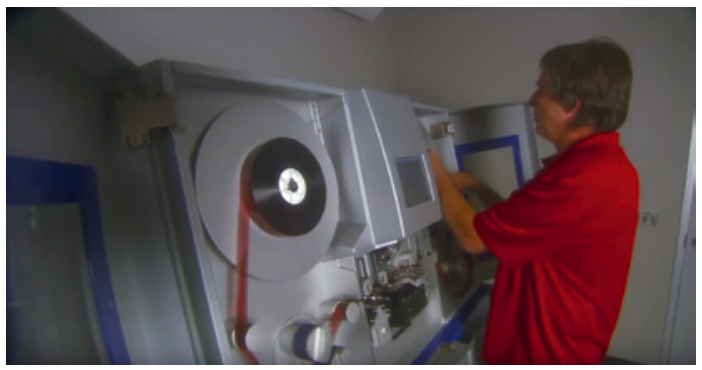




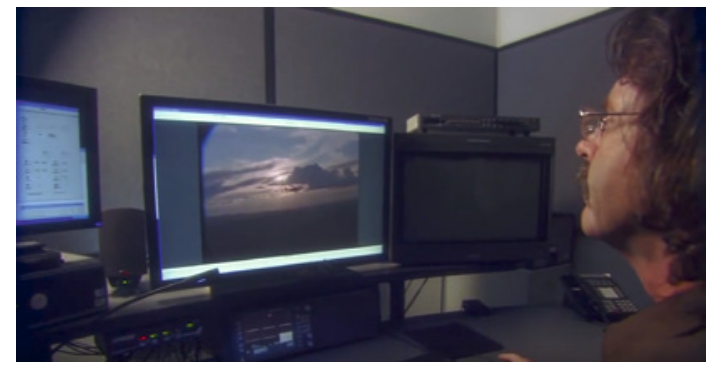

Abb. 4.21

Letztere öffnen damit metaphorisch den Blick ins Unendliche, in die lebendige digitale Zukunft: Filmrestaurierung wird zugleich erneut mit der Metaphorik phantastischer Wiederbelebung und Wiederauferstehung konnotiert, wenn der Ausschnitt eines Frankenstein-Films gezeigt wird - mit der emotional von einer Figur gerufenen diegetischen Dialogzeile: „It's alive, it's alive, it's alive!“ (Abb. 4.22).

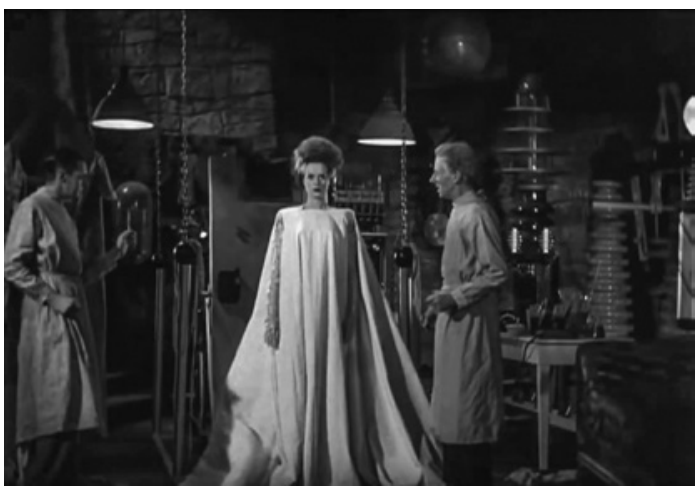

Abb. 4.22

Mit Bezug auf den Anfang des Werbeclips wird in einer zyklischen Struktur nun wieder Bob O'Neill gezeigt: Über die Anstrengungen in Restaurierung und Sicherung würde man es ermöglichen, die Filme noch in 50 und 100 Jahren sehen zu können. Mit dem Zitat des Schlussbilds von Jaws schwimmen zwei glücklich Überlebende des Haiangriffs in Richtung des verheißungsvollen Horizonts ... (Abb. 4.23). Der Werbefilm endet daraufhin mit der Einblendung von Tafeln, die die gezeigten und zitierten Titel auf DVD und Blu-Ray-Disc ankündigen.

Die Schlusssequenz setzt bereits etablierte Verfahren des Werbefilms fort und verdichtet sie: Attraktionen der zitierten fiktionalen Universen und Formen phänomenaler Bild- wie Tonwahrnehmung werden über die Montage auf 
Abb. 4.23

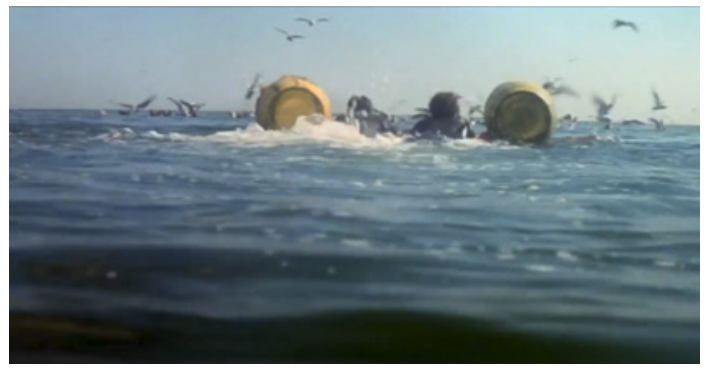

den (technischen) Restaurierungsdiskurs projiziert. Eine hohe Frequenz von emotionalisierenden Einstellungen und Aufnahmen ,durchtränken' die Bilderfolgen (vgl. Begriffsgebrauch von Deleuze 1997a: 150-151). Damit erfahren die tatsächlichen Restaurierungspraktiken eine intensive ästhetische Vermittlung, aufgeladen durch ständig kopräsente Stimmungen und Atmosphären der zitierten Filme. Darüber hinaus wird in der Erfahrung des Zuschauers über Schlüsselreize das positive Resultat der Restaurierung nachhaltig affirmiert und aufreizend-lustvoll aufgeladen. Dem Zuschauer werden über die Montage, etwa von Gelächter oder den rhythmischen Tanzszenen, appellativ und ostentativ Emotionen und körperliche Reaktionen auf die zitierten Filme sowie auf die beworbene Aktualisierung nicht nur nahegelegt, sondern fast schon auferlegt. So generiert die ästhetische Struktur den Eindruck einer Verheißung - aus dem Moment heraus hin auf die besondere potenzielle Erlebnisqualität und kommende körperlich fühlbare Vergegenwärtigung der Filme.

Filmerlebnis und Filmrestaurierung - und mittelbar auch Film- und Technikgeschichte - werden als ein umfassendes organisches, konfliktfreies bewegendes Ganzes vermittelt, in dem zeitlose Unterhaltung im Vordergrund steht; dies wird mit universellen Topoi einer generationsübergreifenden globalen Gemeinschaft (man denke an die sich drehende Weltkugel im Logo von Universal) verbunden. Diskursiv wird dies übertragen auf die zwei medientechnischen Welten - analog und digital -, die in einem konfliktfreien Austauschverhältnis stehen und wieder als in einem Universum geeint dargestellt werden. Immersives, von Spannung, Unterhaltung und Affekten tief imprägniertes Filmerleben an sich wird im Kontext dieses Werbefilms zu einem fetischisierten, überhöhten zeitlosen Mythos, den man zu Hause medial individuell verfügbar halten kann. Die Faszination bleibt aber nur dann als Mehrwert bestehen, wenn der Zuschauer/Konsument sich auf das hier ästhetisch zelebrierte Ritual der zeitlichen Vielschichtigkeit der wechselseitigen Bilder einlässt und damit stets etwas Abwesendes im Moment mitspürt - das immer präsente Verlangen auf ein Mehr auf unterschiedlichen 
Ebenen. So versprechen diese Bilder unter anderem auch paradoxerweise trotz aller möglicher medialer Verfügbarmachung in der Privatheit des eigenen Heimes -, Teil einer virtuellen Erinnerungsgemeinschaft zu werden: Es ist das Versprechen der Teilhabe am kollektiven Gedächtnis der Filme beziehungsweise der filmischen Universen. Dies sichert einen Wahrnehmungsmodus, welcher die notwendige Überhöhung wahrt, die das sinnliche Gebrauchswertversprechen der digitalen Edition und Distribution ausmacht.

\subsection{Fetischisierung phantastischer Erinnerungs-Bilder. Werbeclip zur Platinum Edition (2007) von Disneys Peter Pan (1953)}

Die zweite Untersuchung widmet sich exemplarisch den ästhetischen Strategien des Clips zur Re-Edition eines sogenannten ,Klassikers', der die DVD mit all ihren digitalen Qualitäten als Träger wie Zugangsform bewirbt. Ähnlich dem Verfahren des ersten Beispiels werden hierbei Erinnerungs- und Affekt-Bilder funktionalisiert, die sich aber noch stärker als im Werbefilm von Universal auf das ,Image' des beworbenen digitalen Dispositivs richten. Auch in diesem Beispiel finden sich Mechanismen der Fetischisierung, die allerdings deutlicher auf die räumliche Dimension des Dispositivs weisen. Gleichzeitig werden Topoi des Märchen- wie Zauberhaften und Phantastischen in Verbindung mit dem digitalen Dispositiv gebracht. Dadurch wird diesem eine die Realität überschreitende und transzendierende Qualität zugeschrieben. ${ }^{27}$

Das besprochene Beispiel ist ein Werbeclip zu der Platinum Edition von Disneys Peter Pan (1953) in einer 2-Disc-Special-Edition (2007). Der knapp anderthalbminütige Clip ruft zum einen die bekannten Motive des Märchens auf, zeigt aber zugleich die neuen Qualitäten und den Mehrwert der aktuellen Edition. Dabei verwendet er vornehmlich eine Voice-Over, die mit Szenen aus dem historischen Disney-Film montiert werden.

So dominieren den Clip von Anfang an ästhetische Gesten, die darauf angelegt sind, den Zuschauer in seiner Kenntnis des präsentierten fiktionalen Universums abzuholen beziehungsweise die Präexistenz des Werkes im kulturellen Kanon zu suggerieren. Auf dieser Basis wird dann Aufmerksamkeit und Neugier auf die kommende Attraktion, auf die Variation in der Aktualisierung, geschaffen. ${ }^{28}$

27 So lautete auch in den 2oooer Jahren ein Werbeslogan des Disney-Konzerns für seine DVD-Editionen: „Pure Digital Magic“. Das entsprechend auch visuell gestaltete Logo ist auf DVD-Editionen zu finden.

28 Hediger (2001: 225 ff.) hat das Wechselspiel zwischen Neugier, Attraktion und Referenzierung auf Bekanntes als „Nostalgia for the Coming Attraction“ bezeichnet. 
Aus einem blauen Nachthimmel fliegt ein goldener Schriftzug heran: „Coming to Disney DVD“. Ähnlich wie bei dem vertrauten Slogan „bald im Kino" wird der Erscheinungsort des Films zuerst genannt: Von Beginn an wird der Blick darauf gerichtet, wo, wie, über welche Form der Film zu sehen sein wird. Die Kenntnis des Films wird dabei - wie angesprochen - als selbstverständlich vorausgesetzt. Dies wird mit dem Eintritt des Zuschauers in das fiktive Universum gekoppelt: Erst der Establishing Shot auf eine nächtliche Straße in London - man wird räumlich in der Zeichentrickwelt verortet -, dann Peter Pan, der durch ein Fenster in das Dachzimmer einsteigt und seinen kindlichen Mitstreitern das erste Mal begegnet. Die Voice-Over verknüpft auf der extradiegetischen Ebene die visuelle Immersion des Zuschauers in die präsentierten Bilder mit der inneren phantastischen Logik des fiktiven Universums. Das Märchen begann, so die Voice-Over, „because they believed“: Man müsse daran glauben, dann könne man mit Peter Pan Abenteuer erleben dies gilt für die Kinder in der Geschichte wie für den Zuschauer/zukünftigen Konsumenten, dem das Universum über die DVD zugänglich wird.

Die Logik der fiktionalen Welt und die der Nutzung der DVD durchdringen sich hier bereits nachhaltig. Peter Pan formuliert mit seiner diegetischen Stimme in einem zitierten Fragment aus dem Film die Bedingung: „All it takes is a little bit of pixie dust." Dies wird nun von dem Clip explizit auf die Archivqualität des Films und damit symbolisch auf den Status des fiktiven filmischen Universums als wertvolle kollektive Erinnerung übertragen: Aus Feenstaub heraus materialisiert sich eine Tresortür, die sich langsam zum Zuschauer hin öffnet: „Finally releasing from the Disney vaults: Walt Disney's Peter PaN.“ Es ist aber kein gewöhnlicher Tresor, sondern der auf diese Weise konnotierte Archivschrank hat die Form des konzerneigenen Markenzeichens (Abb. 4.24).

So ist die sich öffnende Tresortür in der Silhouette der weltbekannten Mickey-Mouse-Ohren geformt. ${ }^{29}$ Dieses Bild offenbart mehrere erinnerungspolitische Dimensionen: Zunächst untermauert es den Status des Films als präexistierend, er hat ein Vorleben in bestehenden Diskursen, symbolisch vermittelt über die Institution des Archivs. ${ }^{30}$ Das Archiv als überindividuelles, kollektives Gedächtnis wird somit in den Vordergrund gestellt und gleichzeitig über die Form des Archivschranks von der Firma Disney motivisch vereinnahmt: Selbst das kulturelle Gedächtnis ist Teil des Disney'schen Universums.

29 H. Böhmes Befund zum Verhältnis von Museen, Fetischisierung und Ästhetisierung ist an dieser Stelle sehr sprechend: „Museen arbeiten gegen den Abfall (das Ausgesonderte der Kultur, das Veralten). Sie folgen der Ökonomie der Schatzkammer. Sie betreiben die Anhäufung von stillgelegtem, unproduktivem Kapital“ (H. Böhme 2012: 372). 


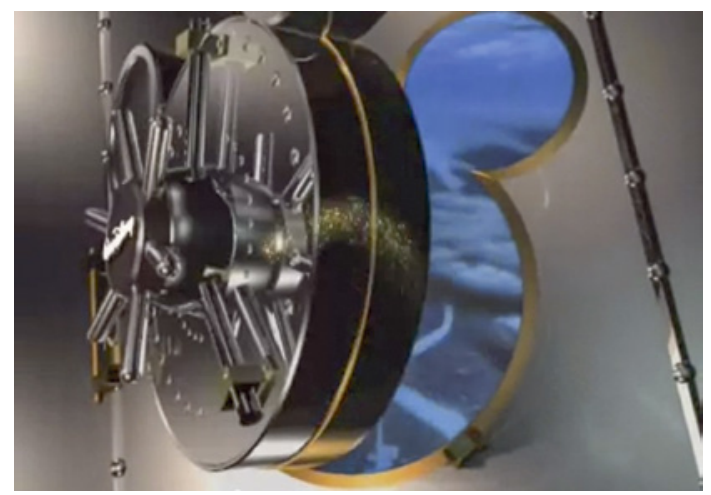

Abb. 4.24

Gleichzeitig funktioniert der Archivschrank wie ein Tresor, in dem etwas besonders Kostbares gelagert wird. Insofern wird der besondere Wert des Inhalts hervorgehoben. Dadurch, dass aber keine Filmrollen im Tresor liegen, sondern die Tür den Blick in das fiktive Universum immersiv freigibt, wird deutlich: Der Wert liegt in dem Versprechen auf das Erleben der phantastischen Welt von Disney. Dies ist das Ziel der Vermarktung, des warenästhetischen Versprechens auf Mehrwert. Die Filmrollen als historisches Artefakt, die im Archiv liegen, wie es etwa im ersten Analysebeispiel dieses Kapitels der Fall war, sind hier in dem Diskurs mitnichten präsent.

Aus einem weiteren Sternenschweif aus Feenstaub offenbart sich nun die hier beworbene Attraktion des neuen Trägers und damit des neuen Zugangs: "Walt Disney's Classic Peter PAN for the first time on a 2-Disc Special Edition DVD“. Mit Momentaufnahmen aus dem Film werden die gewünschten $\mathrm{Zu}$ schauerreaktionen auf diese Ankündigung antizipiert: „Amazing“ - ein kleiner Junge aus Wendys Familie reibt sich ungläubig die dicken Brillengläser. Die Leitmotivik des Feenstaubes wird nun auch in den eingeblendeten Textteilen aufgenommen: „Anything can happen ... with a little pixie dust“. Über die Montage bekannter ikonischer Bilder aus dem Film wird die Verbindung zur historischen Dimension des Werkes aufrechterhalten: So pendelt der Clip in seiner ästhetischen Struktur zwischen fragmenthaften Anstößen zum subjektiven wie kollektiven Erinnern und der ständigen Suggestion, der Grenzüberschreitung von der Realität hin zum Phantastischen zu folgen.

Zugleich wird auf der Basis des Symbolrepertoires dieses fiktiven Universums explizit mit Rekurs auf die materialästhetische Ebene nun die Differenz durch die Neuheit eingeführt. Zur Ankündigung „Newly restored“ sieht man in einem Split Screen eine Aufsicht der phantastischen Welt von Neverland, über das sich ein bunter Regenbogen erhebt (Abb. 4.25). 

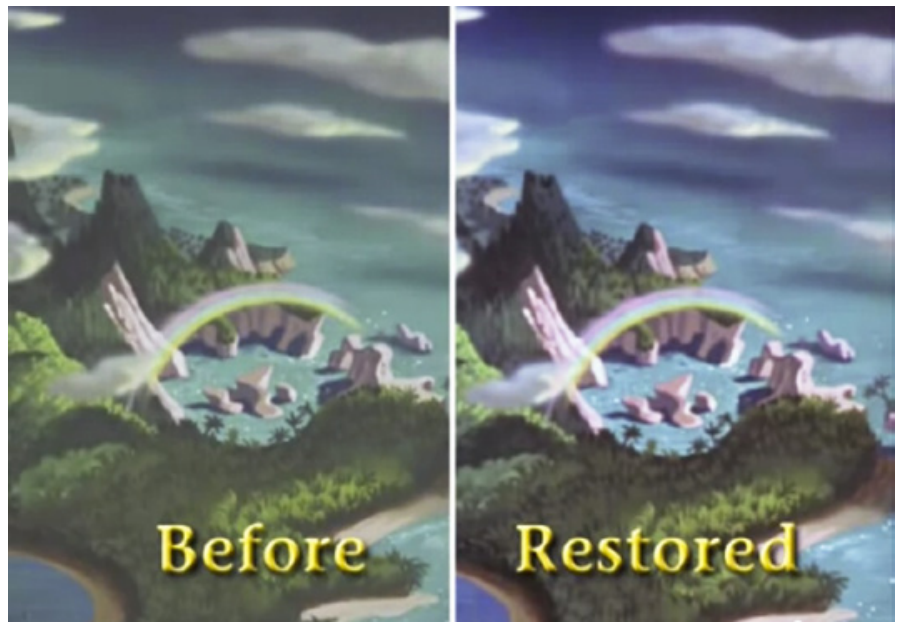

Abb. 4.25

Das linke Bild, mit „before“ markiert, ist bräunlich verfärbt, die Kontraste sind schwach, das Bild wirkt dunkel und verschmutzt; dagegen wird das rechte Bild gestellt, in dem nun das ,Nachher' zu sehen ist. Die Farben sind intensiv, das Bild wirkt im Vergleich klar, lebendig und scharf. Die Anordnung der Bilder in der Leserichtung von links nach rechts lässt das Auge des Zuschauers den Prozess vom ,Vorher' zum ,Nachher', den des Verbesserns, buchstäblich nachvollziehen: Die Qualität der Überarbeitung wird im konkreten Vergleich im nachvollziehenden Wahrnehmungsakt erfahrbar gemacht (vgl. grundsätzlich $\mathrm{zu}$ dieser Bildkonfiguration die Ausführungen in $\rightarrow$ Kap. 7 , Stichwort „vergleichendes Sehen“).

Leicht variiert, aber in ähnlicher Weise auf der phänomenalen Ebene funktioniert die Vermittlung der restaurierten Tonqualität. Die eingeblendete Textzeile verkündet: „Newly restored [...] with Disney Enhanced Home Theatre Mix Surround Sound“. Auf das von der Voice-Over gesprochene „enhanced“ fliegt plötzlich Peter Pan nah an der Kamera vorbei - Wendy wiederholt seine Bewegung, sie fliegt noch einmal um einen Schornstein herum: exakt abgestimmt auf das Stichwort „surround“.

Peter Pans plötzliche Bewegung hin zum Bildvordergrund überrascht den Zuschauer zunächst. Dies kann auf der phänomenalen Ebene der Bildbewegung die erhoffte Überraschung beim Zuschauer über die neue Tonqualität vermitteln, die anders als die neue Bildqualität nicht konkret illustriert wird und somit in dem Clip nicht hörbar ist. Wendy wiederholt umkreisende Bewegungen. Damit konnotiert sie auf der Ebene der Bildbewegung die Idee eines immersiv umhüllenden räumlichen Surround-Sounderlebnisses. Diese 
Vermittlungsformen der restaurativen Eingriffe beziehungsweise der Anpassung des historischen Films an aktuelle Geschmackspräferenzen über rhythmische Bewegungen der Filmszenen und Montagen in Affekt-Bildern, die unmittelbar wirken, sind Programm dieses Clips. Auf der Ebene der unmittelbaren Bewegtbildwirkung wird so eine Zuschreibung, ein Mehrwertversprechen - in diesem Fall eine Qualitätsaussage über den Ton - über das hier vermarktete Trägermedium und dessen räumliches Erlebnispotenzial („surround sound“) zum Ausdruck gebracht.

Ein zentraler Mehrwert der DVD als digitales Speicher- und Wiedergabemedium ist neben der beworbenen verbesserten Bild- und Tonqualität vor allem auch die Anreicherung der Filmedition mit (interaktiven) Bonusmaterialien. Auch diese werden in dem Clip mit dem fiktiven Universum gekoppelt. So offeriert die DVD „a treasure chest of bonus features“. Dazu ist die Fee Tinkerbell über einer Schatzkarte zu sehen. Auf diese Weise wird das Abenteuer von Peter Pan in Neverland gleichgeschaltet mit dem phantastischen, die Realität überschreitenden Abenteuerversprechen, das den Konsumenten in der (interaktiven) Nutzung der DVD erwartet. Und nicht zuletzt wird das Bonusmaterial als wertvoller "Schatz“ benannt, den es zu entdecken gilt. ${ }^{31}$

Das alles - so die Rhetorik und auf Affekt-Bildern basierende Ästhetik des Clips - kann man nur erleben, wenn man den Regeln des fiktiven Universums folgt. Aus Vogelperspektive verfolgt man den Gleitflug der Kinder über das nächtliche London. Damit kann der Zuschauer diese fliegende, gelöste Bewegung miterleben. Die Texteinblendung formuliert hierzu die einschwörende Bedingung „Believe“ (Abb. 4.26).

Nur Kraft des Glaubens können die Kinder in der Fiktion am Abenteuer von Peter Pan teilnehmen, nur mit dem Glauben an Disneys DVD kann der Konsument Teil dieses Erlebnisses werden, das die Realisierung der Phantasie, des Imaginären verspricht. Mit den Möglichkeiten der Nutzung wie etwa der Navigation und Selektion über das DVD-Menü wird darüber hinaus eine direkte Interaktion zwischen außermedialem Zuschauersubjekt und fiktivem Universum des Abenteuers versprochen. Damit wird implizit zugleich eine Verbindung zur Alltagsrealität des Konsumenten angedeutet. Dies verspricht auch eine räumliche Transgression in das Heim und die Lebenswelt des Konsumenten.

31 Zu den Mehrwertversprechen von Special Features vgl. Distelmeyer (2012: 71). Weiterhin zu der Metaphorik des Entdeckens und der Hebung eines Schatzes: Klinger (2006a) bzw. $\rightarrow$ Kap. 7 der vorliegenden Studie. 


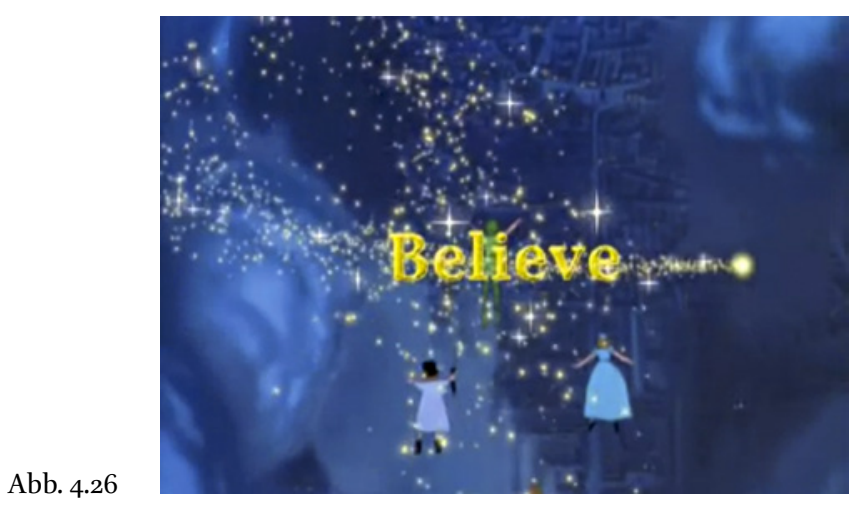

Jan Distelmeyer (2012) hat auf den Zusammenhang von den in Spielfilmen eröffneten fiktiven Universen und ihrer Ausdehnung auf die ästhetische Gestaltung von DVD-Editionen ausdrücklich hingewiesen: Nicht nur eignet der DVD eine spezifische räumliche Komponente über ihre Präsenz und interaktive Nutzung zu Hause, im Rezeptionsraum des Privaten (im Unterschied zum öffentlichen Raum des Kinos, vgl. hierzu Klinger 2006a). Darüber hinaus ist auch die Form der Darstellung sowie die Strukturierung des Zugangs zu den auf der DVD gespeicherten Informationen räumlich zu denken - und dies hängt mit der hier zum Ausdruck gebrachten Vorstellung von digital zusammen (vgl. hierzu Ausführungen unter anderem zu Flusser 1992 und Manovich 2001 in $\rightarrow$ Kap. 2).

Nach Distelmeyer orientiert sich die Ästhetik der DVD auffällig an dem, was Rolf Nohr Raumfetischismus nennt (Distelmeyer 2012:170-171). Raumfetischismus als obsessive Präsenz topografischer Elemente kennzeichnet nicht nur die Entwicklung der Computer- und Videospiele - die Exponierung von Räumlichkeit betrifft darüber hinaus den allgemeinen Erfolg der digitalen Medien und ihrer diskursiven Überformungen. Lev Manovich beschreibt ,New Media‘ vor allem über zwei Organisationsformen, über Datenbank und Navigation: „Räume der Neue(n) Medien' sind für Manovich ,immer Navigationsräume““ (Manovich nach Distelmeyer 2012: 171). Dies findet sich in der Praxis des DVD-Designs:

Die Menüs (von DVDs) [...] wollen ihre Räumlichkeit auf den ersten Blick und Klick beweisen. Was damit ausgestellt wird, ist die Differenz der DVD zu den früheren (aber nicht nur analogen) Speichermedien für Film und Video: ,das Digitale der DVD (Distelmeyer 2012: 172).

Während sich einerseits die Welt des Hauptfilms auf das Interface-Design der DVD ausdehne, was im Sinne des Immersions-/Involvierungsversprechens als 
Remediationsstrategie der Unmittelbarkeit verstanden werden könne, werde gleichzeitig die damit geschaffene Möglichkeit filmbezogener Raumerfahrung als eigene Attraktion von Interaktivität vor Augen, Ohren und Hände geführt (Distelmeyer 2012: 172).

Der Werbeclip bildet also eine Form des Raumfetischismus aus, der über die wirkungsästhetischen Strukturen dem Mehrwertversprechen des digitalen Trägers DVD zugutekommen soll. Raumfetischismus bedeutet hier - in Anlehnung an Nohrs Begriff von der „obsessiven Präsenz topografischer Elemente“ (Nohr, zit. n. Distelmeyer 2012: 170-171) -, dass der Clip eine besondere Präsenz von ästhetisch-immersiven Strukturen aufweist, die über das (körperlich) Imaginäre den Prozess des Eintauchens in ein phantastisches Universum stimulieren und simulieren. Dieser permanente Stimulationsprozess einer phänomenalen Eintauchbewegung wird verschaltet mit der räumlichen Dimension des Dispositivs der DVD - konkret über die Aneignung im Privaten sowie über die Interaktivität (des Entdeckens der zusätzlichen Bonusmaterialien). Fetischisiert wird somit das Konglomerat aus phantastischem Erleben sowie den medialen Möglichkeiten eines digitalen Trägers. Entscheidend wirkt - und dies ist auch für die warenästhetische Vermittlung der Qualität des ,Digitalen' zentral - hierbei die Tatsache, dass der Glaube des Zuschauers/ Konsumenten im Mittelpunkt steht; der Glaube an den Film, die Logik der phantastischen Fiktion und an das Produkt der DVD.

An dem Beispiel wird deutlich, wie wiederum wechselseitige Bilder eingesetzt werden, um über Wahrnehmungsstrukturen kollektive Erinnerungen zu suggerieren, subjektive Erinnerung zu aktivieren und beides in Kombination mit unmittelbarem Erleben über Affekt-Bilder zu funktionalisieren: Zunächst geht es darum, eine Überlagerung von fiktivem Filminhalt und den $\mathrm{Zu}$ schreibungen an die neue Medienumgebung zu erreichen. Dies dient der sinnlichen Vermittlung der Überzeugungsstrategie zum Kauf des neuen Trägers, der neuen Fassung des Films. Interessant ist, dass sowohl für die Aktivierung der Erinnerung des Zuschauers als auch zur Inszenierung des Neuen ähnliche phänomenale wirkungsästhetische Strategien verfolgt werden, die mit der (räumlichen) Immersion in das fiktive Universum interagieren. Es ist ein ähnliches Symbolrepertoire, allein der Rhythmus und die Montage zusammen mit der Voice-Over schaffen eine relative Differenz in dem sinnlichen Erlebnis von nostalgischem Alt und faszinativem $\mathrm{Neu}$. Was sich der Clip speziell zunutze macht, ist die besondere Rolle der Phantasie und des Imaginären: Im Märchenhaften ist das Potenzial des Unfassbaren, des die Realität Überschreitenden extensiv präsent. Damit wird der Topos einer Transgression des empirisch Fassbaren etabliert. Dieser Gestus - im Filminhalt bereits angelegt -, dass das Unfassbare erlebbar gemacht werden kann, wird übertragen auf die Erlebensdimension der Re-Edition auf einem digitalen Träger. 
Grundsätzlicher formuliert, das Neue wird mit dem Imaginären und den sinnlichen, unmittelbaren Erlebensmodi von Bewegtbildern konnotiert und verschaltet. Der digitale Träger ist der augenblickliche, vorläufige Ort des Films - er erhält aber seinen aktuellen Wert über die Imagination des $\mathrm{Zu}$ schauers und Konsumenten; darüber, dass dieser daran glaubt! Auf diese Weise wird das Warenobjekt der DVD über das phantastische Universum und seine Erlebensformen fetischisiert. So lassen sich die formal- wie wirkungsästhetischen Strategien des Clips frei nach H. Böhme mit Blick auf die Funktionsweise des (Waren-)Fetischs pointiert zusammenfassen: Die digitale Qualität eines Filmes ist nie das, was von sich aus immer schon digital ist, sondern es muss der Glaube (als spezifischer Wahrnehmungsmodus, FH) erzeugt werden, dass es so sei (H. Böhme 2012: 370).

\subsection{Fetischisierung des Neuen}

Die folgenden Abschnitte vertiefen die Reflexion über einen grundlegenden medienhistoriografischen Topos, der implizit bereits in den beiden vorhergehenden Analysen zum Tragen kam: die ästhetische Vermittlung der Differenz von alt und neu in der Erfahrung von Bewegtbildern. Vor diesem Hintergrund werden im Folgenden Verfahren unter dem Gesichtspunkt ästhetischer Prozesse untersucht, in denen sich der Wahrnehmungsmodus der Fetischisierung auf die Vermittlung einer Qualität des Neuen richtet, was sich paradoxerweise immer im Differenzverhältnis zu etwas als älter Bestimmtem definiert. ${ }^{32}$ Wie sich schon in dem Begriff ,New Media' andeutet, wird neu wissenschaftsgeschichtlich wie auch in populären Zusammenhängen oft synonym für digital gebraucht. ${ }^{33}$ Es soll deshalb im Folgenden auch nicht darum gehen zu definieren, was an digital essenzialistisch neu sei. Vielmehr liegt der Fokus genau auf der Offenheit, Vielschichtigkeit und damit Unbestimmtheit der Kategorie digital, die insofern in pragmatischer Perspektive als Wahrnehmungseffekt diskursiver und ästhetischer Praktiken verstanden wird. Vor diesem Hintergrund steht wieder im Mittelpunkt der Untersuchung,

32 Philip Rosen (2001) spricht im Kontext von digitalisierten analogen Filmen auch von „digital mimicry“. Diese Form der Mimikry bringe in ihrer notwendigen Bezogenheit auf ,ältere' Medien „temporal or historiographic conflations“ hervor (Rosen 20o1: 314-331). Zu diesem grundsätzlichen Problem, verstärkt durch die Eigenschaft digitaler Bilder, stets von Interpretationsvorgängen abhängig zu sein, vgl. $\rightarrow$ Kap. 2.

33 Vgl. zum Zusammenhang von digitalen Medientechnologien und der Zuschreibung des Labels neu unter anderem Hartmut Winkler, der bereits in Docuverse (1997: 11) angesichts des Hypes um Multimedia und der Computerfaszination Einspruch gegen die affirmative „Rhetorik des Neuen“ erhoben hat (vgl. hierzu auch Distelmeyer 2012: bes. 175-176). 
wie der Zuschauer über Affekt-Bilder und Erinnerungs-Bilder als Funktionsgröße in mediale Vermittlungsprozesse eingebunden wird.

Exkurs I: Historiografische Dynamik der Remediation.

Kollaborative Vernetzung von alt und neu

Bei dem Problem der ästhetischen Vermittlung des Verhältnisses von alten und neuen Medien sei an dieser Stelle kurz auf das bereits erwähnte Konzept der Remediation von Bolter/Grusin (1999) verwiesen. Im Kern geht es in diesem um die Frage, wie und wann ältere mediale Formen ins Verhältnis zu neueren gesetzt und unter Umständen in ihnen aufgenommen werden - zwischen offensichtlichem Zitat, Ausstellen des aufgenommenen Mediums (Hypermediacy) und Funktionalisierung der unmittelbaren Wirkungsstruktur des zitierten Mediums (Immediacy). Bolter/Grusin untersuchen ihre Schlüsselfrage nach Immediacy und Hypermediacy in historischen Konfigurationen wie etwa dem "Cinema of Attractions" (Bolter/Grusin 1999: $156 \mathrm{ff}$.). Die Autoren diskutieren so mediengeschichtliche Entwicklungen im Spannungsfeld der Frage, wann etwa technologische Innovationen zur Attraktion und die Remediation Teil der Faszination wird. ${ }^{34}$ Sie fassen mit Blick auf das Attraktionspotenzial des ostentativen Zitierens älterer Medien zusammen:

[T] he amazement [...] requires awareness of the medium. If the medium really disappeared, as is the apparent goal of the logic of transparency, the viewer would not be amazed because she [sic!] would not know of the medium's presence (Bolter/Grusin 1999: 158).

Um die Attraktion der Remediation überhaupt würdigen zu können, benötige man ein Bewusstsein davon, die Möglichkeit der Wahrnehmung, dass hier ein älteres Medium aufgegriffen wird. Gleichzeitig bringe das remediierte Medium auch immer wieder eigene Wirkungsstrukturen mit, die ihrerseits unmittelbar Effekte entfalten könnten. Dies sei die doppelte Logik der Remediation (Bolter/ Grusin 1999: 2 ff.).

Wie bereits in $\rightarrow$ Kap. 2 eingeführt, lassen sich vor allem zwei Modelle der geschichtlichen Dynamik im Verhältnis von vordigitalen und digitalen Medientechniken ausmachen, gerade unter dem Vorzeichen der Möglichkeiten digitaler Medien, analoge Medien zu simulieren und in sich aufzunehmen: das bellizistische und das koevolutive Modell (Segeberg 2012b). Insbesondere Thorburn/H. Jenkins (2004) und auch Segeberg plädieren mit Blick auf digitale

34 So verweisen Bolter/Grusin etwa auf Praktiken rund um das Kinobreitwandformat Cinerama und untersuchen dessen Rekurs auf Attraktionen aus den Jahrmarkttraditionen des frühen Kinos. 
Technologien für das koevolutive Modell, in dem die vernichtende Ablösung der analogen Medien durch die digitalen nicht als Konkurrenzkampf zweier antagonistischer Kategorien gesehen wird. Alt und neu sollte man weniger in einem kompetitiven Verhältnis denken als vielmehr als kollaboratives Netzwerk im Kontext einersich wandelnden medialen und kulturellen Umgebung. ${ }^{35}$ Damit sich überhaupt Kategorien wie alt und neu herauskristallisieren können, bestimmen Thorburn/H. Jenkins als entscheidende Prinzipien historiografischer Dynamik zum einen die Institutionalisierung, zum anderen die Standardisierung - beides kulturelle, gesellschaftliche und ökonomische Prozesse, gepaart mit Technikentwicklung. So plädieren Thorburn/H. Jenkins für ein Gedankenmodell der Evolution anstelle einer bellizistischen Sichtweise, die eine Revolutionsrhetorik bemüht.

Dieser dynamische, koevolutive Netzwerkgedanke geschichtlicher Dynamik, der sich auch im Remediation-Konzept im Zeichen des Zitierens und ReFormulierens wiederfinden lässt, spiegelt sich zudem in meiner methodischen Vorgehensweise, die Fallstudien - gerade im Modus der Reprise - als zeitliche Cluster zu behandeln, in denen mehrere historiografisch wirksame Schichten koexistieren, die simultan wirksam werden können und als Wahrnehmungsangebote und -möglichkeiten vorhanden sind.

Analysebeispiel: Werbeclip BEN Hur vs. StAR WARS

Das folgende kurze Beispiel um den Filmklassiker BEN HUR (1959) soll in methodologische Überlegungen einleiten, die sich mit der Frage nach der populären Vermittlung von sogenannten neuen Techniken auseinandersetzen. Der diskutierte Werbeclip für die Elektrofachkette Saturn hat unter dem Titel Ben Hur unterliegt Rakete im Jahr 2011 mediale Aufmerksamkeit in Deutschland erregt (Werben \& Verkaufen 2011).

Es sind bekannte Bilder, allerdings mit einer überraschenden Wendung: Ben Hur alias Charlton Heston treibt sein weißes Pferd kämpferisch an, die antiken Rennwagen jagen nebeneinander her durch die Arena - ganz zur Begeisterung des tosenden Publikums. Der mit dem ,Klassiker' aus den 195oer Jahren vertraute Zuschauer erkennt im Gegenschuss den arabischen Patron Ben Hurs, wie er aufgeregt gestikulierend den Titelhelden anfeuert. Wieder Nahaufnahme: Ben Hur schaut sich nach etwaigen Verfolgern um ... Von hinten rast plötzlich - begleitet von einem spielerischen Rhythmuswechsel in der Musik ein Raketenfahrzeug heran. Das antike Publikum auf den Rängen springt in der

35 „T] $]$ o focus exclusively on competition or tension between media systems may impair our recognition of significant hybrid or collaborative forms that often emerge during times of media transition“ (Thorburn/H. Jenkins 2004: 3). 
Totale auf und jubelt begeistert. Durch die Montage scheint das futuristische Fahrzeug Ben Hur und alle anderen antiken Pferdewagen rasant zu überholen und in einem wahren Geschwindigkeitsrausch hinter sich zu lassen. Es rast nun jenseits der Arena in die offene Weite der Landschaft. Als das Raketenfahrzeug gen Horizont verschwindet, materialisieren die Kondensstreifen sich zu einem Schriftzug. Dieser wird affirmativ von einer Frauenstimme pointiert ausgerufen: „Weil neue Technik besser ist!“ (Hervorh. FH).

Mit dem neuen Claim ,Soo! muss Technik' wirbt die Elektrofachmarktkette Saturn im Advent [2011, FH] um Kunden. Nach dem 5o. Geburtstag und dem Start des Online-Shops stellt sich das Unternehmen in der Marketingkommunikation neu auf. [...] Im ersten Spot der Kampagne [...] inszeniert sich Saturn ganz unbescheiden in der Szenerie des Filmklassikers BEn HUR. Ein Raketenfahrzeug überholt alle Pferdewagen., Verrückt nach Technik zu sein, ist Emotion pur. Das sollen die Filme für Saturn zeigen', sagt Martin Pross, Vorstand [...] der Scholz \& Friends Group. ,Saturn ist ein Leistungsriese, da hat Hollywood genau das richtige Format' (Werben \& Verkaufen 2011).

Das zitierte filmische Beispiel ist ebenso wie seine öffentliche Wahrnehmung deshalb beredt, weil es nachstehende Aspekte illustriert: Filmhistorisches Material - in diesem Fall BEN HUR - wird aufgrund seines präexistenten, kanonischen Charakters ausgewählt, um auf verschiedenen Ebenen bewusst heterogen das kollektive Gedächtnis und Erlebnis des Publikums anzusprechen. Es wird zur Vermittlung der Qualitäten einer neuen Technik eingesetzt. Die doppelte Anmutung von BEN HUR als alt - sowohl mit Blick auf den Filminhalt als auch auf die Entstehungszeit des Films (1959) - wird über die BildTon-Montage in ein kompetitives Verhältnis zu etwas Neuem gebracht, in dem innerhalb der Diegese eine aus der Zeit fallende Technik bruchlos eingefügt wird. Zudem wird mittels der Ikonografie auf eine weitere Hollywood-Fiktion verwiesen, die ihrerseits Zukunftsvorstellungen konnotiert: Mit der Rakete wird zugleich Star WARS verbunden. Man denke etwa an das Pod-RaceRennen aus Episode I - The Phantom Menace (1999), das bewusst von George Lucas an das Wagenrennen aus BEN HUR angelehnt wurde und die Szenerie offensichtlich zitiert. ${ }^{36}$

In dem Zusammenspiel dieser unterschiedlichen Ebenen geht es darum, die Differenz, das Neue der Technik, die Saturn verkauft, sinnlich zu

$3^{6}$ Dem cinephilen Betrachter dürfte sich noch eine weitere zeitliche Clusterebene eröffnen, wenn ihm bewusst ist, dass das Wagenrennen in der 1959er Version bereits eine recht nahe Reinszenierung der Sequenz aus dem Ben-Hur-Film von 1925 mit Ramón Novarro in der Hauptrolle und unter der Regie von Fred Niblo ist. 2016 ist nun eine wiederum aktualisierte Version in die Kinos gekommen (Bekmambetov, 2016). 
vermitteln. Diese Neuheit wird maßgeblich an die Imaginations- und Illusionsmaschinerie von Hollywood und seiner Industrie geknüpft. Sie wird ästhetisch wie entwicklungsgeschichtlich als qualitativer Sprung dramatisch inszeniert: das Monumentale des Hollywoodkinos als sinnliche Analogie zur Größe der Leistung der neuen Technik bei Saturn. Ästhetisch wird dies vor allem im Zusammenspiel aus der narrativen Grundsituation eines hoch emotionalisierten Wettkampfs, dem antiken Setting und der kontrastiven Montage realisiert. Hinzu kommt aber auch der Wiedererkennungseffekt des Schauspielers Charlton Heston im Kontext der Szenerie, der die Präexistenz des Films als Klassiker - auch in der Opulenz der Bilder - unterstreicht. So wird das kurze Filmfragment zur Chiffre der monumentalen Emotionsmaschine Hollywood, die über das pointierte Zitat selbst in ihrer Wirkungskraft und als Geschwindigkeitsrausch ins Unendliche und Unbegrenzte unmittelbar und phänomenal erlebbar wird. ${ }^{37}$ Die Präexistenz und das Monumentale - als zeitlose Überhöhung - werden zwischen individuellem Erleben und dem Status als kollektive Chiffre fetischisiert und vermitteln damit das medientechnologisch Neue als transzendentale Qualität, an der man als aktiver Konsument nun teilhaben können soll.

\subsection{Warenästhetik der neuen Technologien in Bewegtbildern. Werbeclip zur Blu-Ray-Disc von Universal (2010)}

Im Zeichen der Fragestellung nach ästhetischen Praktiken der sinnlichen Vermittlung des Differenzverhältnisses von alt und neu sollen in einem letzten Beispiel Formen der somatisch spürbaren Bewegungsspannung erläutert werden. Es wird - so die These - in dem Beispiel eine Wahrnehmungshaltung hervorgerufen, in der das erlebende Subjekt die Neuheit des beworbenen Produktes über phänomenal wirksame (An-)Reize ständig selbst erprobt.

Der untersuchte Werbeclip ist als exemplarisch anzusehen, da - wie weitere Ausführungen zu Wahrnehmungs- und Erwartungskonfigurationen der Relativierung und des Vergleichens vor allem in $\rightarrow$ Kap. 7 zeigen werden - sich die Topoi und die ästhetischen Vermittlungsformen von Werbeclips in diesem Bereich nicht grundsätzlich verändern, selbst wenn etwa bei der Blu-Ray-Disc neue medientechnologische Entwicklungen hinzukommen. So lassen sich speziell ästhetische Verfahrensweisen, die mit Affekt- wie Erinnerungs-Bildern

37 Vgl. zum Prinzip der phänomenologischen Einbindung des Zuschauers in Bewegtbilder über Unendlichkeit, Unermesslichkeit und Unabgeschlossenheit meine Überlegungen zu Gaston Bachelard (F. Heller 2010a; vgl. bes. Kap. 3). 
arbeiten, in Werbeclips ausmachen, die auch andere digitale Dispositive wie Video-on-Demand bewerben. Exemplarisch sind Clips von Netflix mit den Titeln Hold on (2014) oder Do You WANT TO HAVE AN ADVENTURE? (2013). Sogar kurze Werbefilme, die sich Virtual Reality Glasses (Virtual-Reality-Brillen) oder Augmented Reality Apps - wie etwa der von Ikea - widmen, weisen ähnliche ästhetische Strukturen auf.

\section{Exkurs II: Alt und neu im Horizont von Heimkinotechnologien.} Vorbemerkung zu medienhistoriografischen Konsequenzen

Das im Folgenden vorgestellte Beispiel widmet sich der warenästhetischen Dimension des digitalen Dispositivs der Blu-Ray-Disc. Die vor diesem Hintergrund behandelten ästhetischen Vermittlungsformen des Neuen implizieren auf konzeptioneller Ebene medienhistoriografische Konsequenzen - wie es auch schon der paradoxe Begriff Heimkino nahelegt. Klinger (2006a) hat das Verhältnis von medialer Gegenwart und Geschichte - gerade im Kontext von Heimkinotechnologien - in einer eher koevolutiven und alinearen Perspektive zusammengefasst: ,While a focus on technological innovation tends to privilege the new, developments in home film exhibition have always found a significant place for the old“ (Klinger 2006a: 14-15). Betrachtet man die ästhetischen Verfahrensweisen der zitierten Werbeclips zur Blu-Ray-Disc, wird deutlich, dass er mehr oder weniger offen auf die Überwältigung, insbesondere mit Rekurs auf die Größe der Kinoprojektion und damit auf eine historisch institutionalisierte Aufführungssituation von Filmen, abzielt. Wie in dem Beispiel deutlich werden wird, nimmt die Vorstellung eines immersiven Erlebens von Bewegtbildern eine wichtige Rolle ein - interessanterweise kommt hier das Wechselverhältnis zwischen individuellen und kollektiven Rezeptionsmodi zum Tragen. Topoi von besonderer Nähe im ständigen Wechselspiel mit Distanz zum Geschehen rücken in den Mittelpunkt. Auf diese Weise wird die emotionale und affektive Ein- und Anbindung in die Bewegtbilder sowohl konnotiert wie zugleich provoziert. Vor allem durch eine phänomenale, überraschende, schockartige Einbindung mittels klassischer Attraktionsmuster wird ein Mehrwert an Erlebniswelt über den Träger Blu-Ray-Disc transportiert und versprochen. Der vermittelte Mehrwert ist das Neue des Trägers und der Zugangsform - dabei erscheint das Differenzielle $n e u$, das sich ästhetisch artikuliert, entscheidender als die tatsächlichen Eigenschaften und (technisch-abstrakten) Definitionen von digital als Qualitätsmerkmal. Somit hat hier die Warenästhetik von digital zwei Dimensionen: Zum einen erweist sie sich als ästhetische Strategie, die auf die unmittelbare Wahrnehmung des Rezipienten wirkt. Zum anderen zeitigt diese Strategie der Warenästhetik historiografisch wirksame Konsequenzen, da sie auf die Differenzerfahrung von alt und neu beziehungsweise vergangen, 
gegenwärtig und zukünftig rekurriert und die Ebenen (implizit) einer Aushandlung anheimstellt.

Distelmeyer beschreibt die Neuheit von DVD und Blu-Ray-Disc in einer methodologischen Perspektive. Er stellt die Schlüsselbegriffe Flexibilität, Versatilität und Selektivität in den Mittelpunkt (Distelmeyer 2012: 178; vgl. hierzu auch Ausführungen zu Eigenschaften digitaler Bilder in $\rightarrow$ Kap. 2). Diese Begriffe sprengen, so Distelmeyer, maßgeblich das Verständnis von der standardisierten, oft in der Forschung angenommenen stabilen und damit idealen Rezeptionssituation im Kino. Distelmeyer verweist auf die konzeptuellen Probleme: „In Gegenwart der Heimvideotechnologie lösen sich Kategorien und Denkmuster (weiter) auf" (Distelmeyer 2012: 40). Dies weist auch auf die von H. Jenkins (2004) viel zitierte Medienkonvergenz hin. So zeichnet Distelmeyer nach, wie sich von der Laserdisc über die DVD vor allem die Vorstellung der digitalen Interaktivität als Zugangsform zu Filmen entwickelt habe: „Die DVD hat ganze (Vor-)Arbeit geleistet, auf die sich die BluRay verlassen kann, um an geeigneter Stelle (zum Beispiel bei BD-Live und In-Movie Experience) ihre neuen Formen von Interaktivität hervorzuheben“ (Distelmeyer 2012: 172). Genau dieser Mythos der Interaktivität als eines der Synonyme für digital (vgl. hierzu auch $\rightarrow$ Kap. 2) wird in der nachfolgenden Untersuchung später eine wichtige Rolle einnehmen.

\section{Der ,technologische Sprung' von der DVD zur Blu-Ray-Disc} ästhetisch artikuliert

Ein Universal-Clip aus dem Jahr 2010 zur Bewerbung der Blu-Ray-Disc als Speicher- und Wiedergabe- sowie als Zugangsmedium von Filmen erweist sich als sinnliches Achterbahnerlebnis, das einen appellativen Exzess ${ }^{38}$ in nur 1:52 Minuten entwickelt. Es ist der Aufruf an den Konsumenten, die eigene Filmsammlung auf einen weiteren neuen digitalen Träger umzustellen.

Besonders hervorzuheben ist die Tatsache, dass der im Folgenden untersuchte Clip im Gegensatz zu anderen dieser Art keine Voice-Over verwendet, die die technischen Neuheiten und ihre Versprechen erklären würde. Das vorliegende Beispiel verlässt sich nahezu allein auf die sinnliche Kraft audiovisueller Bilder, und dies markiert exemplarisch die besondere Bedeutung der audiovisuellen Bewegtbildwirkung für die Wahrnehmung dessen, was wir als neu oder digital begreifen sollen.

38 Vgl. zu den allgemeinen (formalästhetischen) Verfahren der Werbetrailer: Hediger (2001: 230). Hediger beschreibt die formalen Kennzeichen von Filmtrailern unter anderem mit Redundanzen (semantischer Dichte), hoher Reizdichte, semantischen Kontrasten und hohen Schnittfrequenzen. 
Die erste Einstellung ist schon emblematisch für die Botschaft. Die Augen werden geöffnet für die neue Sichtweise: Wie von einer augenförmigen schwarzen Maske gerahmt, erblickt man einen fahlblauen, luminiszierenden, bühnenartigen runden Raum, in den sekundenschnell aus der Zuschauerrichtung das Universal-Logo rast. Die Lichtreflexionen evozieren Assoziationen von Spotlights. Die momenthafte Blendung des Zuschauerblicks und die Lens Flares einiger dieser Spots erinnern an den Bildstil von Regisseur Michael Bay, wie er sich in dessen technizistischer, artifiziell anmutender Kamerästhetik in seinen Filmen von The Island (2005) bis Transformers (2007) findet. ${ }^{39}$

Mit einer hellen Lichtkugel, die laserartig über das Logo von der Seite fährt dies ließe sich auch als verfremdete Anspielung auf die Leseweise der Disc sehen -, wird der Schriftzug gedreht und enthüllt somit die ,neue' Seite von Universal: In dunklerem, leicht schraffiertem Blau manifestiert sich das „Bluray-Disc ${ }^{\text {mus }}$-Logo. Das große darüberstehende B ist teilweise gerahmt von einem Halbkreis, der ikonisch die runde Form der Disc zitiert. Über diese Form wird bereits deutlich: Man ist weit entfernt von der linearen Struktur eines fotochemischen Filmstreifens. Dazu hört man treibende, leicht repetitive Musik. Das Blu-Ray-Disc-Logo materialisiert sich nur für Sekundenbruchteile, bevor wieder ein neuer Schriftzug aus der Zuschauerrichtung auf der horizontalen Achse geflogen kommt. Man liest nun die Bedingung „When Blu-ray joins forces ..." (Abb. 4.27). Der Schriftzug glitzert im Licht in der hellblauen Umgebung. Er rast nach nur kurzem Stillstand wieder auf den Zuschauer zu.

Es folgt die audiovisuelle Vorbereitung auf die Konsequenz dieses Arrangements: Russell Crowe in Nahaufnahme aus Ridleys Scotts Robin Hood (2010). Im Bildvordergrund leicht unscharf der gespannte Bogen, Crowes

39 Lens Flare bezeichnet die sichtbare Reflexion und Streuung von Gegenlicht in einem Linsensystem - auch bezeichnet als Blendenflecke oder Linsenreflexion. Beim Film tritt sie meist bei Einsatz mit anamorphotischen Objektiven auf, wenn sich eine helle Lichtquelleknapp außerhalb des Bildes befindet (Flückiger 2008:511). Diese Reflexionen werden von Regisseuren wie Michael Bay oder J. J. Abrams als Stilmittel eingesetzt. Letzterer begründete den exzessiven Einsatz etwa in seinen STAR-TrEK-Filmen (2009) damit, dass diese Bildästhetik für „episches Kino“ („big Screen“) stehe (vgl. J. J. Abrams Voice-Over in "on lens flare“: http://www.youtube.com/watch?v=hiAToA3qZcI ; 16.01.2012). Interessant ist hier, dass Michael Bay dies auch in seinen Transformers-Filmen nutzt. Denn der Effekt verweist doch eigentlich auf ein tatsächlich anwesendes, optisch aufzeichnendes Linsensystem. Diese ursprüngliche Konnotation wird nun genutzt, um in computergenerierten Bildern (etwa den Autobots-Aufnahmen in der TrANSFOrmERs-Reihe) eine solche Aufzeichnungsinstanz wieder mitzuimplementieren, obwohl diese doch bei den Aufnahmen der Roboter eigentlich abwesend ist. Dies ist ein Verfahren zum Suggerieren einer größeren Wirklichkeitsnähe - scheinbar verweisend auf eine profilmische Realität (Flückiger 2008: 351-352). 
Abb. 4.27

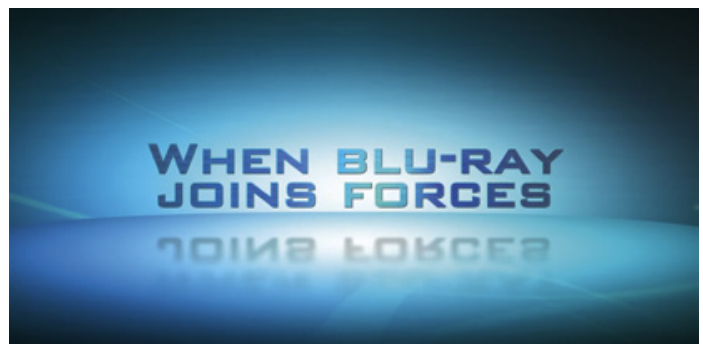

konzentriertes Gesicht zur Hälfte mit Blut überströmt (Abb. 4.28). Die Einstellung vermittelt vor allem ein Innehalten in der Bewegung. Dies geschieht über die besondere plötzliche, unvorbereitete Nähe zu Crowes Gesicht, dessen Körper sich in extremer Zeitlupe nur minimal zu bewegen scheint. Es bedeutet einen visuellen Rhythmuswechsel im Vergleich zu dem vorher abstrakten Bildraum. Gleichzeitig illustriert das Bild auch motivisch ein retardierendes Spannungsmoment. Der Bogen wird gespannt. Man wartet, bis der Pfeil, das Geschoss, losgelassen, die Kraft entfesselt wird. Es ist die sinnliche Vorbereitung des Zuschauers auf die Konfrontation mit etwas Unbekanntem.

Abb. 4.28

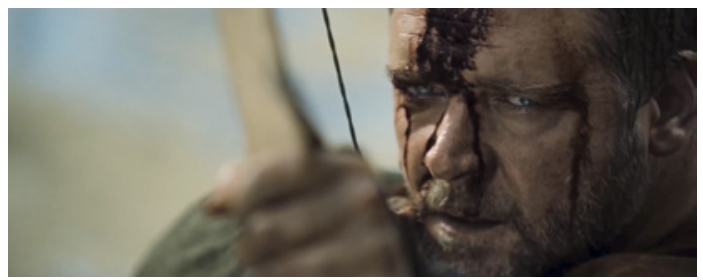

Und der Clip nimmt die Konfrontation entschlossen an: Mit energischem Schritt tritt ein Junge in einer Gasse direkt auf die Kamera zu und reißt sein Hemd auf, um ein Superheldenkostüm zu entblößen (Ausschnitt aus KICK Ass, 2010). Die Bewegung des Jungen in Richtung der Kamera verstellt für kurze Momente deren Blick, um dann identifikatorisch auf Johnny Depp als einen der Protagonisten in Public Enemies (2009) überzugehen, der sich wagemutig an einem Seil in Richtung Kamera schwingt.

Der vermittelte Bewegungsdrang findet sein Ziel in der argumentativen $\mathrm{Zu}$ sammenführung (,joint forces“) der Techniken: Auf der blauen Bühne wird in einem weiteren Schriftzug der technische Partner der Blu-Ray-Disc im Kampf („Blu-ray joins forces“) vorgestellt, nämlich „with your HD TV“. Zu beachten ist hier, dass HDTV in der Rhetorik des Clips mitnichten als Objekt der notwendigen Anschaffung erscheint, sondern vielmehr als ein Waffenbruder der 
Blu-Ray-Disc, deren gemeinsame Macht es (in ihrer Wirkungsästhetik) zu entdecken gilt.

Das angenommene Filmpublikum wird kurz darauf thematisiert und in Habachtstellung versetzt. In einer seitlichen Kameradrehung werden Russell Crowe und sein Gefährte in der Gladiator-Arena (2000) umrundet, sie schauen in die Ränge (Abb. 4.29), um sich des Publikums zu vergewissern. Schauen auch alle zu?

Die Musik treibt weiter auf den Höhenpunkt zu: Ein Mann springt über ein Hausdach, dann ein anderer über eine Gasse: Der Titelheld aus THE InCREDIBLE HulK (2008) attackiert die Kamera frontal (Abb. 4.30). Kurz bevor sein Körper den Kamerablick verdeckt, wird die entscheidende Frage im blauen Raum gestellt: Was gewinnt man bei dieser Revolution? „What do you get?"

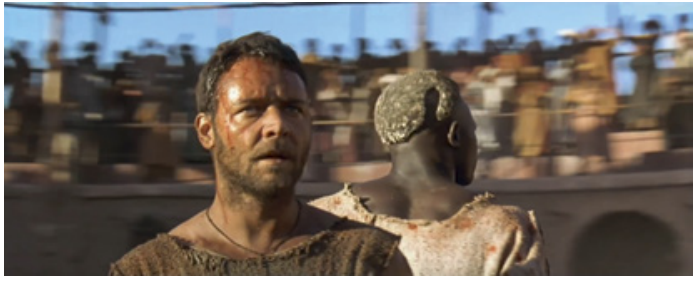

Abb. 4.29

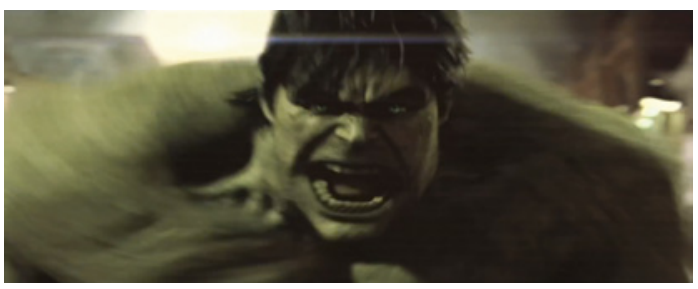

Abb. $4 \cdot 30$

Dass hier etwas Neues vermittelt werden soll, wird noch einmal betont: Was bietet uns die Universal-Blu-Ray-Disc technologisch? Der Vater aus CorALine (2009) präsentiert es in einer buchstäblich ausladenden Geste. Mechanische Roboterhände kommen aus einem Piano auf die Kamera zu und öffnen sich bereitwillig (Abb. 4.31).

Das, was man zu sehen bekommt, stellt - so das Versprechen - eine neue raumzeitliche Erfahrung dar, in der wir Dinge so sehen, wie es sonst nicht möglich ist. Ja, mehr noch: Es sind Handlungen, die jenseits bekannter menschlicher Fähigkeiten liegen. Dies zeigt das Hit-Girl aus KICK Ass mit ihrer überraschenden Kampfeskunst ebenso wie die Kamera, die uns in der 
Abb. $4 \cdot 31$

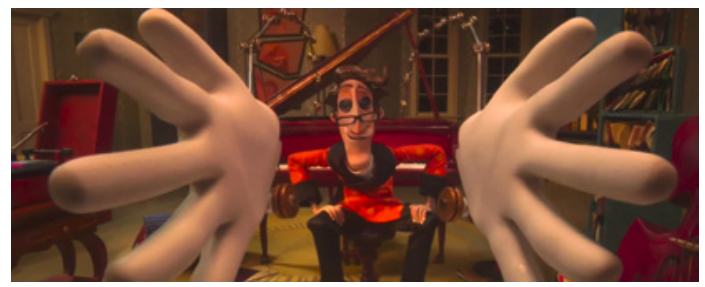

Vogelperspektive eine Pistolenladung fast zum Greifen nah kommen lässt. Vermittelt wird ein qualitativer Sprung in der menschlichen Entwicklung und in der raumzeitlichen Sinneswahrnehmung.

\section{Zeitliche Paradoxa und Sinneserweiterung}

Es ist auch ein chronologischer Sprung. Es fragt sich nur wohin, wenn der folgende Ausschnitt eigentlich filmhistorisch einen Schritt zurück bedeutet. Was man nun sieht, ist nämlich eine seitliche Einstellung auf ein (hinlänglich bekanntes) Auto auf einem Parkplatz, das in einer Feuerwolke aufgeht. Man ist nun „zurück in der Zukunft“ (BACK to ThE FUture, 1985): Marty McFly (Michael J. Fox) und Professor Brown (Christopher Lloyd) schauen erstaunt mit einer überdimensionalen Fernbedienung in der Hand, als die Kamera in Untersicht an sie heranfährt (Abb. 4.32); derselbe Ausschnitt wurde bereits in dem zu Beginn des Kapitels analysierten Werbeclip Restoring THE CLAssics aus dem Jahr 2012 von Universal verwendet.

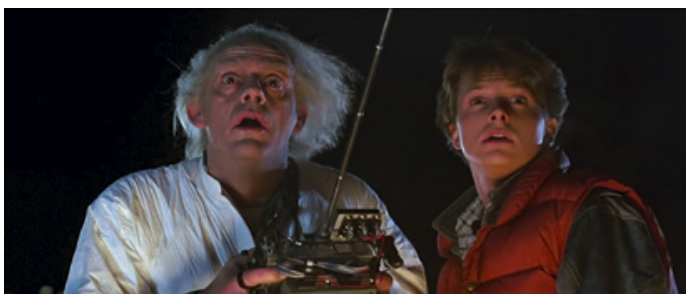

Es sind altbekannte Bilder, Impressionen eines ikonischen Films der 1980er Jahre. Diese werden - so der Eindruck - ein wenig länger stehen gelassen als die vorherigen Snippets aus den aktuelleren Filmen. Vielleicht um ein deutliches Wiederkennen zu ermöglichen? Denn dieser altbekannte, über 20 Jahre alte Filmausschnitt erzählt gerade über seine ikonografischen Kürzel den technologischen Sprung in die Zukunft der Sinneswahrnehmung via Blu-Ray. In der Dramaturgie des Clips ist es der Moment der Einführung des größten qualitativen (technischen) Unterschieds. Denn der blaue Schriftzug liefert 
sofort den Kommentar (und die Antwort auf die zuvor gestellte Frage nach dem Effekt der ,joint forces"): „5 x picture quality of DVD“ (Abb. 4.33).

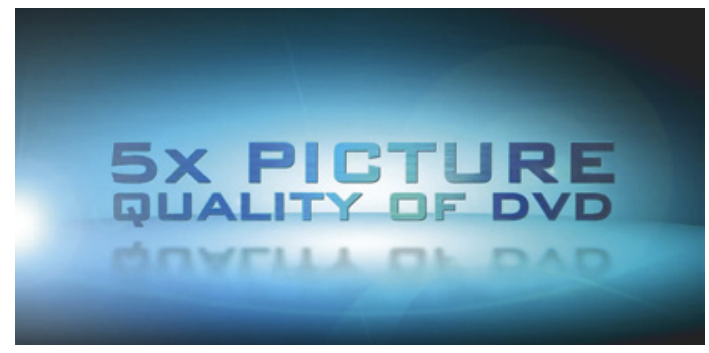

Abb. 4.33

Die neue Qualität wird nun auch somatisch-kinästhetisch wirksam ausgestellt: Die fünfmal höhere Bildqualität wird mit einem Point-of-View-Shot (PoV) in einer animierten Welt kommentiert (Ausschnitt aus dem Animationsfilm Despicable Me, 2010). Der PoV-Shot lässt den Zuschauer in die Tiefe einer Achterbahnfahrt auf einem Jahrmarkt stürzen (Abb. 4.34-4.35):

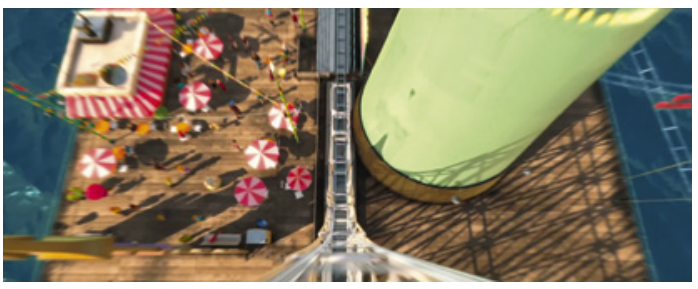

Abb. 4.34

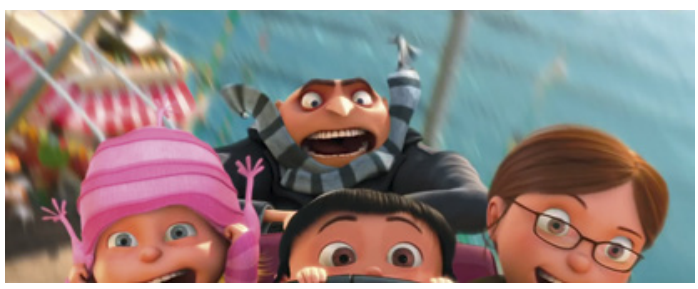

Abb. 4.35

So radikal soll das neue Seherlebnis sein! Visuell wird dies verstärkt in dem folgenden Gegenschuss auf die schreienden Insassen des Achterbahnwagens. Mit weit aufgerissenen Augen starren sie in das, was da gleich kommen mag.

Interessant ist besonders an dieser Stelle, dass ausgerechnet die BluRay-Disc, die sich medienhistorisch so weit von dem, was Film Anfang des vorigen Jahrhunderts bedeutete, entfernt zu haben scheint, nun motivisch sowie konnotativ wieder auf den Jahrmarkt und das Cinema of Attractions 
rekurriert. ${ }^{40}$ Die mit dem filmischen Medium auf den Kopf gestellte menschliche Raum- und Zeitwahrnehmung wird in der Zukunftsperspektive von Blu-Ray aktualisiert: Dies zeigt im Clip der folgende PoV-Shot, als die Achterbahn einen Looping vollführt. Schon Rodowick (2007) hat eine grundsätzliche medienhistorische Parallele hervorgehoben, als er schrieb, dass das Aufkommen der Nickelodeons einst in ähnlicher Weise die Wahrnehmung der Zeitgenossen verändert habe wie heute die Digitalisierung der Medien (Rodowick 2007: 2; ferner zu narrativen Registern und zur Darstellung von Digitalem in Fiktionsfilmen: Rodowick 2007: 5 f.).

Nachdem der Clip also die neue Wahrnehmungsform (via Blu-Ray) als ,auf den Kopf stellend' eingeführt hat, werden alle Kräfte („forces ${ }^{441}$ ) freigesetzt. In Detailaufnahme sieht man nun, wie endlich der eingangs von Russell Crowe gespannte Pfeil in extremer Slow Motion den Bogen verlässt. Einen Beweis für die besondere Bewegungsqualität - und gleichzeitig auch einen Hinweis auf die besondere Detailgenauigkeit der Bildqualität - stellen die Wassertropfen dar, die wie ein Schweif den Moment des Freisetzens begleiten. Sie machen die Bewegung sichtbar.

Übermenschliche Kräfte werden freigesetzt - so der Eindruck -, wenn , the incredible Hulk ${ }^{\prime}$ über ein Gebäude springt. In einer Großaufnahme bedroht der Hulk uns mit einem Urschrei. Mittlerweile hat sich ein Chor in die treibende, archaisch anmutende Musik des Clips gemischt.

Die Konsequenzen der Mutation der Wahrnehmung werden momenthaft gezeigt. Eine Pupille verändert sich, eine Großaufnahme zeigt eine Hand, die sich zur tierischen Klaue entwickelt, im Profil fletscht The Wolfman (gespielt von Benicio del Toro, 2010) die Zähne.

Nicht nur der menschliche Körper wird transformiert, sondern auch sonstige Ordnungen und Formationen - immer unter dem Vorzeichen einer aggressiven, kampfbetonten Grundstimmung. In einer gelben (Wüsten-)Landschaft mäht ein Flugzeug Bataillone von Soldaten nieder, ein Tank explodiert in der Luft, während er noch über ein weiteres Auto fliegt. Herkömmliche (außerfilmische) raumzeitliche Ordnungen gelten in diesem Universum nicht mehr, Details kommt eine spezifische eigene Dauer und Ästhetik zu: Wenn James McAvoy seine Pistole in Zeitlupe zückt und die Kugel an Angelina

40 Vgl. überblicksartig zu dem von Tom Gunning geprägten Begriff und seiner Rezeption Blom (2005: 178-183). Ferner einführend zum Verhältnis von Achterbahn und Early Cinema: Rabinovitz (2005: 31-32) zu Amusement Parks.

41 Der Wortgebrauch „force“ lässt neben dem offensichtlichen Rekurs auf Kampfmetaphern auch eine Assoziation an die STAR-WARS-Filme und den kultischen Satz „May the force be with you"zu. 
Jolies Gesicht vorbeischwebt, bewegt sich im Hauch nur eine Haarsträhne (WANTED, 2008).

Die akustische Überwältigung. Einhüllung, Affizierung Im Folgenden werden nun mit dem Schriftzug „Cinema quality surround sound" auch die spezifische Tonqualität und ihre affizierenden Potenziale beworben. Wie zum Beweis der elementaren Ausmaße der neuen Qualität sieht man in Untersicht Peter Jacksons King Kong (KING KonG, 2005) sich auf die Brust trommeln und seinen bekannten Urschrei ausstoßen. Kurz darauf wird die Überwältigungsästhetik mit ihrer Wirkung auch im Bild dargestellt: Eine Energiewelle geht von einer Konzertbühne aus und erfasst das gesamte diegetische Publikum vor der Bühne (Scott PILGRIM vs. The WorLd, 2010; Abb. 4.36).

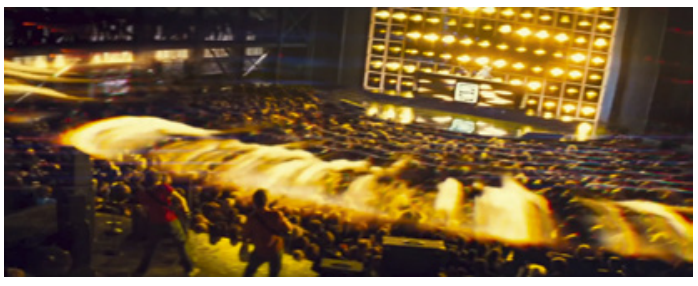

Abb. 4.36

Dies findet sich auch auf der wirkungsästhetischen Ebene des Clips gespiegelt. Das bewusste Setzen auf kollektive Erinnerungsformationen erscheint wie ein aktives Einbinden des Zuschauers. Es wird damit gespielt, dass Erinnerungen an bekannte Filmbilder - ältere wie neuere - aktiviert werden. Denn der Clip geht über in einen der bekanntesten Schreie der Filmgeschichte: Marion (Janet Leigh) unter der Dusche in Alfred Hitchcocks Psycho (196o).

Es mutet schon ein wenig makaber an. Ausgerechnet hier, wenn man an einem höchst meisterhaft inszenierten filmischen Mord teilhat, der filmhistorisch und -theoretisch seine Brisanz eben durch die wirkungsästhetische und psychologische Einbindung des Zuschauers erhält, erscheint der Slogan "interactivity redefined“ (Abb. 4.37-4.39).

Wieder wird anschließend die neue Interaktivität an Kampfmetaphern und an die Konfrontation (über)menschlicher Körper gebunden: Aus Sсотт PILGRIM ... wird in einer intermedialen Ästhetik, gespeist aus Computerspielelementen und Repräsentationsformen von Sound im Comic, der Impact eines Faustschlags als Schriftzug visualisiert („Kroww“; Abb. 4.40). 
Abb. $4 \cdot 37$

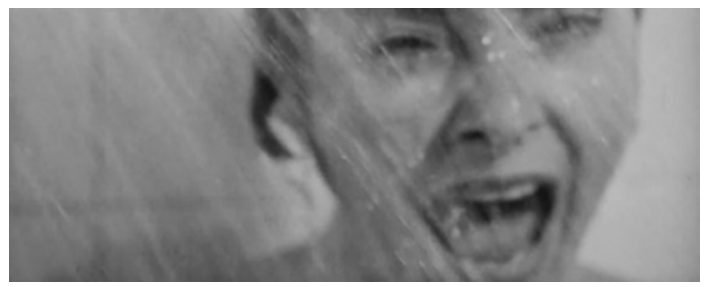

Abb. 4.38

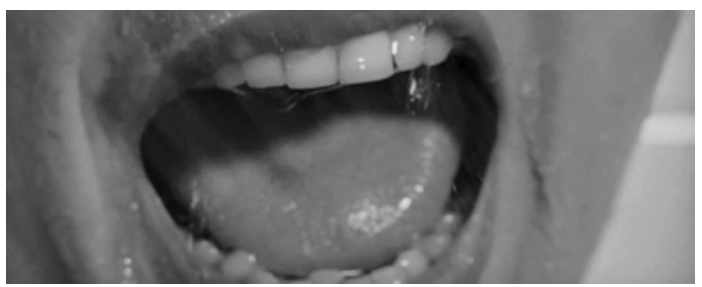

Abb. $4 \cdot 39$

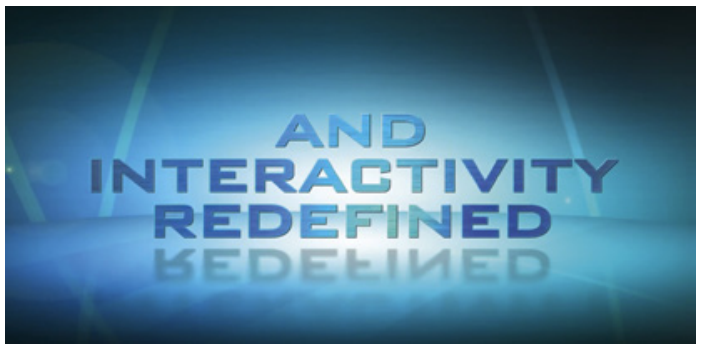

Abb. 4.40

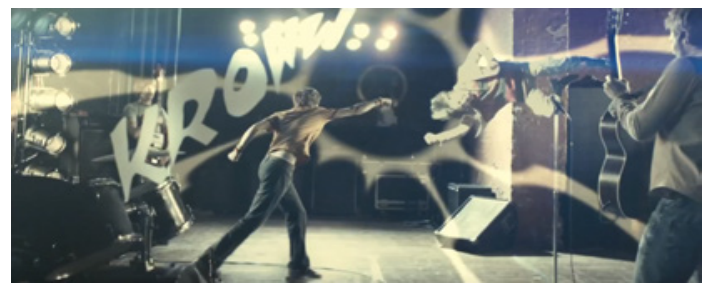

Zirkulation der Bilder. U-Control

Was nun folgt, beschreibt die Möglichkeiten der (ortsunabhängigen) Aneignung der filmisch induzierten Erlebniswelten. Auf den visuell illustrierten (Pauken-)Schlag aus Scott PILgrim ... folgt ein kurzes Innehalten der Musik. Dann die Aufforderung „Take control of your own movie“. Was das im digitalen Distributionskontext von Blu-Ray bedeuten soll, zeigen die folgenden Bilder. Es werden mehrere verschiedene Kader als Screens gezeigt, die um das „Take control“-Diktum kreisen (Abb. 4.41). Es entstehen Mise-en-AbymeBildstrukturen: ,Bild-in-Bild'- oder, neologistisch im digitalen Vokabular, 
,Picture-in-Picture'-Konfigurationen werden vorgeführt. Einer der Bildschirme, in dem die Funktionsbezeichnung „U-Control“ („You control“) steht, rast in den Vordergrund.

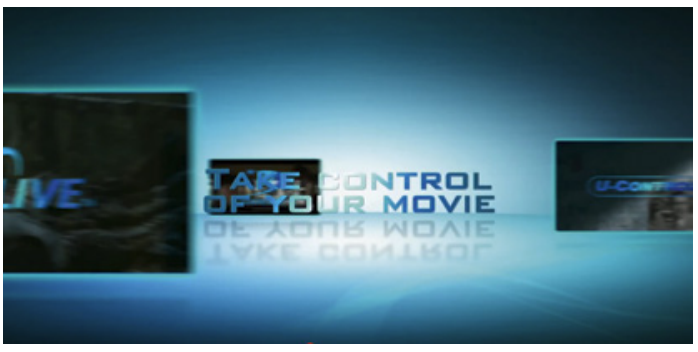

Abb. 4.41

In den nun wild rotierenden Bildschirmen erscheinen die unterschiedlichen anwählbaren Ebenen wie etwa „Video Commentaries“ mit Moderatoren. Es entsteht der Eindruck von einer clusterförmigen Vervielfältigung der Bewegung. Die Gleichzeitigkeit der Ebenen wird in der Kopräsenz der Bildschirme und damit Bildfenster vorgeführt.

Von oben fliegt nun ein Smartphone ins Bild: „Bonus content to go - interact with your mobile device“. In dem Bildschirm des Smartphones scrollen, nun um go Grad gedreht, wieder ThE-Wolfman-Bilder. Die Features werden visuell vorgeführt: Mehrere Frames illustrieren die Chapter Selection.

\section{Aneignung, Kontrolle, Live, Remediation ${ }^{42}$}

Der Screen des Smartphones wird im Folgenden zur Fernbedienung: „Remote Control and more“. Das für die Blu-Ray entscheidende Mantra „Take control of your own movie" rauscht unablässig vorbei. Die Fernbedienung wird als medienhistorisches Artefakt zitiert. Sie konnotiert symbolisch die mögliche Verfügbarkeit und Steuerbarkeit von Bildern: Zum einen kann man in den Bildern navigieren. Zum anderen wird damit auf die räumliche Verlagerung der ehemaligen Kinobilder aus dem öffentlichen Raum in den Home-Bereich verwiesen..$^{43}$ Zugleich ist das Smartphone aber auch eine aktualisierte Version der früheren TV-Fernbedienung: Interaktion, Bildaneignung und Kommunikation

42 Vgl. das bereits oben besprochene Konzept von Bolter/Grusin (1999). Zur Kritik an diesem Konzept vgl. u. a. Flückiger (2008: 400 ff.).

43 Vgl. hierzu die Studie von Winkler (1991). Ausgangspunkt von Winklers Überlegungen zu Switching-Zapping ist die Trennung der Bedienungselemente von den (TV-)Geräten und die Platzierung der Fernbedienung beim Rezipienten (Winkler 1991: 10). Ähnlich wie der vorliegende Ansatz untersucht Winkler die Folgen der technischen Modifikationen 
kommen in einem Gerät zusammen. Die Fernbedienung ist nur noch ein Tool innerhalb des Smartphones (Abb. 4.42).

Abb. 4.42

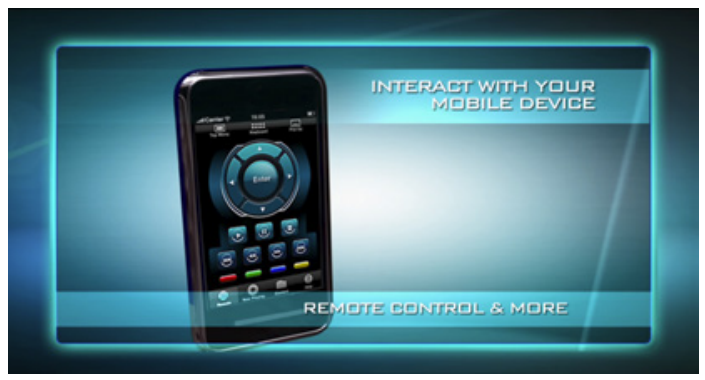

Unter den Schlagworten Aneignung und Kontrolle über Bilder wird nun die Lebendigkeit und Unmittelbarkeit des Mediums beworben. Die eingeführte Funktion BD-Live steht für die neue Interaktivität, in der man sich über Internetkonnektivität zusätzliche ,Bonus'materialien herunterladen kann.

Bedenkt man, dass zu Beginn des vorigen Jahrhunderts die Lebensnähe des Mediums Film vor allem ob seines Abbildungscharakters gepriesen wurde, so verlagert sich nun die Idee auf live. In der Verbindung der Begriffe live und interaktiv wird eine Vorstellung von Anwesenheit und Kopräsenz vorgegaukelt, die eine Interaktion in der alltäglichen außermedialen Wirklichkeit zum Vorbild hat. Die neue Nähe entsteht aber hier zu exklusivem Content und zu Previews - zu einem exklusiven Zugang zu neuem Material und Wissen. Live bedeutet nicht die Nähe zu einem spezifischen außermedialen Ereignis, sondern man verbleibt in einem selbstreferenziellen medialen Universum, das (in diesem Falle) von ökonomischen Interessen strukturiert ist.

Wichtig ist insofern, dass man mit diesem Livegedanken in ein eigenes sinnliches Universum eintaucht. Emblematisch visualisiert wird die bizarre Verbindung von Interaktivität und Immersion in ebenjenes Universum mit einem freien Fall in die Tiefe. Ein Superheld im roten geflügelten Kostüm schwingt sich vom Dach (KICK Ass): „You've got the HDTV“ - dafür gibt es Applaus mit Bildern aus Despicable me (2010) (Abb. 4.43-4.44).

Es folgt die humorvolle Antizipation des augenöffnenden Effekts, wenn man sich denn der Technik hingibt: Der nackte Alec Baldwin fragt: „What?“, Steve Martin entfährt ein staunendes „Wow!“ (Abb. 4.45), und Meryl Streep hält sich überwältigt die Hand vor den Mund (alle aus IT's ComplicATED, 2009).

in ihren Wechselwirkungen mit gesellschaftlichen, ökonomisch-politischen, kommunikativen und pragmatischen Aspekten. 


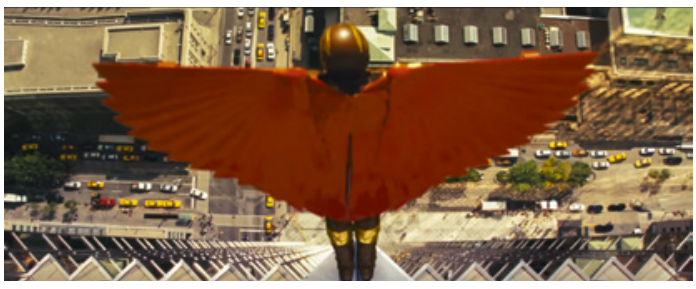

Abb. 4.43

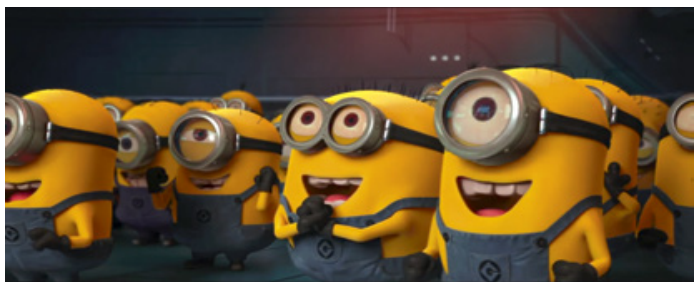

Abb. 4.44

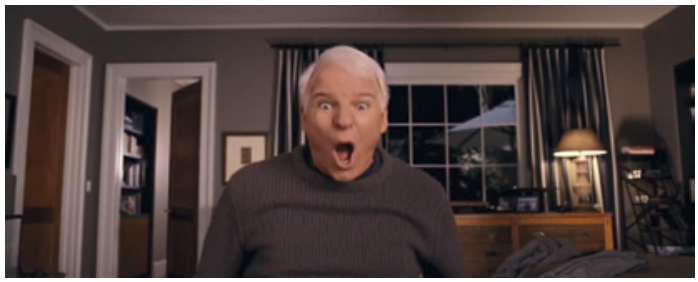

Abb. 4.45

Unleashing Moments. Das Potenzial erleben

„Now unleash its full potential“ - es folgen kraftvolle Bilder, die jeweils das Bewegungsmoment von sich entfaltender Kraft vermitteln: HIT GIRL führt einen martialischen Tritt aus, ein bewaffneter Mann wird überwältigt durch einen Gegner, der durch ein Fenster springt. Es sind allesamt Snippets, die Übermenschliches zitieren, das über die normale physische Kraft gegenüber den Gegenständen und über physikalische Gesetze hinausgeht.

Dies führt zur zentralen Botschaft und (Kauf-)Aufforderung: „Join the Blu Revolution“ (Abb. 4.46).

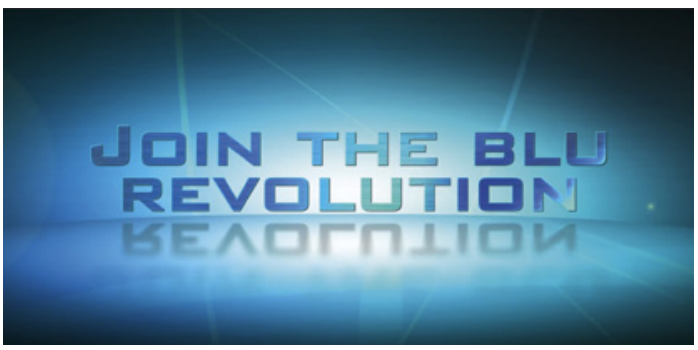

Abb. 4.46 
Zwei übermenschliche Fäuste prallen in einer Großaufnahme aufeinander (Hellboy 2: The Golden Army, 2008): „For true High-Definition“. Es erscheint wie eine antizipierte Verbeugung vor der technischen Leistung und der Wahrheit („true“): Der Zirkusdirektor in CoRALine verbeugt sich, Kinder applaudieren. Die nun gezeigte Konsequenz versinnbildlicht Freiheit und Hingebung an das Gefühl: MAMA-MiA!-Meryl-Streep (2008) springt von einem Hafenpier ins Meer. In Zeitlupe fliegen ihre Haare, sie schwebt, bevor sie eintaucht.

Nun werden Gesten des ,Erfasstwerdens' montiert: Bei Scot Pilgrim ... schaltet buchstäblich das Gehirn von "no clue“ auf "gets it“ (Abb. 4.47). Es folgen ,Erfassungsmomente', in denen plötzlich ein Objekt energisch angegriffen wird: Brad Pitt aus INGLORIU OS BASTERDS im weißen Smoking wird seitlich von einem Nazi umgerissen; ein Flugzeug schwebt über dem Empire State Building, um - auch diese Szene ist bekannt - unvermittelt von KING Kong (2005) attackiert zu werden (Abb. 4.48).

Abb. 4.47

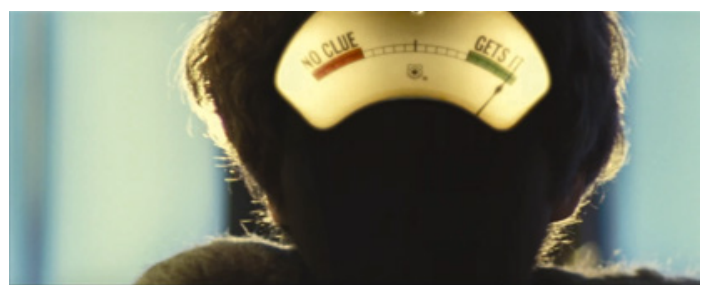

Abb. 4.48

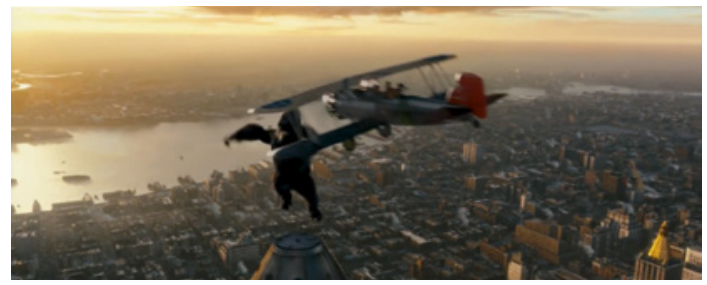

Am Ende schließt sich der Kreis: Die Kraft ist entfesselt, der Kampf, die Überwältigung angesichts der neuen technischen Qualität kann beginnen: Russell Crowes Robin Hood_taucht in Zeitlupe aus dem Wasser auf und erhebt mit einem lauten, hallenden Schrei sein Schwert (Abb. 4.49). Die Revolution, die Auflehnung hat begonnen: „For true High Definition.“ 


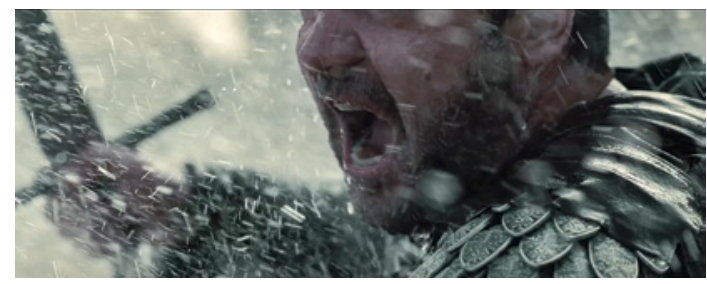

Abb. 4.49

\subsection{Fetischisierung des Neuen in der filmischen Erfahrung. Modellierung memophänomenaler Wahrnehmungsmodi}

Mit Blick auf die hier untersuchten Problemaspekte spreche ich - wie eingangs des Kapitels erwähnt - in Anlehnung an Hedigers Studie zum Trailer, wenn von ,Schlüsselszenarien' die Rede ist, von Schlüsselreizen oder -spannungen als ästhetischen Verfahren (dies auch mit Anlehnung an Deleuzes zeitphilosophische Konzeption der "Glanzpunkte“, die als strahlende Elemente die Interaktion verschiedener Zeitschichten im Bild markieren). ${ }^{44}$

Einer der wichtigsten Aspekte in den entfalteten Überlegungen ist die Tatsache, dass in dem zuletzt behandelten Beispielclip kein singulärer Film, sondern eine Technologie beziehungsweise - abstrakter formuliert - das Differenzverhältnis älter vs. neu beworben wird. Wenn nach Hediger Trailer Unterhaltungswerte simulieren (Hediger 2001: 235), so simuliert der UniversalClip das Unterhaltungspotenzial der Blu-Ray-Disc auf einer übergeordneten Ebene, und zwar in Form einer Zitat- und Fragmentstruktur. Diese wird über die fiktionalen, extrem kurzen Filmausschnitte und über ein ineinander verschachteltes Cluster von mitschwingenden Storys der zum Teil sehr aktuellen Produktionen (aus dem Zeitraum von 2010) geschaffen - ganz ähnlich dem ersten Fallbeispiel aus Restoring the Classics. Die Filme werden auf einzelne Affekt-Bilder reduziert, sie konstruieren persönliche wie kollektive Erinnerungs-Bilder und montieren diese neu. ${ }^{45}$ Dadurch entsteht eine ganze Reihe von neuen sinnlichen Reizen und Attraktionen. ${ }^{46}$ Die einzelnen zitierten

44 Vgl. zu Beginn dieses $\rightarrow$ Kap. 4 die Ausführungen zu Affekt- und Erinnerungs-Bildern bei Gilles Deleuze.

45 An dieser Stelle ließe sich weiter erörtern, ob nicht das von Deleuze konzipierte reflexive Potenzial ästhetischer Erfahrung (Morsch 2010), das darin liegt, sich von einem anthropozentrischen Verständnis, von einem psychoanalytisch definierten Subjekt abzulösen, hier produktiv weiterzudenken ist - gerade in dem stattfindenden Wechselspiel zwischen individuellen und kollektiven Wahrnehmungen und Erinnerungen.

46 In diesem Falle ist es schwierig, zwischen Erinnerungs- und Affekt-Bildern auszudifferenzieren. In dem Universal-Clip gibt es nur wenige Momente, in denen die 
Filme fügen sich zu einem panoramahaften Erlebnisuniversum. Im Unterschied zum ersten Beispiel Restoring THE Classics, in dem das Thema der digitalen Filmrestaurierung über wechselseitige Bilder vermittelt und damit das Zeitlose der filmischen Klassiker als Erfahrung fetischisierend profiliert wurde - analoge und digitale Filmgeschichte wurden zu einem organischen Erlebnisuniversum verschmolzen -, richtet sich im letzten Beispiel die zeitliche Wechselseitigkeit der Bilder auf die Brüche in der Medienentwicklung zugunsten einer omnipräsenten Transzendenz und Zukunftsutopie. Das Erleben von Differenzen, das Spielen mit sinnlichen Erwartungen an Zukünftiges, steht im Mittelpunkt.

Die Reduktion auf Bewegung und Rhythmus, die immer wieder auf die sinnliche Affizierung, wenn nicht gar Überwältigung des Zuschauers, im wahrsten Sinne ,auf ihn' zielt, findet visuell ihre Entsprechung im Leitmotiv des gespannten Bogens von Robin Hood, bei dem es in der auf Rhythmus basierenden Dramaturgie des Clips darum geht, somatisch wirksame Kraftentfesselung zu übertragen.

Diese Bewegungsspannung in Richtung einer Entladung der Kräfte steht im Dienste der sinnlichen Vermittlung einer sich vollziehenden Revolution. Diese Umwälzung zur Durchsetzung der Blu-Ray-Disc hat vielfältige Implikationen. Ästhetisch wird sie transponiert über eine Revolution der medialen und menschlichen Wahrnehmung. Das Versprechen eröffnet ein neues (Wahrnehmungs-)Universum. Hinter ihm steht indes die Formierung einer neuen (Kauf-)Gemeinschaft. Bereits die ersten Bilder im abstrakten Raum wie auch die Schriftzüge erscheinen als Enter-Befehle (Hediger 2001: 233).

Wirkungsästhetisch artikuliert sich dies als revolutionäre Mobilisierung, als Aufbruchsbewegung: Eine alte Ordnung (in diesem Zusammenhang das ältere Medium) wird überholt und in der Utopie einer besseren Zukunft angesiedelt (am Ende eines ähnlichen Clips von Fox steht: „The Future is Blu“47; vgl. auch die Analyse des Werbeclips von Saturn). Die Zukunft ist mehrfach präsent - ob in BACK TO THE FUTURE oder in der Verwendung der sprachlichen Formel „force“, über den das Sci-Fi-Märchen StaR WARS konnotiert wird. Hier verbleibt man stets in einer mediatisierten, fiktionalisierten Vorstellungswelt. Über die Vielzahl der Action- und Kampfbilder wird man zum imaginären Waffenbruder, da man immer mehr in den Sog des Bewegungs-

Bekanntheit der Filme explizit suggeriert wird. Vielmehr vertrete ich die These, dass in diesem Clip das Erleben der Gegenwärtigkeit - mit dem Potenzial eines sinnlich attraktiven ,Mehrwerts' (vgl. meine Ausführungen zum Fetischismus) - im Vordergrund steht.

47 „The future is blu. The best way to watch movies at home. Ever“. Vgl. Fox-BLU-RAY: ThE FUtURe Is Blu - Trailer (2012) $\rightarrow$ Filmverzeichnis. 
exzesses mit hineingezogen wird; der einsetzende Chor verleiht ihm hymnisch ritualisierende, gemeinschaftsbildende Weihen. Auch der menschliche Körper mutiert und transzendiert seine physischen Grenzen: Superhelden und ihre übermenschlichen Fähigkeiten werden filmisch formelhaft zitiert. Zugleich stellen die (digitalen) Special Effects an sich eine Attraktion und Demonstration aktuellster Filmtechnik dar.

Vor allem die aufgebaute Bewegungsspannung arbeitet dem Reprisemodus der Erprobung zu: Die ästhetische Struktur dieses Clips ist darauf angelegt, dass man als Zuschauer ständig das Neue der Blu-Ray-Disc überprüft und in seiner emotionalen, faszinativen Reaktion/Involviertheit affirmiert. Diese Überprüfung geschieht im Erleben der ständigen Reizüberflutung und appellativen Addressierung. Die so etablierte Spannung dient als phänomenales Mittel, den Zuschauer immer wieder einzubinden. Über den Bewegungssog und über dramaturgische Steigerungsmomente, die mit retardierenden Elementen durchsetzt sind, wird das Bedürfnis auf Lösung der Spannung formiert. Diese eigentlich unspezifischen, auf der phänomenologischen Ebene evozierten Empfindungen übertragen sich auf den Zweck dieses Clips: Es wird ein Bedürfnis auf dieses Mehr an Erleben, das Neue stimuliert. Zwischen der phänomenologischen Vermittlungsstruktur und der inhaltlichen Botschaft kommt es nun allerdings zu einigen Paradoxa: Auf der einen Seite steht die ästhetische und damit affektive Überwältigung. Anderseits wird inhaltlich aber die Aneignung gerade ebenjener Erlebniswelten beworben - vor allem wird deren Kontrolle und Beherrschung nahegelegt.

Ästhetisch-narrativ wird die Zugehörigkeit zu einer Gemeinschaft beziehungsweise Bewegung („Join the revolution“) vermittelt. Das Verkaufsversprechen der Blu-Ray-Disc beinhaltet aber auch, dass man nun die Erlebniswelten bei sich zu Hause im Privaten durchleben kann. Daraus ergibt sich eine paradoxe Situation - zwischen Aneignung im Wohnzimmer mit dem Versprechen auf exklusiven, individuellen Zugang zu Bonuswissen; zugleich ereignet sich eine Öffnung des privaten Raums über die Chatfunktion hin zu einer virtuellen Kommunikationsgemeinschaft. Es ist ein Spannungsverhältnis zwischen Exklusivität, die einem als häuslicher Konsument zugänglich wird, und dem, was Klinger im memopolitischen Horizont "personal mass culture" genannt hat (vgl. $\rightarrow$ Kap. 3). In Klingers Formulierung wird erneut die Widersprüchlichkeit der verschiedenen Sphären deutlich: zwischen persönlicher Aneignung sowie Teilhabe an Kollektivität über offene Marktstrukturen und der An-/Einbindung an kollektive Erinnerungspraktiken in Form von kanonisiertem und fetischisierendem Gedächtnis (im Falle der Vermarktung der Re-Edition von alten Filmen). 
Es gibt zwar Topoi, die im Kontext des Diskurses um die Blu-Ray-Disc immer wiederkehren - in Distelmeyers Begrifflichkeit hieß dies Flexibilität, Versatilität und Selektivität sowie Interaktivität. Gleichwohl kann die Werberhetorik der Blu-Ray-Disc nicht auf den Dienst der unmittelbaren Wirkung der von ihr re-editierten Filme verzichten: Sie benötigt den Modus der Reprise, um ihre Neuheit vor allem phänomenal als zeitliches Cluster entwickeln zu können. Die dazugehörige Erwartungshaltung sowie die sich vollziehende Wahrnehmungserfahrung sind die einer Fetischisierung von Filmerlebnissen, welche sich wiederum, dies ist ein weiteres Paradox, wirkungsästhetisch auf das Erlebnis von Filmen im Kino bezieht.

So stellt sich letztendlich - angesichts all dieser Widersprüche - die Frage nach dem spezifischen Mehrwert der Blu-Ray-Disc gegenüber anderen Trägern. Die Pointe meiner Untersuchung liegt darin, dass die Argumente für die Blu-Ray-Disc in medienhistorischer Sicht im rhetorisch-formalen Kern - betrachtet man die Diskursgeschichte um den Film im Kontext anderer technischer Neuerungen und AV Medien - sich nicht wesentlich von ästhetischen Strategien der Vermarktung früherer medientechnologischer Entwicklungen unterscheiden; so sind solche zu beobachten etwa bei der Promotion der DVD gegenüber der VHS-Kassette, der VHS gegenüber dem Kino oder auch schon früher bei der Vermarktung von 3-D-Technik oder der des Cinerama gegenüber normalen Projektionsformen und Formaten im Kino. ${ }^{48}$ Einen in diesem Kontext immer wieder auftauchenden audiovisuellen Topos filmischer Attraktion stellt die Evozierung einer Achterbahnfahrt dar. ${ }^{49}$

Tatsächlich liegt hier eine ästhetische Metanarration aus (Film-)Fragmenten (wie auch schon im einführenden Beispiel!) vor, die eine neue, höchst interessante Form der Warenästhetik mit Blick auf die digitale Domäne entwickelt. Will man unter diesem Gesichtspunkt das „ästhetische Gebrauchswertversprechen" der Blu-Ray-Disc (oder anderer aktueller und womöglich zukünftiger digitaler Dispositive von Filmen) nach Haug in den Fokus nehmen, so ergibt sich die pikante Pointe, dass der Gebrauchswert ebenfalls in der ästhetischen Dimension liegt: Die Blu-Ray-Disc verspricht ein erweitertes ästhetisches Erleben, ein gesteigertes Unterhaltungs- und Genusspotenzial. Die ästhetische Verpackung des Versprechens (Filmbilder) fällt zusammen mit

48 Vgl. hierzu etwa die Dokumentation This is Cinerama (1952), die 2012 auf DVD und Blu-Ray veröffentlicht wurde. Vgl. zur Restaurierung von Cinerama-Filmen: http:// www.in7omm.com/news/2011/cinerama/index.htm und http://dvdbiblog.wordpress. com/2011/og/o5/cinerama-wird-restauriert/ (alle Abrufe 09.07.2019).

49 Vgl. hierzu: Schweinitz (2006: 135-152, hier bes. $142 \mathrm{ff}$ - - auch mit direktem Bezug zu Cinerama). 
dem Objekt (die wiederaufgenommenen, re-aktualisierten Filmbilder auf BluRay) der Vermarktung. ${ }^{50}$ Umso mehr gilt hier:

Die Warenästhetik ist gemacht, damit die Bedürfnisse sich in ihr spiegeln. [...] Diese Akzeptanz [des Produktes bei den Kunden, FH] wird primär angestrebt durch Gebrauchswertversprechen im Modus der Imagination oder des auf eine Kaufentscheidung hin perspektivierten imaginären Raumes, der die Waren umgibt. Mehr als im Fordismus verschiebt sich die Darstellung von den Dingen auf die ihnen angedichteten Erlebnisfolgen (Haug 2009: 220, Hervorh. FH).

Insbesondere auch mit dem Beispiel zu der Re-Edition auf DVD von Peter PAN habe ich hier die Rolle des Glaubens hervorgehoben.

Die angedichteten Erlebnisfolgen müssen im gegebenen Kontext dem Modus der Fetischisierung unterliegen, der grundlegend auf dem Prinzip des Wechselspiels - mit Deleuze gesprochen - von Aktuellem und Virtuellem basiert. H. Böhme nennt dies beim Fetisch eine „Kompromissfigur“, welche die heterogene Haltung beschreibe:

Diese markiert ebenso die Abwesenheit des Initialobjekts (des Fetischs), das oft der Amnesie unterliegt, wie sie zugleich das Abwesende, als Deckerinnerung, in eine seriell verlängerbare Präsenz zwingt - in jedem neuen Fetisch-Schuh ist die verdrängte Szene aufgerufen, von der der erregende Zauber seinen Ausgang nahm (H. Böhme 2012: 394).

Dieser „erregende Zauber" schafft einen sinnlichen Erfahrungshorizont, der nach den obigen Ausführungen die warenästhetische Dimension digitaler Filmbilder mit Alterswert belegt. Dem arbeiten ästhetische Praktiken zu, die - in Anschluss an Konzeptionen von Deleuze - mitaffektiven und erinnerungs-bildlichen Potenzialen von Bewegtbildern arbeiten. Diese sinnlich-unmittelbare und zugleich zeitlich heterogene Wirkungsdimension von Bewegtbildern, die mit individuellen wie kollektiven Erinnerungsprozessen spielen, bezeichne ich fortan als memophänomenal. Bewegtbildliche ästhetische Praktiken im Zeichen einer memophänomenalen Wirkung machen einen entscheidenden Aspekt von audiovisueller Geschichtsbildmodellierung aus. In $\rightarrow$ Kap. 6 wird dies in Zusammenhang mit dem Begriff des Filmisch-Imaginären noch weiter

$5^{\circ}$ Haug ist vor diesem Hintergrund zuzustimmen, wenn er schreibt: „Die Warenästhetik selbst $[\ldots]$ ist in vorher ungekannter Weise selbst zum Gegenstand eines paradoxen „Konsums' geworden, indem ihre Grenzen zum Gebrauchswert der Waren, aber auch zu Information und Unterhaltung und allgemein zu den Produkten der Kulturindustrie durchlässig geworden sind“ (Haug 2009: 219). 
diskutiert - nicht zuletzt auch unter Berücksichtigung metatheoretischer Implikationen für Formen der Geschichtsschreibung; hierbei gilt es, das charakteristische Verhältnis von Vorstellungs- und Wahrnehmungsbildern des Filmisch-Imaginären mit in die Überlegungen mit einzubeziehen. Speziell wird dies virulent in Hinblick auf fiktive wie nichtfiktionale Repräsentationsformen filmischer Paratexte, die in besonderer Beziehung zum Technoimaginären der digitalen Domäne stehen. ${ }^{51}$

Prozesse einer solchen Geschichtsbildmodellierung benötigen grundsätzlich einen spezifischen Subjektbegriff. Dieser wird insofern zunächst unter dem Stichwort Performance im nachstehenden $\rightarrow$ Kap. 5 näher präzisiert und theoretisch verortet.

51 Zu dem phänomenologisch ausgerichteten Wahrnehmungsmodell und der Vorstellung eines körperlich erfahrenen ,Nachlebens‘ oder ,Eigenlebens‘ von Filmbildern vgl. die ergänzenden Anmerkungen zum ersten Fallbeispiel in diesem $\rightarrow$ Kap. 4; zu einer möglichen Anschlussfähigkeit an Konzepte Aby Warburgs vgl. Sierek (2007). 